\section{Journal of Home \\ Economics}

http://homeEcon.menofia.edu.eg

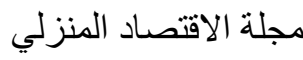

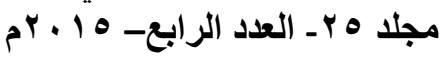

ISSN 1110-2578

\title{
وعي ربة الأسرة بإسلوب التعامل مع الحوادث المنزلية وعلاقته بالسلامة المنزليةة للأطفال الحواد
}

\section{شيماء الحسيني تحمل صقر}

أستاذ مساعد إدارة المنزل و المؤسسات_كلية التصاميم و الاقتصـاد المنزلي -جامعة الطائف المملكة العربية السعودية

ملخص الدراسة

تهاف اللراسة الحالية إلي الكثثف عن العلاقة بين مستوي و عي ربه الأسرة بإسلوب التعامل

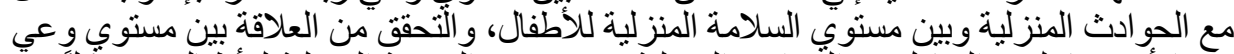

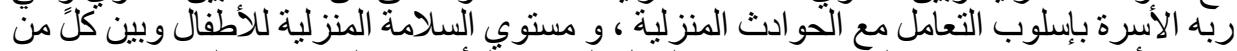

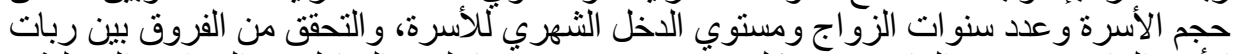

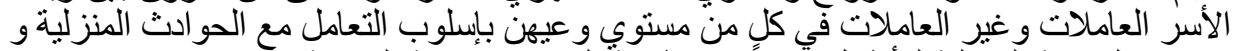

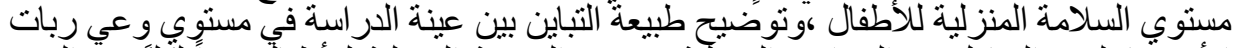

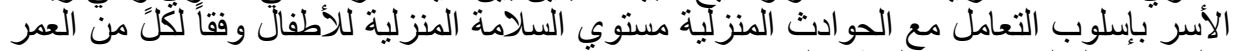

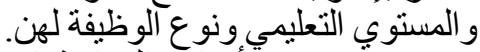
وتضضمنت أدوات الدر أسة استمارة البيانات العامة للأسرة ، و واستبيان وعي ربة الأبة الأسرة

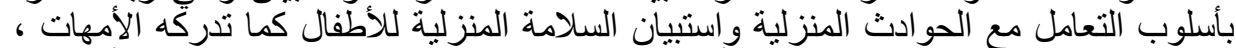

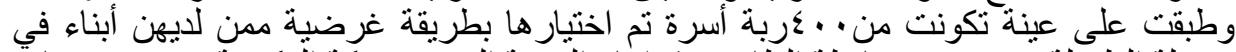

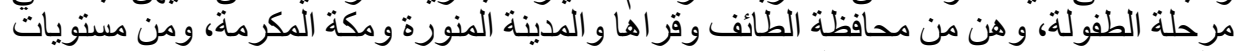
تعليمية اجتماعية و اقتصادية مختلفئة

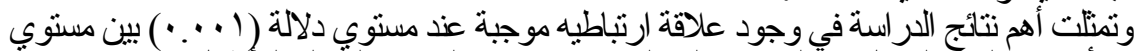

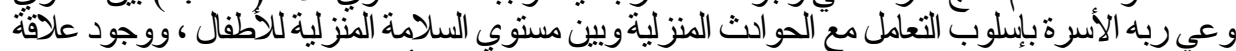

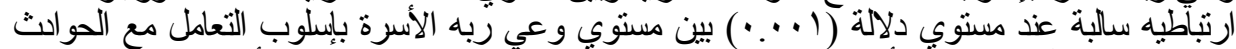

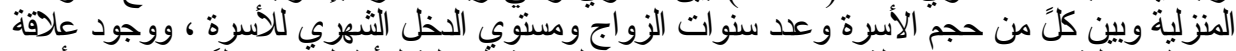

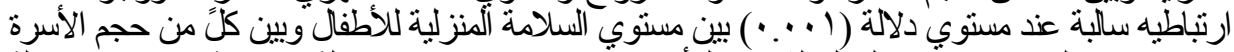

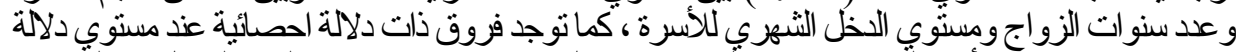

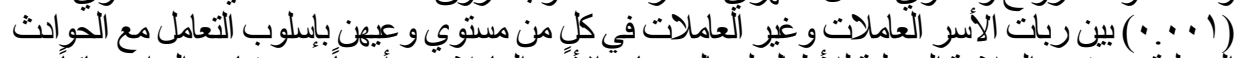

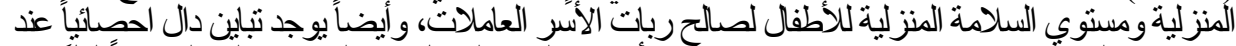

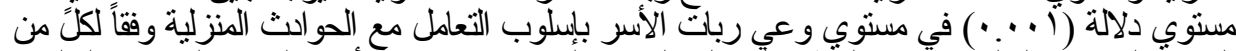

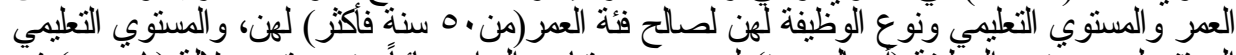

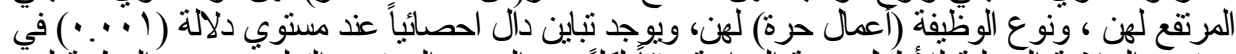

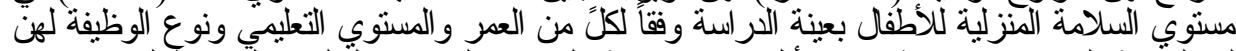

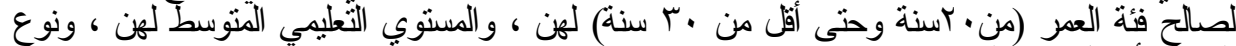

وقلمت الدراسةّة مجمو عة من التوصيات الفعالة منها توجيه اهتمام الباحثين إلي إعداد البرامج الإرشادية

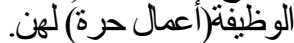

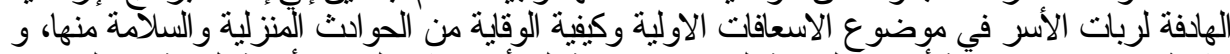

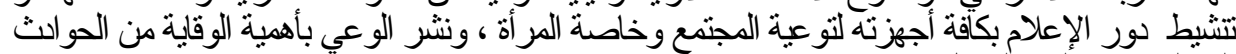




$$
\text { مجلة الاقتصاد المنزلي- مجلد هب ـ العدد الرابع ـ } 10 \text { • بم }
$$

المقدمة و المشكلة البحثية

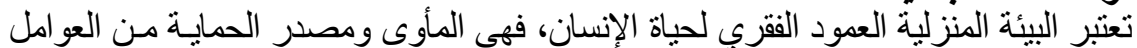

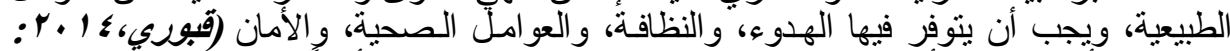

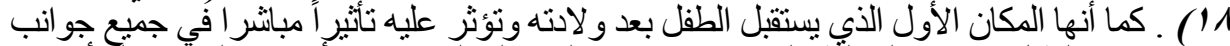

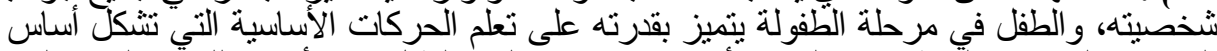

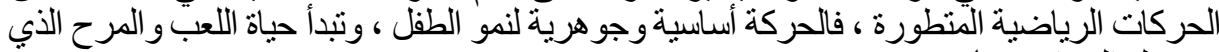

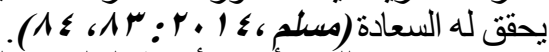

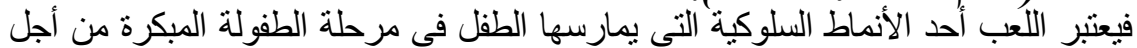

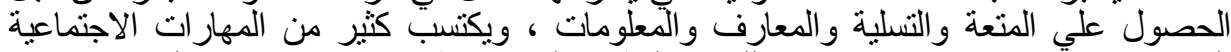

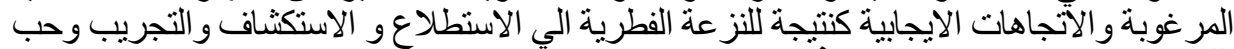

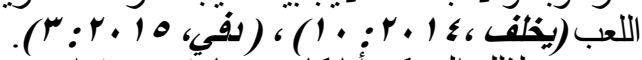

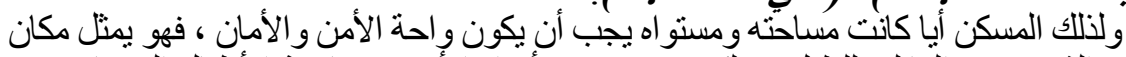

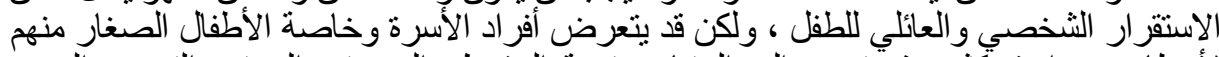

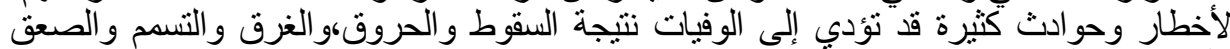

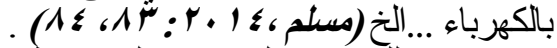

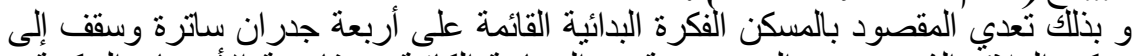

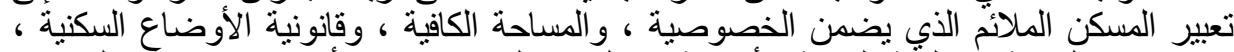

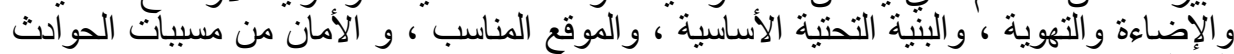

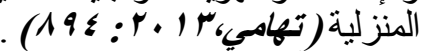

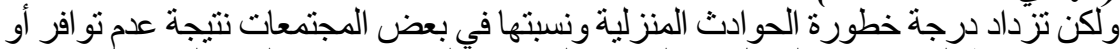

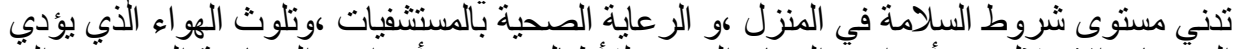

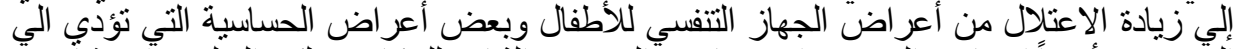

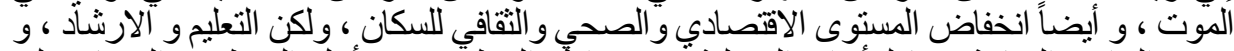

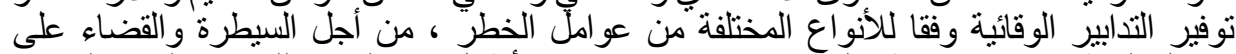

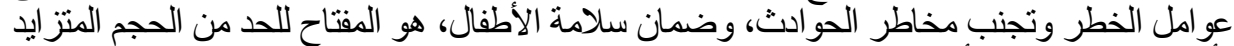

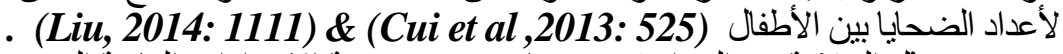

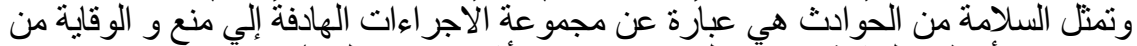

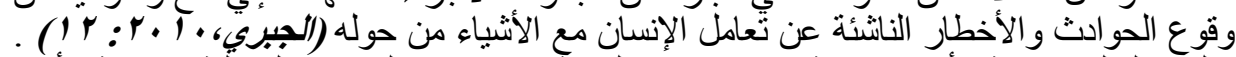

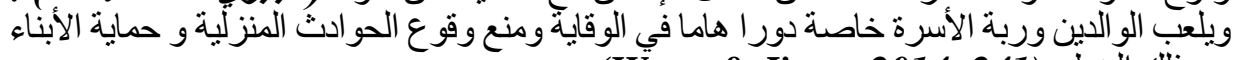

من ذلك الخطر (Wang \& Jiang, 2014: 241).

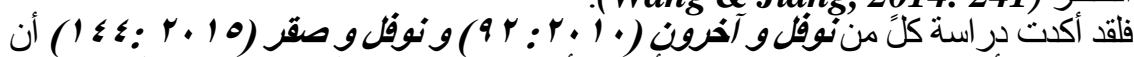

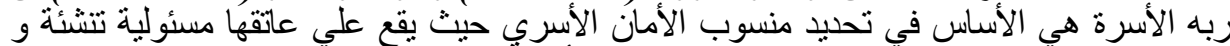

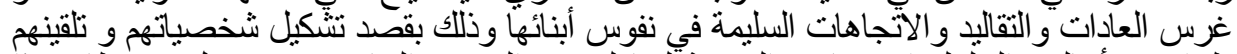

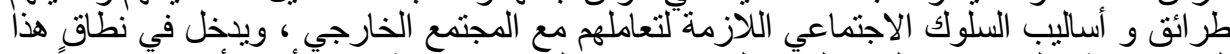

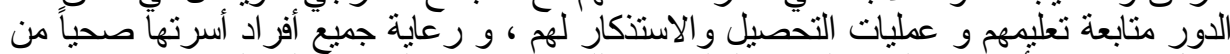

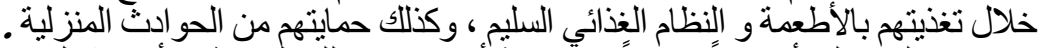

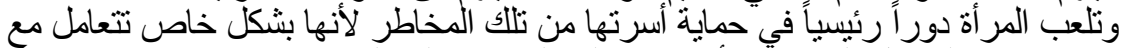

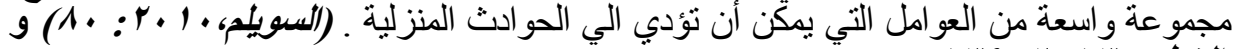
ومع ارتفاع مستوى تعليم المر أة وارتفاع تكاليف المعيشة ، خرجت أعداد متز ايدة من النساء

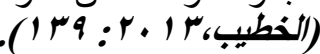

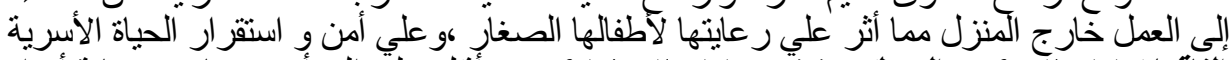

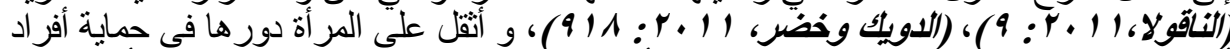

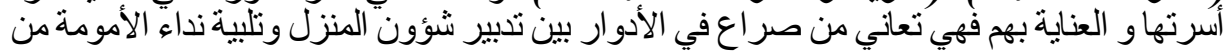




$$
\text { مجلة الاقتصاد المنزلي- مجلد هب ـ العدد الرابع ـ } 10 \text { • بم }
$$

جهة وتحقيق المكانة الاجتماعية المرموقة من جهة أخرى مما يجعلها لا تستطيع إنقان الدورين معا

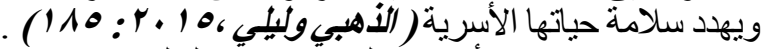

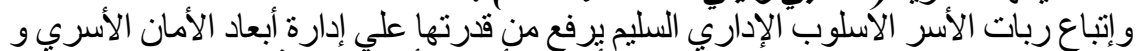

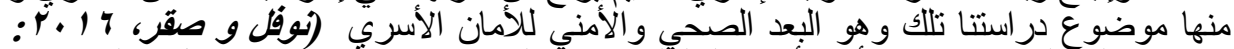

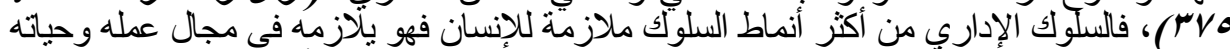

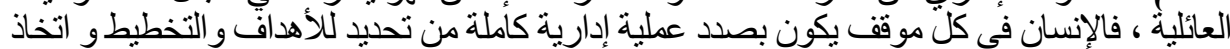

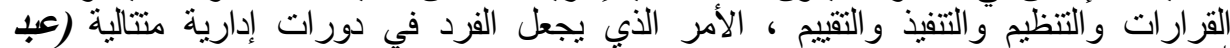

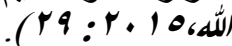

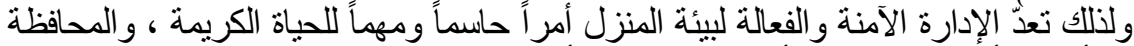

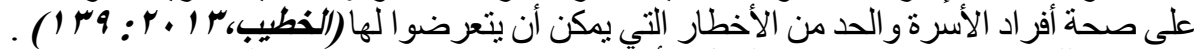

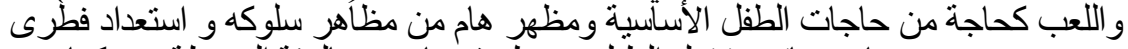

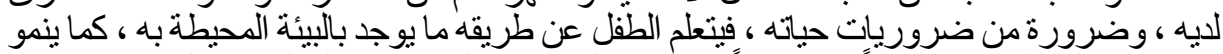

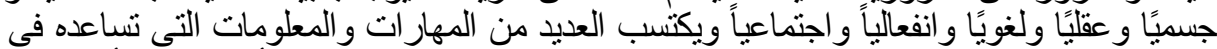

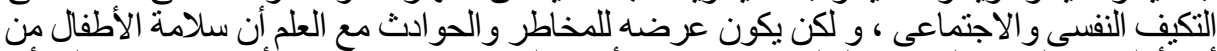

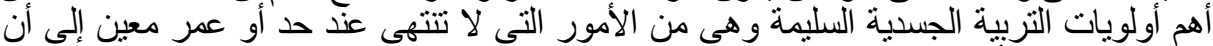

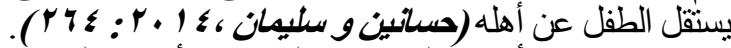

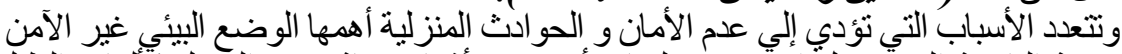

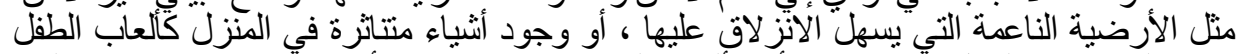

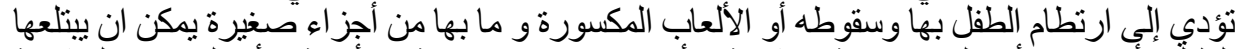

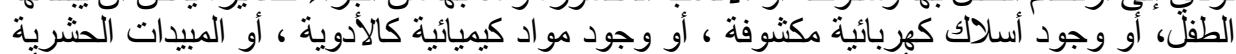

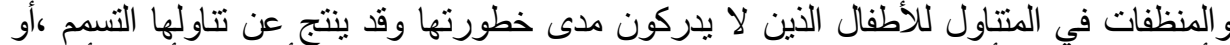

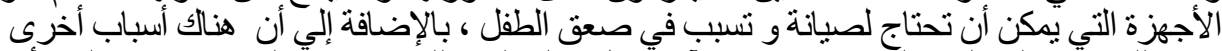

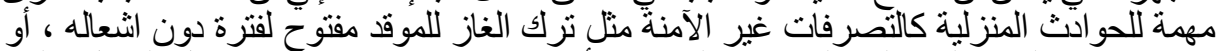

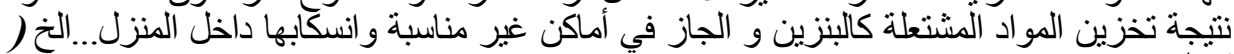

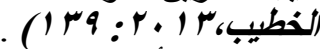

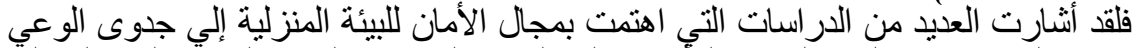

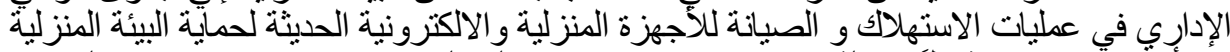

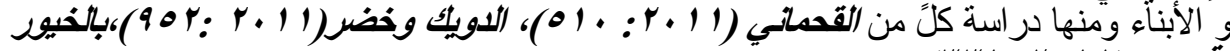

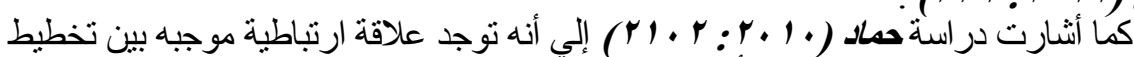

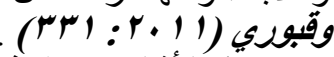

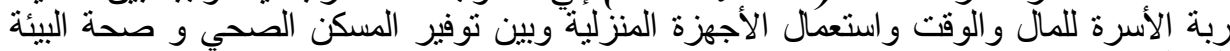
وأثثتت دراسة (2014) 1191 : Yahya et al, وجوب الاهتمام بالبيانات الأنثروبومنرية المنز لية.

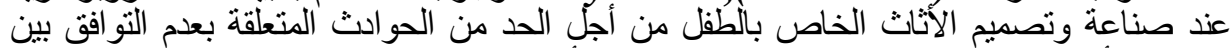

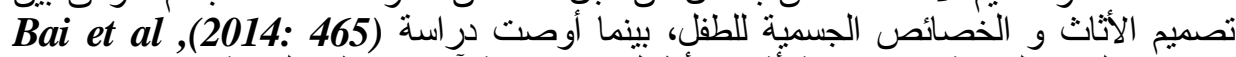

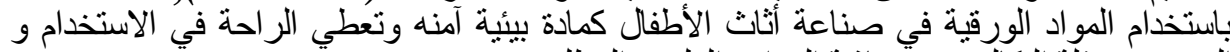

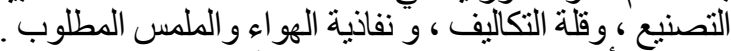

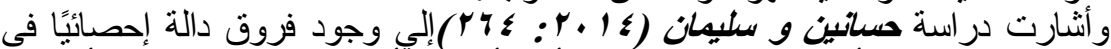

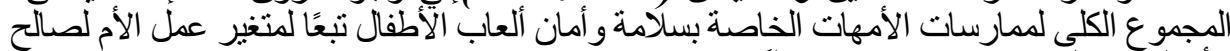

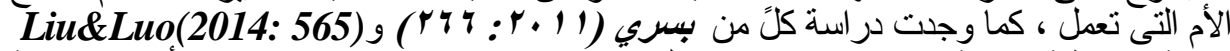

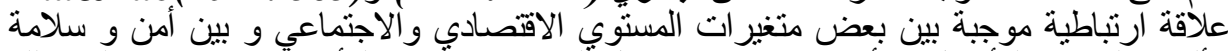

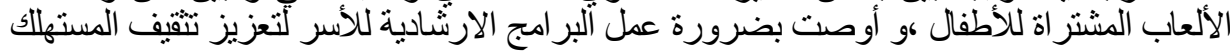




$$
\text { مجلة الاقتصاد المنزليـ مجلد هب ـ العدد الرابع - } 10 \text { • بم }
$$

للتعرف علي الأسس العلمية في اختيار العاب الأطفال و ضرورة قيام المسئولين بوزارة التجارة بوضع بالئ

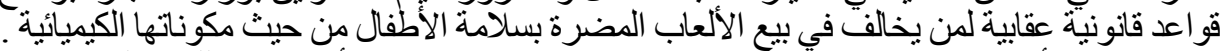

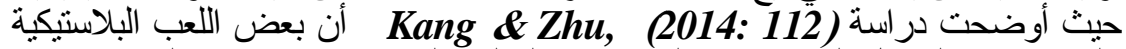

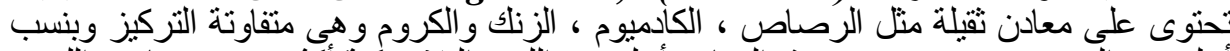

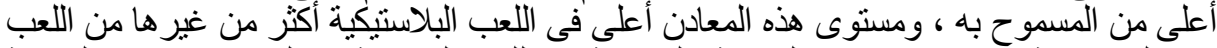

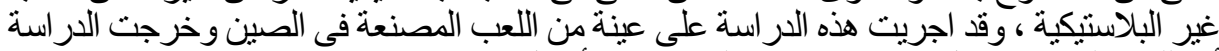

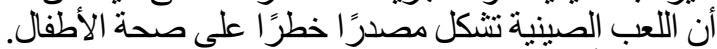

و أوضحت دراسة (أهمية عناصر الأمان و السلامة في

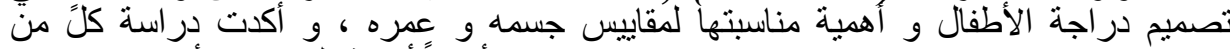
Li , 2014: 354 و أيضاً أهمية الجودة و الأمان في اختيار

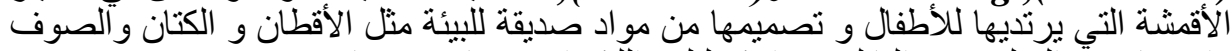

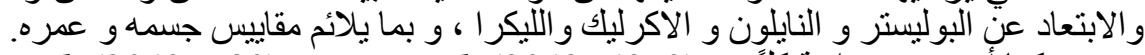

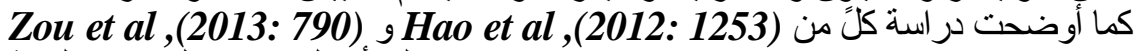

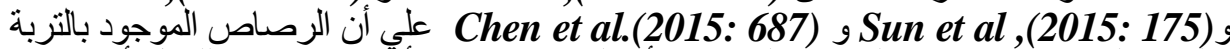

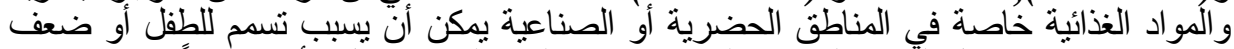

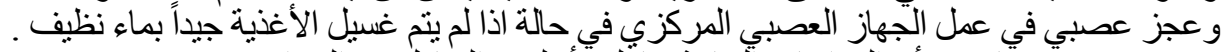

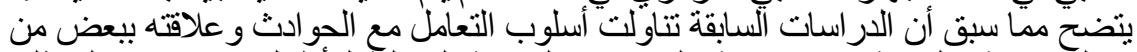

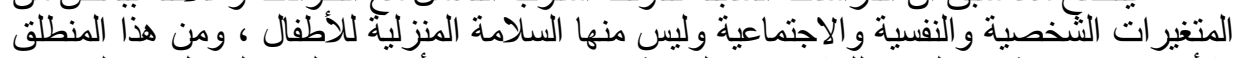

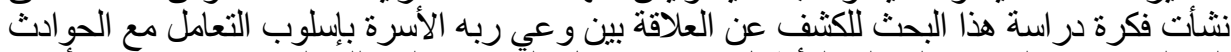

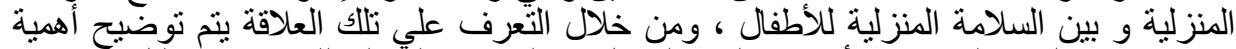

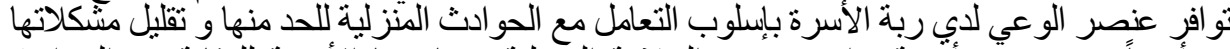

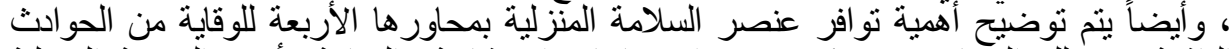

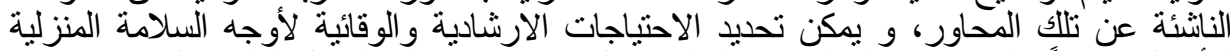

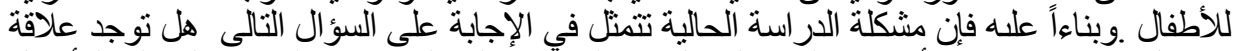

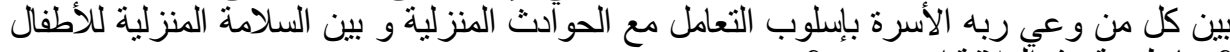

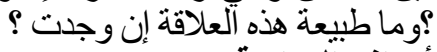

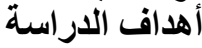

تهدف الدراسة الحالية بصفة رئيسية إلى الكثف عن العلاقة بين وعي ربه به الأسرة

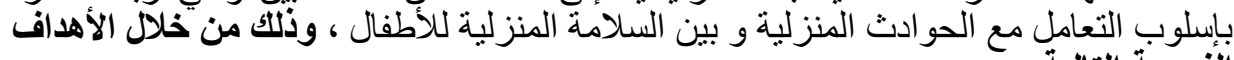

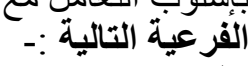

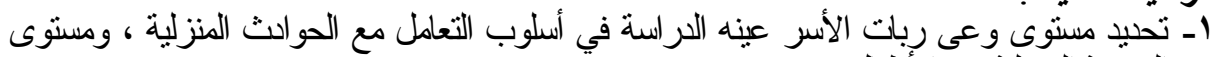

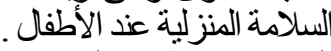

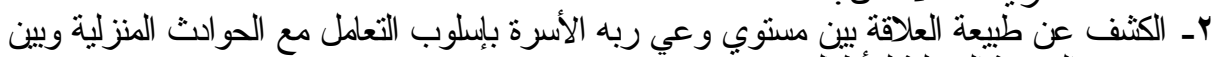

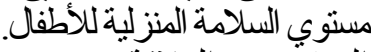

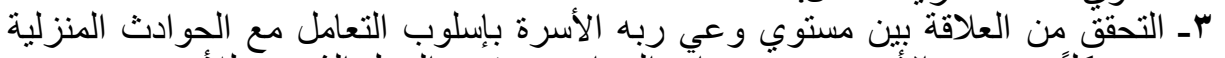

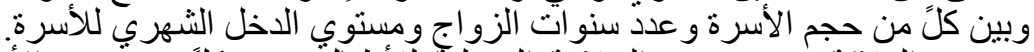

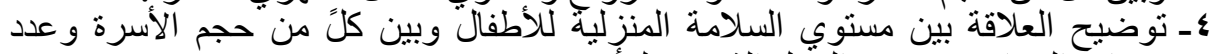

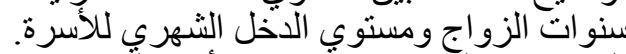

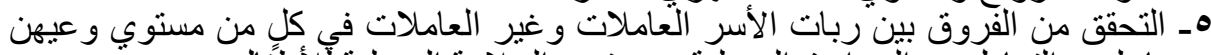

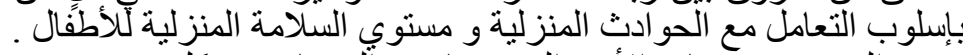

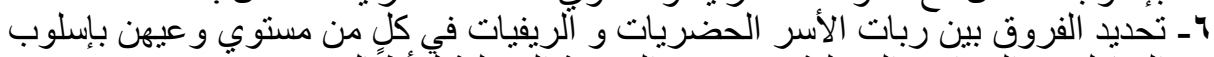

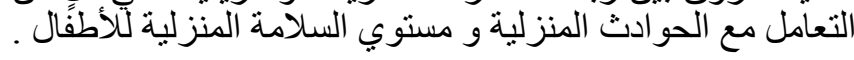




$$
\text { مجلة الاقتصاد المنزليـ مجلد هب ـ العدد الرابع ـ } 10 \text { • بم }
$$

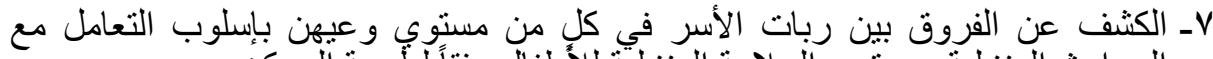

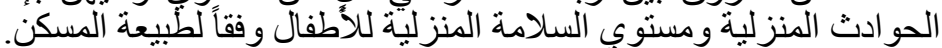

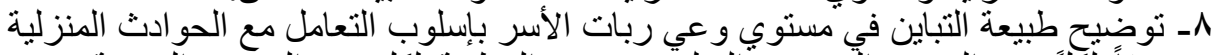

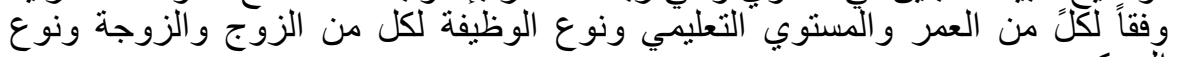

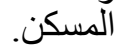

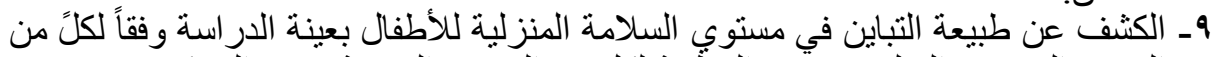

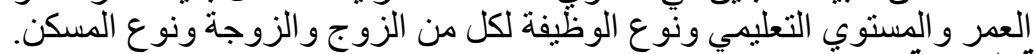

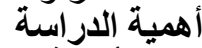

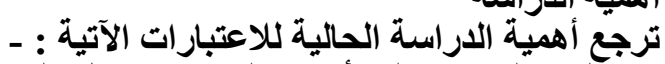

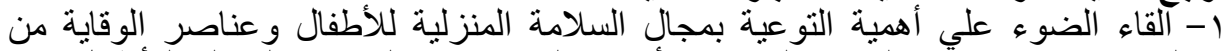

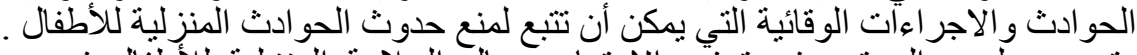

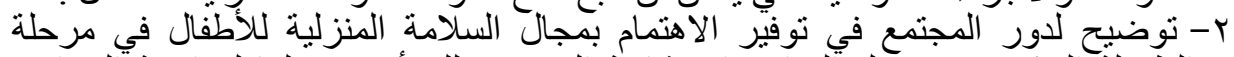

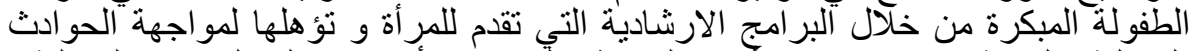

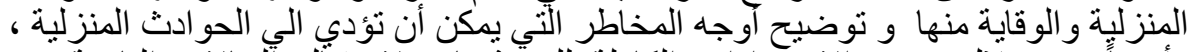

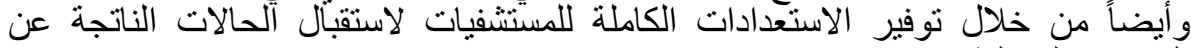
الحو ادث المنزلية r- يمكن أن تساعد نتأنج هذه الدراسة في الخروج بمحاور وأبعاد جليلة لإعداد برنامج ارشادي لربات الأسر في مجال السلامة من الحو ادث المنزلية لتلاطظفال.

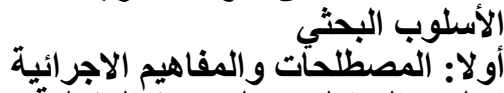

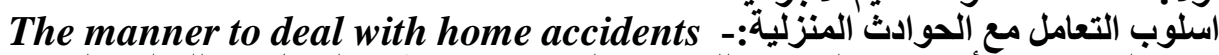

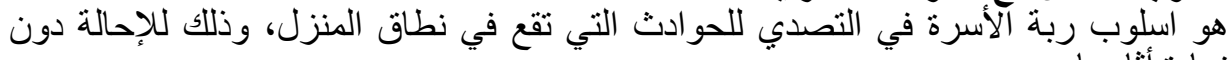

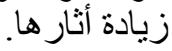

Awareness of The manner to deal with home الوعي بإسلوب التعامل مع الحوادث المنزلية:و اكتساب المعلومات و الممارسات السليمة نحو التصدي و الحيل دون زيادة أثنار الحو ادث accidents المنز لبة. . the safety -: السلامة

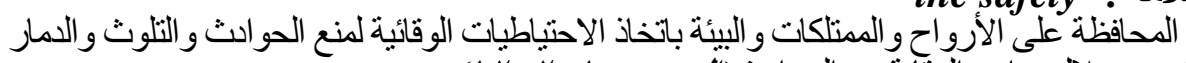

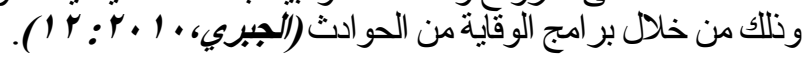

the Home safety -: السلامة المنزلية

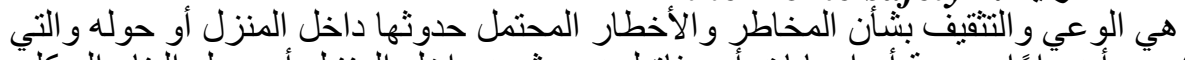

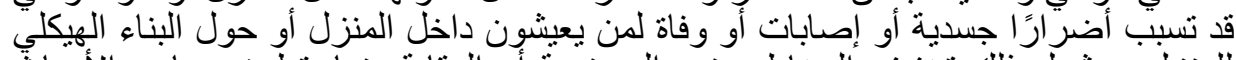

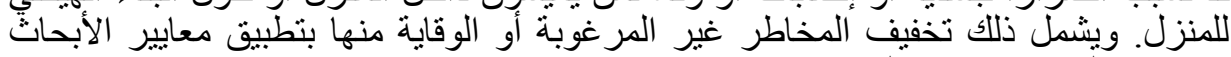
و الاعتماد للاستخدامات و ألممارسات (https://ar.wikipedia.org/wiki.2016.

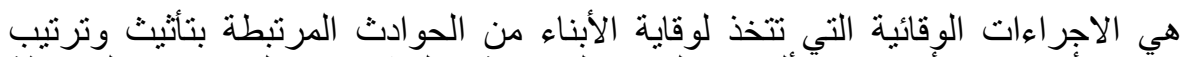

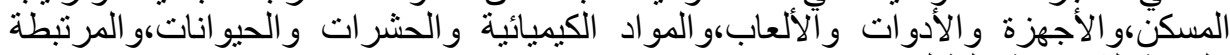
بالعناية الثخصية بالطفل. 


$$
\text { مجلة الاقتصاد المنزلي- مجلد هب ـ العدد الرابع ـ } 10 \text { • بم }
$$

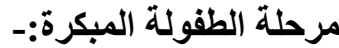

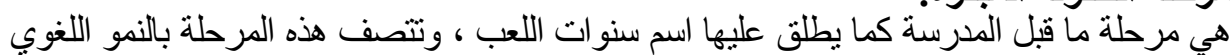

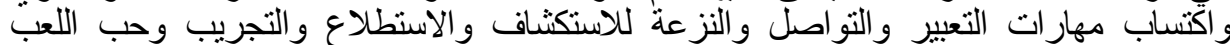

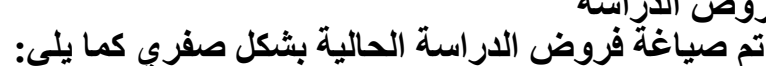

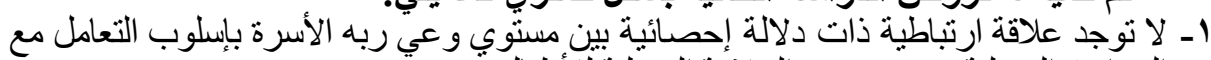

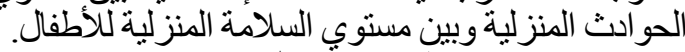

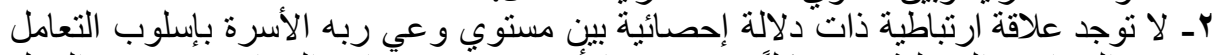

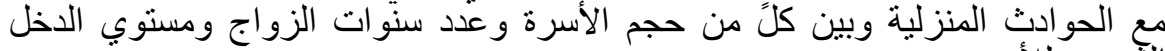
الشُهري للأسرة.

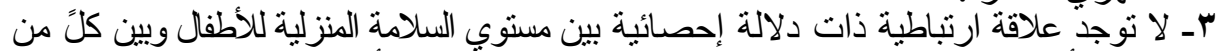

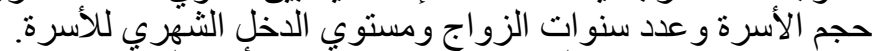

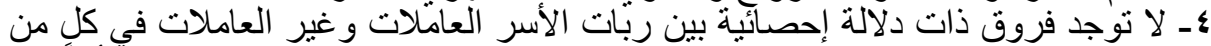

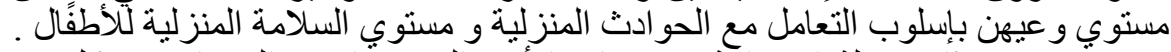

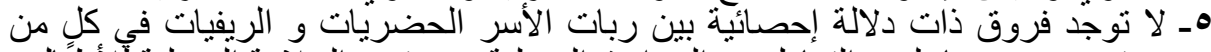

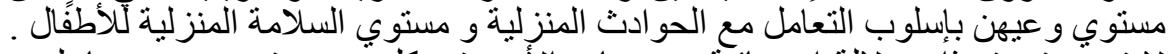

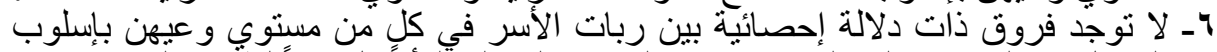

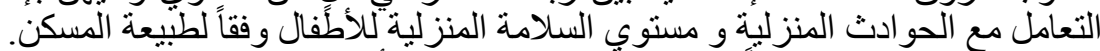

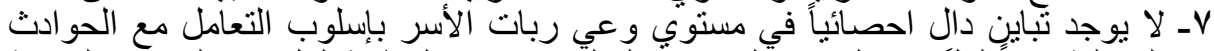

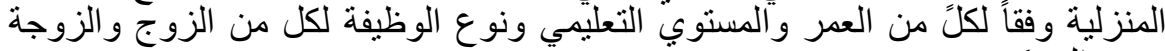

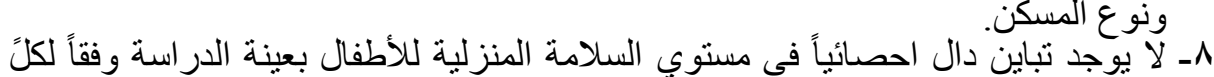

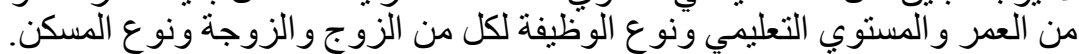

تالثا: منهج الدراسة

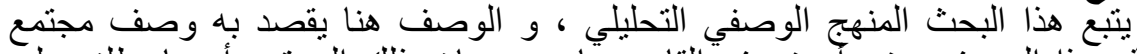

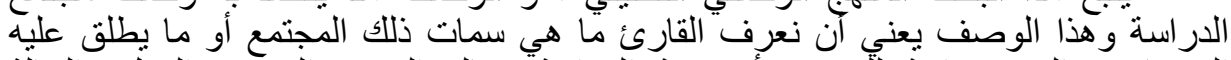

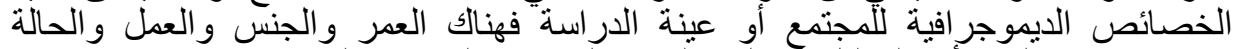

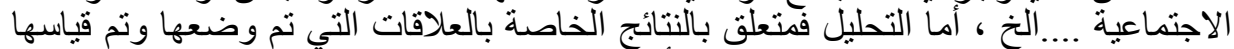

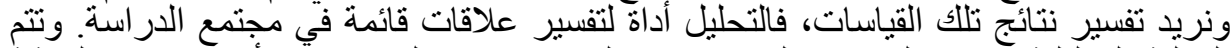

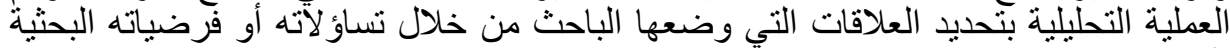

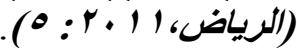

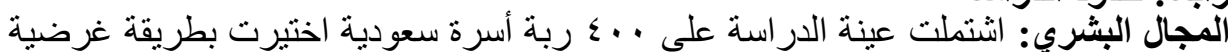

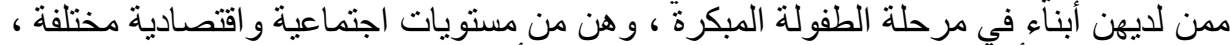

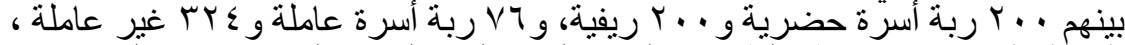

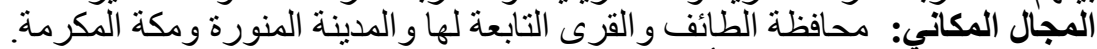

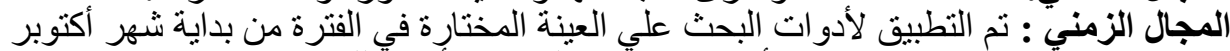

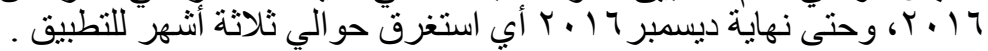


مجلة الاقتصاد المنزليـ مجلد هبـ العدد الرابع ـ 10 • ب م

خامسا: تصميم وبناء وتقتين أدوات الدراسة الداتة

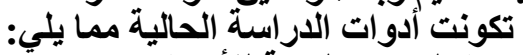

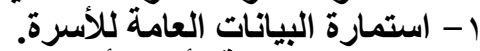

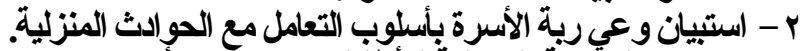

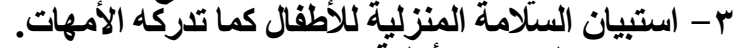
ا ـ استمارة البيانات الأولية: البية:

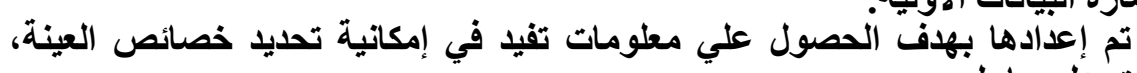

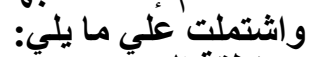

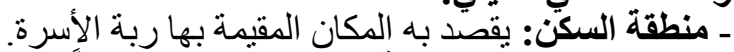

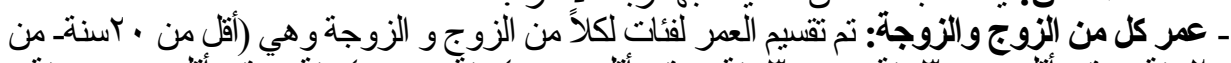

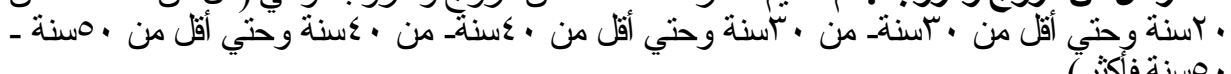
. مسنة فأكثز).

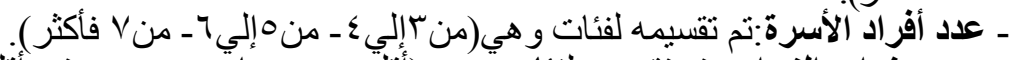

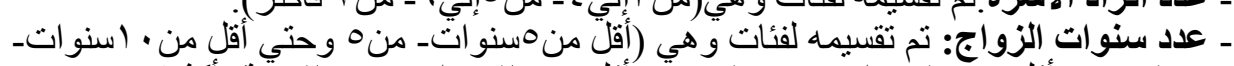

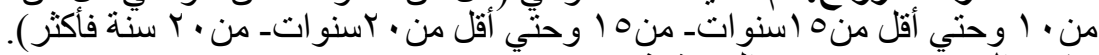

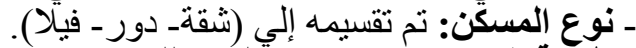

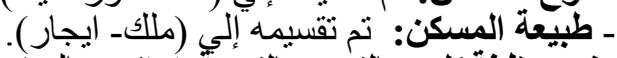

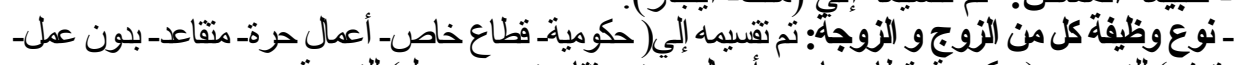

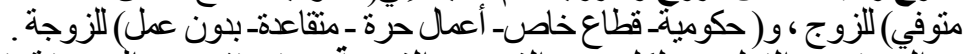

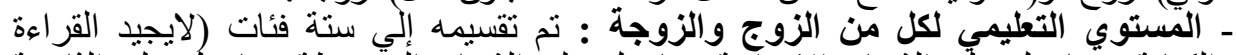

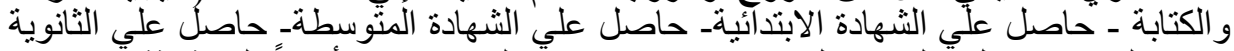

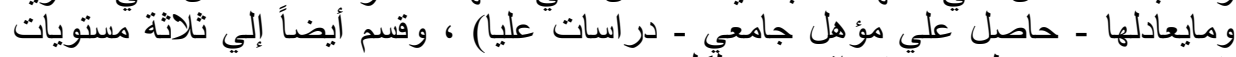

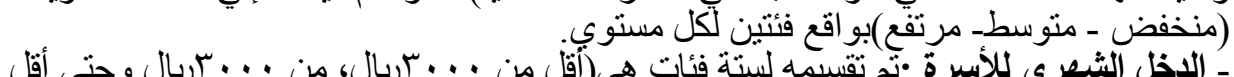

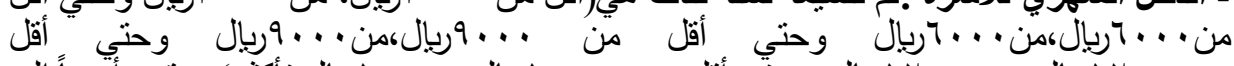

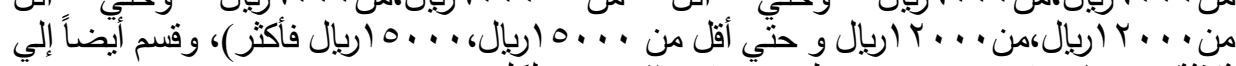

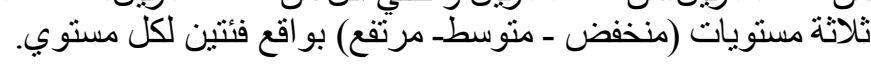

r - استبيان وعي ربة الأسرة بأسلوب التعامل مع الحوادث المنزلية:

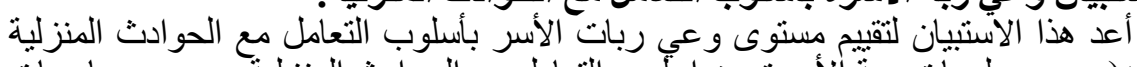

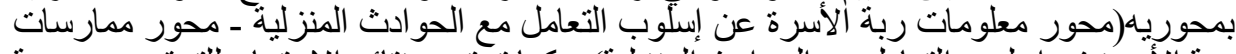

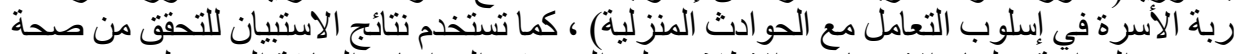

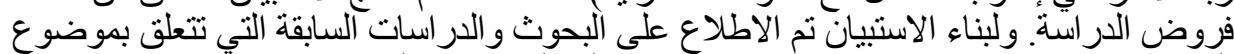

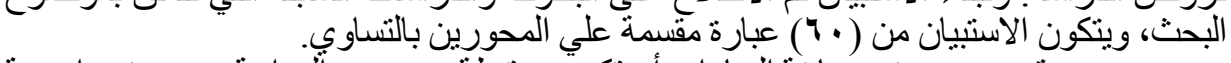

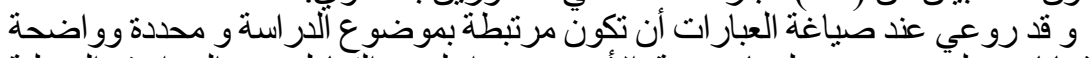

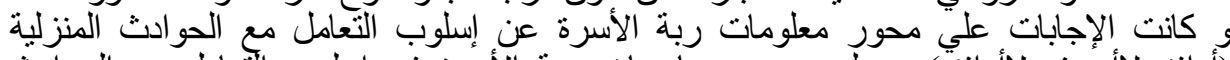

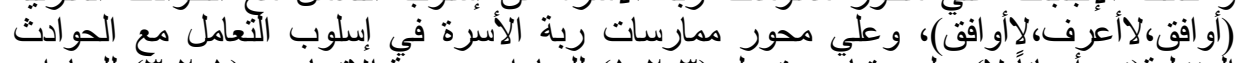

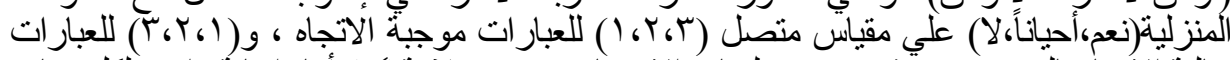

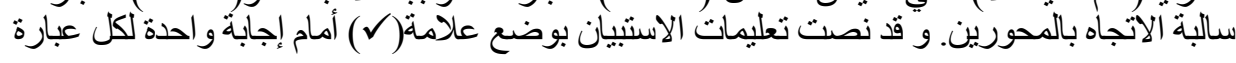

$$
\text { أولاً: حساب صدق الاستبيان بطريقتين هما: }
$$

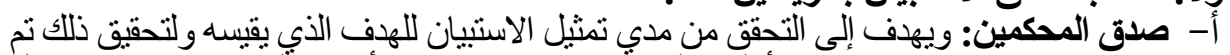
عرض الاستبيان في صورته الأولية على عدد 10 محكم من الأساتذة ألمتخصصين الأنين في مجال 


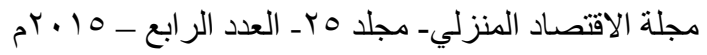

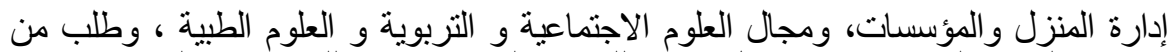

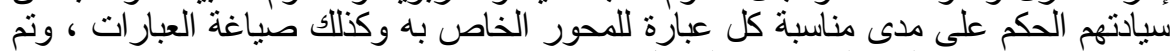

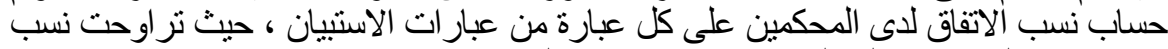

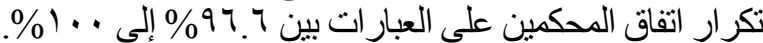

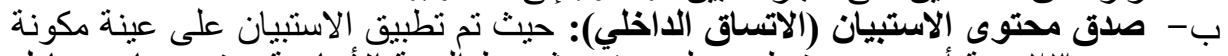

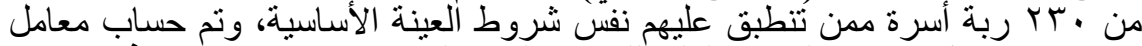

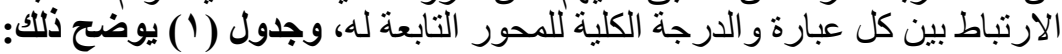

جلول (1) معاملات الارتباط بين عبارات كل محور من محاور الاستبيان ومجموع درجات المحور

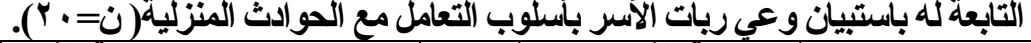

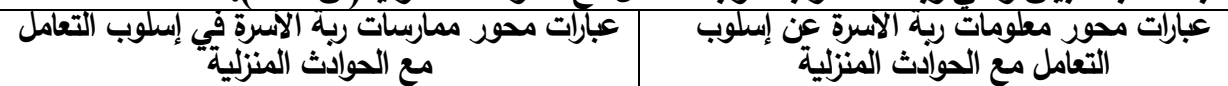
مع الحوائث المنزلية

\begin{tabular}{|c|c|c|c|c|c|c|c|}
\hline معامل الارتباط & r & معامل الارتباط & p & معامل الارتباط & م & معامل الارتباط & م \\
\hline 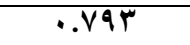 & 17 & $0.0 \leqslant Y$ & 1 & $\cdot . \wedge \otimes \wedge$ & 17 &..$\leqslant 70$ & 1 \\
\hline .9797 & IV & $.0 Y 7$ & $Y$ & .70 & IV & $\cdot r \leqslant 0$ & $Y$ \\
\hline.$Y 07$ & 11 & $\cdot . \Lambda \leqslant \Lambda$ & $r$ & . YY. & 11 & .70 & $r$ \\
\hline.$\mu V \cdot$ & 19 & .189 & $\varepsilon$ & •. $\varepsilon \Psi$ & 19 &.$Y O \Lambda$ & $\varepsilon$ \\
\hline $.70 Y$ & $Y \cdot$ & .1890 & 0 & . & $Y \cdot$ & $\cdot .7 \wedge 9$ & 0 \\
\hline $.0 \vee 0$ & YI & $\because 1890$ & 7 & .700 & YI & - IYYT & 7 \\
\hline.$V 10$ & YY & . YMY & $V$ & •.\&W & YY & $\cdot . \leqslant \leqslant T$ & $\mathrm{~V}$ \\
\hline. .107 & YT & $\cdot . \xi \mid Y$ & $\Lambda$ &.$\mu \Delta \Lambda$ & YT &.$v 01$ & $\Lambda$ \\
\hline $.0 \vee 0$ & YE & .VY. & 9 & - TYY & YE & •.THV & 9 \\
\hline$\cdot \tilde{E} \cdot Y$ & Yo & $\because 1890$ & 1. & $\cdot . \varepsilon \wedge \varepsilon$ & Yo & $\because Y \otimes \Lambda$ & 1. \\
\hline .047 & Y7 & $\cdot r \leqslant \Lambda$ & 11 & $\cdots V r$ & Yq & $\cdot r \cdot \theta$ & 11 \\
\hline$\cdot . \wedge r$ & YV & .Y.O & TY & .700 & YV &.$Y 70$ & IT \\
\hline$\cdot . \wedge r$ & YN & . rqV & $T$ & $\cdot r \cdot \theta$ & YN & $\cdot . \leqslant \Lambda \leqslant$ & 14 \\
\hline$\cdot . \varepsilon \cdot Y$ & rq & ..PI & $1 \varepsilon$ & . YYA & rq & $\because Y O \Lambda$ & $1 \varepsilon$ \\
\hline$\because 0 \vee 0$ & $r$. &.$r 01$ & 10 & .700 & $r$. & $\bullet \varepsilon \Lambda \varepsilon$ & 10 \\
\hline
\end{tabular}

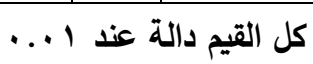

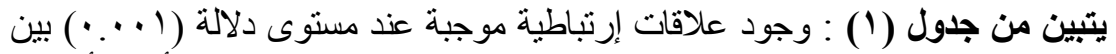

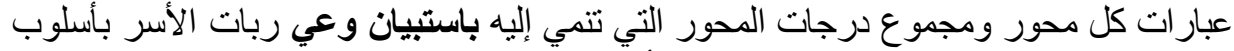

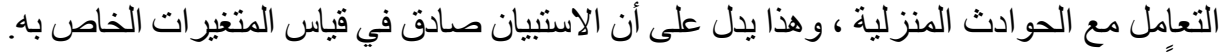

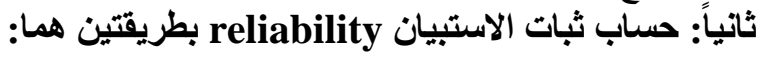

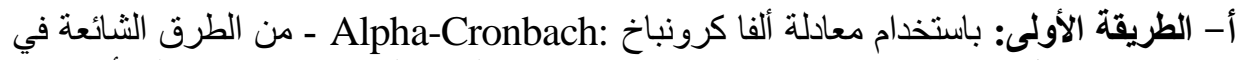

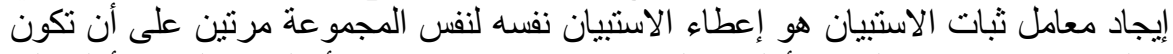

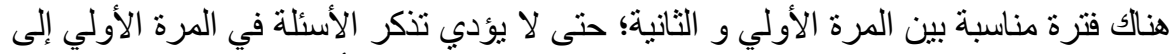

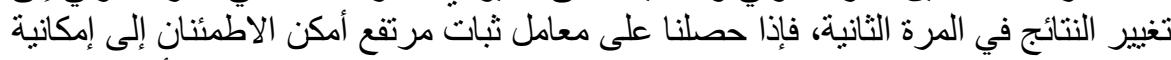

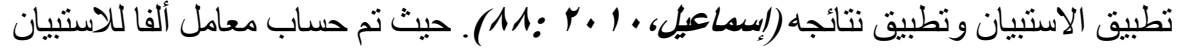

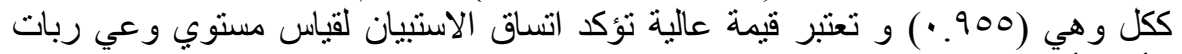

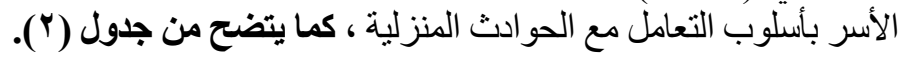




$$
\text { مجلة الاقتصاد المنزليـ مجلد 0rـ العدد الرابع ـ } 10 \text { • بrم }
$$

جدول (Y) معاملات ثبات استبيان وعي ربات الأسر بأسلوب التعامل مع الحوادث المنزلية.

\begin{tabular}{|c|c|c|c|}
\hline \multicolumn{2}{|c|}{ التجزئة النصفية } & معامل & \\
\hline معادلة جتمان & معادلة سييرمان بروان & ألفا & \\
\hline $.91 \%$ & $.97 V$ & .900 & 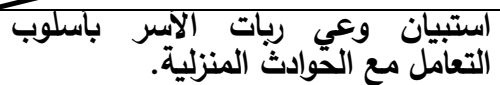 \\
\hline
\end{tabular}

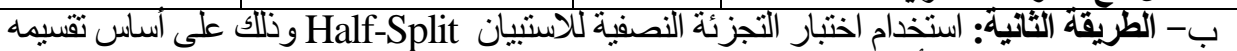

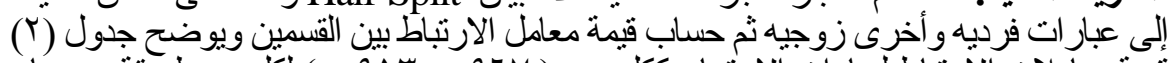

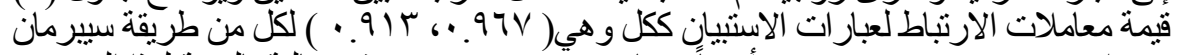

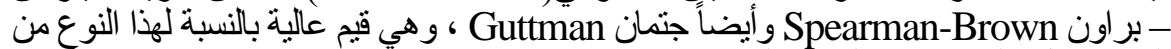

$$
\text { الثنات وتندل على الاتساق الداخلي لعبار ات الاستيان. }
$$

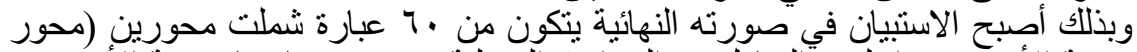

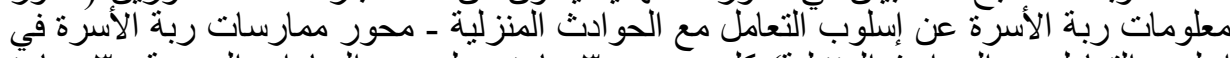

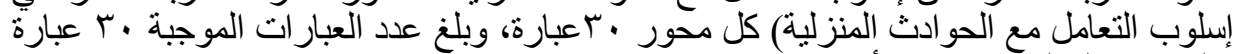

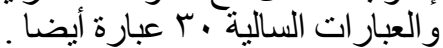

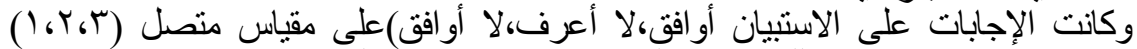

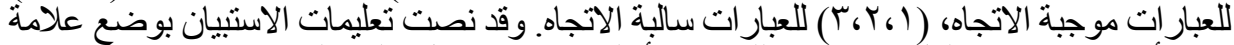

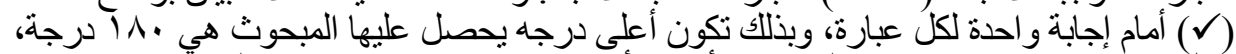

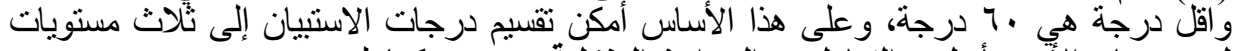

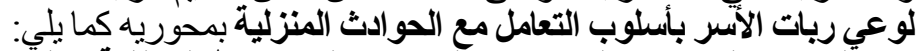

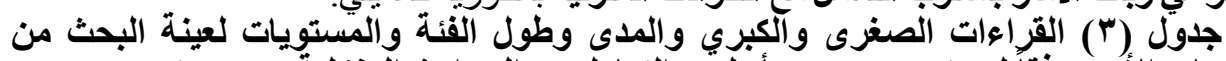

\begin{tabular}{|c|c|c|c|c|c|c|c|}
\hline المرتفعى المستو & المتوستوي & المنخفضتى المست & طولئل & اللمدى & الكبرية القرة & الصغرئ الصغة & البيان \\
\hline$\Lambda \cdot-v_{0}$ & $V \leqslant-71$ & $70-\vee 6$ & $\varepsilon$ & 14 & ^. & 78 & معلومات ربة الأسرة \\
\hline$\Lambda \theta-\Lambda$. & $V q-V \leq$ & $V^{r}-71$ & 7 & 17 & 10 & 71 & ممارسات ربّة الأسرة في إبليلوب التعامل \\
\hline $19 \pi-104$ & $10 Y-1 \leqslant \leqslant$ & $1 \leqslant \mu-1 \% 0$ & 9 & rA & 174 & 1ro & 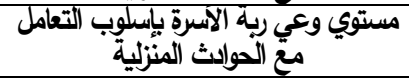 \\
\hline
\end{tabular}

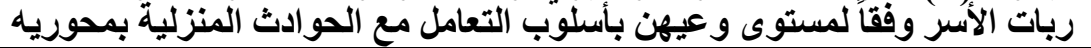

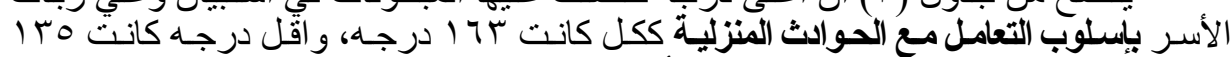

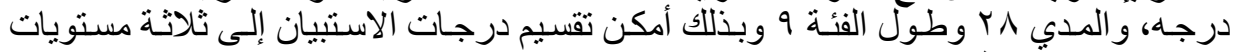
(منخفض - منوسط - مرتفع).

r- استبيان السلامة المنزلية للأطفال كما تلركه الأمهات:

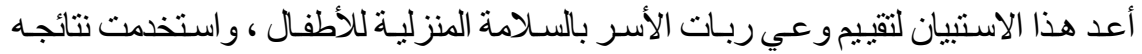

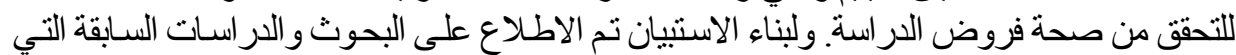

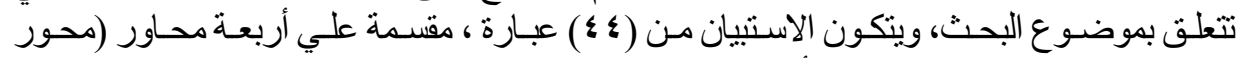

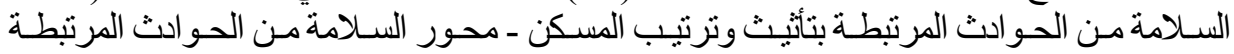

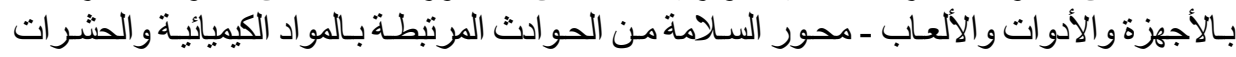

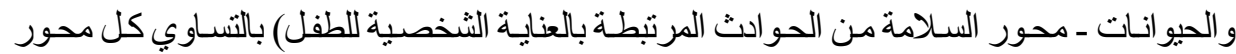




$$
\text { مجلة الاقتصاد المنزليـ مجلد هب ـ العدد الرابع ـ } 10 \text { • بم }
$$

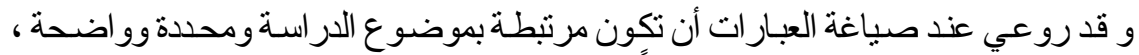

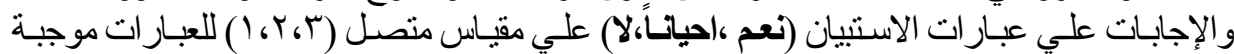

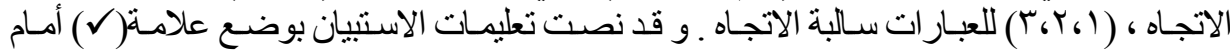

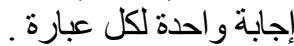

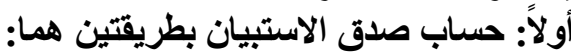

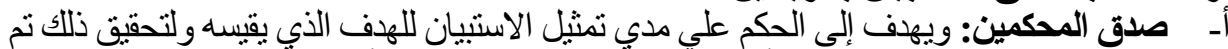

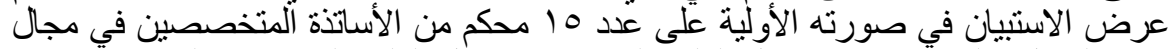

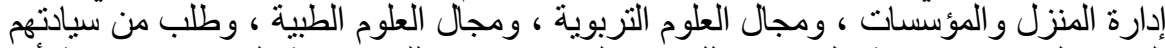

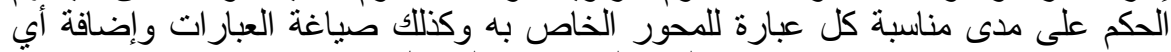

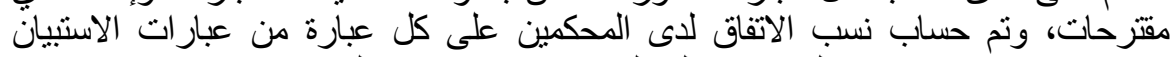

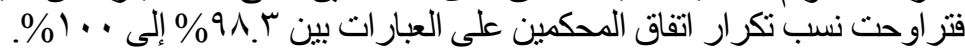

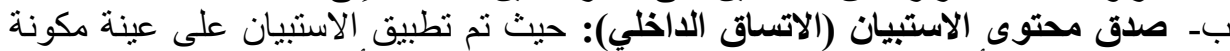

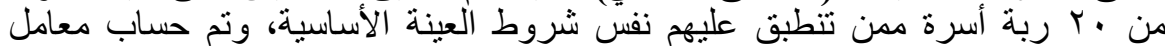

الارتباط بين كل عبارة والدرجة الكلية للمحور التابعة له، ويوضح ذلك جدول (ب):

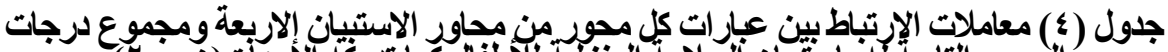

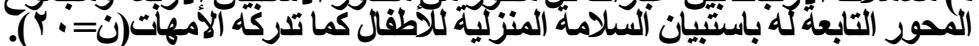

\begin{tabular}{|c|c|c|c|c|c|c|c|}
\hline \multicolumn{2}{|c|}{ 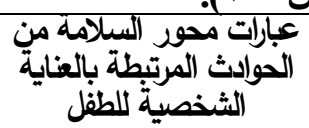 } & \multicolumn{2}{|c|}{ 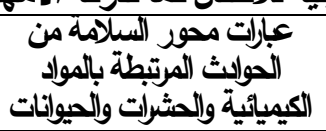 } & \multicolumn{2}{|c|}{ 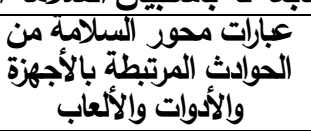 } & \multicolumn{2}{|c|}{ 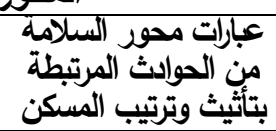 } \\
\hline معامل الارتباط & م & معامل الارتباط & م & معامل الارتباط & م & معامل الارتباط & م \\
\hline..$\$ 90$ & 1 &. .790 & $T$ &. .790 & 1 &..$Y \otimes \Lambda$ & 1 \\
\hline..$\& Y 7$ & r &.$V A r$ & r & $\cdot V \wedge r$ & r &. YMA & r \\
\hline $.0 \leqslant \Lambda$ & $r$ &.$\mu V r$ & $r$ &.$M V H$ & $r$ &.$\% 71$ & $r$ \\
\hline . & $\varepsilon$ &..$M V Y$ & $\varepsilon$ & $\cdot . \varepsilon \backslash$ & $\varepsilon$ & $\cdot . \leqslant 10$ & $\varepsilon$ \\
\hline.$r O r$ & 0 &. .211 & 0 &.$\% 11$ & $\theta$ & .1579 & 0 \\
\hline..$Y I V$ & 7 &.$\mu ा 1$ & 7 & $.09 \%$ & 7 &..$\$ 10$ & 7 \\
\hline $.0 \leqslant \Lambda$ & $\mathrm{V}$ & .094 & $\mathrm{~V}$ & . rra & $\mathrm{V}$ & $.0 \cdot r$ & $V$ \\
\hline. $.71 \%$ & $\Lambda$ & .YYq & $\Lambda$ &.$\% 11$ & $\Lambda$ & $\cdot . r \cdot \Lambda$ & $\Lambda$ \\
\hline. .749 & 9 &.$\mu V Y$ & 9 & $.09 \%$ & 9 &..$M 7 \Lambda$ & 9 \\
\hline$. r \leqslant r$ & 1. & 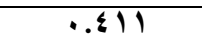 & 1. &. .211 & 1. & $.0 \% 0$ & 1. \\
\hline.$Y \mathrm{YIV}$ & 11 & .1991 & 11 & .1991 & 11 &. rOr & 11 \\
\hline
\end{tabular}

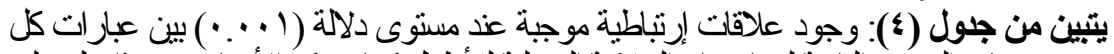

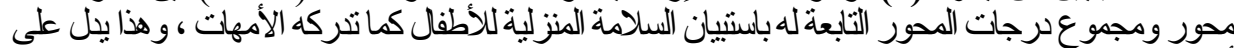

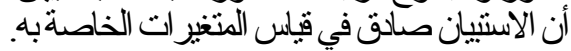

ثثانياً: حساب ثبات الاستبيان reliability بطريقتين هما:

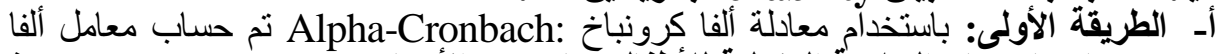

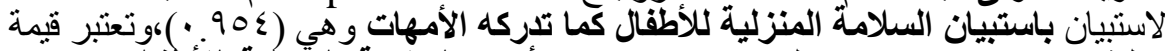

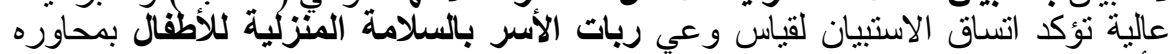

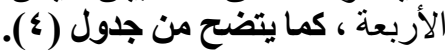


مجلة الاقتصاد المنزليـ مجلد مبـ العدد الرابع ـ 10 • ب م

جول (0) معاملات ثبات استييان السلامة المنزلية للأطفال كما تشركه الأمهات.

\begin{tabular}{|c|c|c|c|}
\hline \multicolumn{2}{|c|}{ التجزئه التصفيه } & \multirow{2}{*}{ معامل } & \multirow[t]{2}{*}{ معامل التبّات } \\
\hline جتمادله & معادله سبيرمان & & \\
\hline$\cdot .9 \cdot r$ &. $.91 Y$ & $.90 \leq$ & استبيان السلامة المنزلية للأطفال كما تركه الأمهات. \\
\hline
\end{tabular}

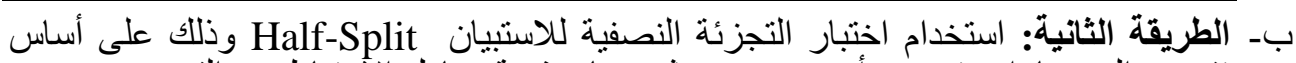

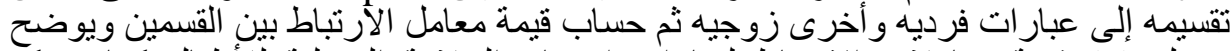

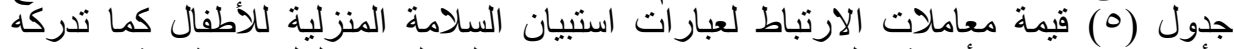

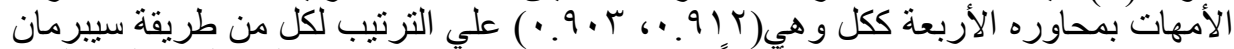

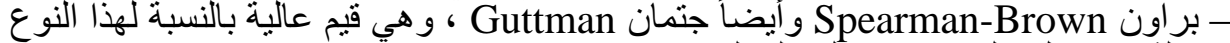
من الثبات وتدل على الاتساق اللاخلي لعبار ات الاستبيان.

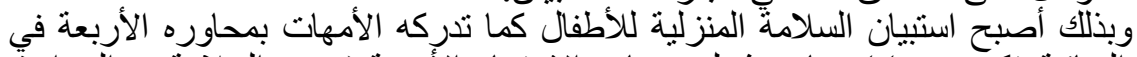

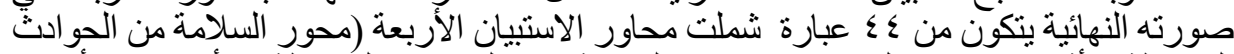

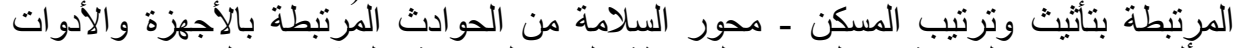

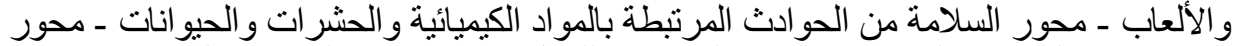

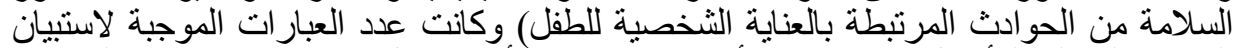

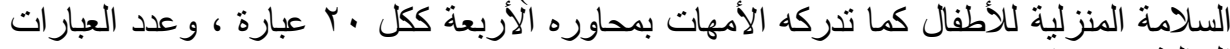

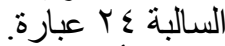

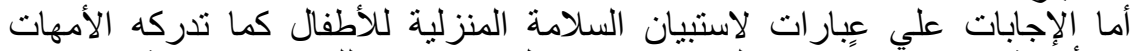

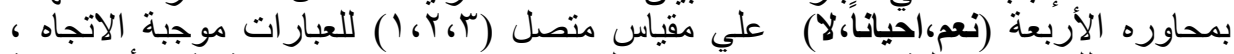

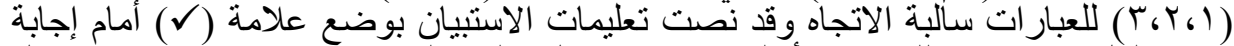

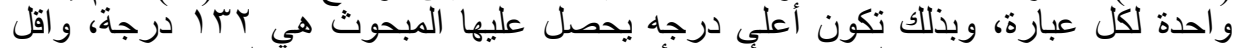

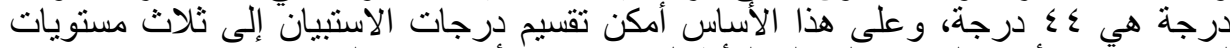

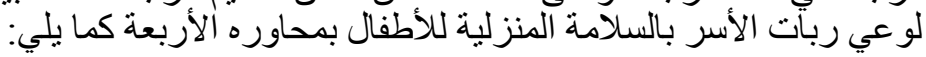

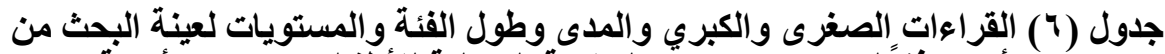

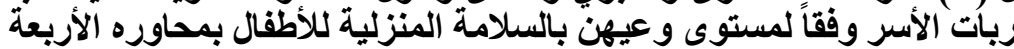

\begin{tabular}{|c|c|c|c|c|c|c|c|}
\hline المرتفع & المتوستوي & المنخفضوى & الفئة & المدى & الكبري & الصغرى الصغة & محاور الالسينيبيان \\
\hline Tr-T. & rq-rV & $Y Y_{-} Y \varepsilon$ & $r$ & 9 & $r r$ & $r \varepsilon$ & 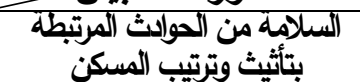 \\
\hline$r r-r \mid$ & $\varepsilon r \cdot-Y \wedge$ & YV_YO & $r$ & 9 & $\mu$ & ro & 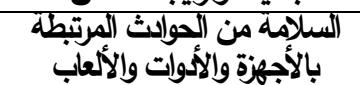 \\
\hline$r r-r$. & rq-Yq & D-YY & $\varepsilon$ & TY & rr & rY & البلموادة الكيميائية وإلحثراتث \\
\hline rY-Yq & $r \Lambda_{-} r^{\circ}$ & $Y \leq-Y I$ & $\varepsilon$ & IY & rr & YI & 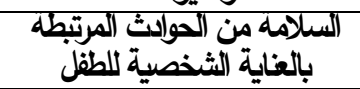 \\
\hline-11 & $119-111$ & 1.1 & 1. & pq & $1 \% 9$ & 1.1 & مستوي السلامة المنزلية للأطفال \\
\hline
\end{tabular}

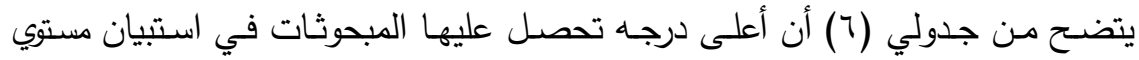

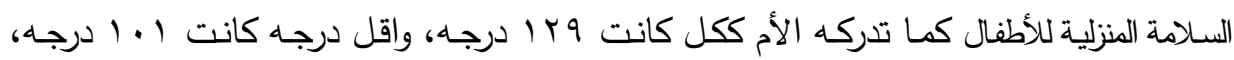




$$
\text { مجلة الاقتصاد المنزلي- مجلد مr- العدد الرابع - } 10 \text { • rم }
$$

والمدي 9 ب وطول الفئة ـ ا وبذلك أمكن تقسيم درجات المقياس إلى ثلاثة مستويات (منخفض

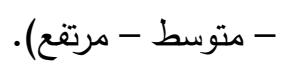

\section{سادساً: أسلوب جمع وتهوليل الببانات}

تم الحصول على بيانات هذه الدراسة عن طريق استخدام الاستبيان الذي تم استيفاؤه

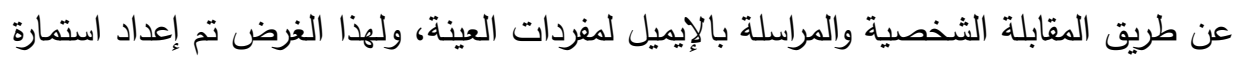
للبيانات الأولية واستبيان وعي ربة الأسرة بأسلوب التعامل مع الحوادث المنزلية واستبيان

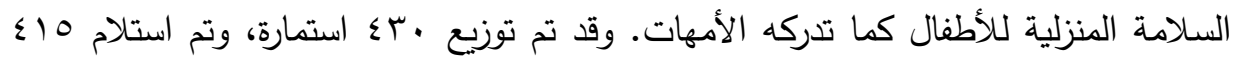

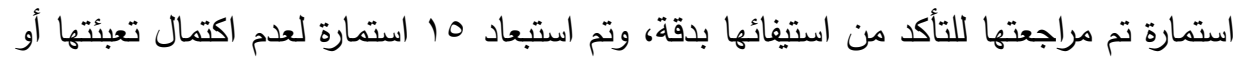
عدم جدية المبحوثات في مله البيانات، وبذلك أصبح العدد النهائي . .ـ استمارة تم تفريغها

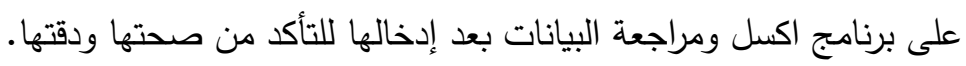

\section{سابعا: المعاملات الإهصائية المستخدمة}

Statistical تم تحليل البيانات وإجراء المعالجة الإحصائية باستخدام برنامج Package for Social Sciences Program (Spss.) البيانات وتفريغها على أوراق خاصة ومراجعتها بعد إدخالها للحاسب من أجل ضمان صحة

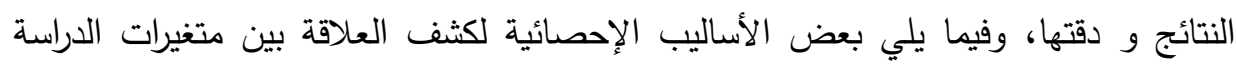
واختبار صحة الفروض:

$$
\text { 1- حساب التكرارات والنسب المئوية لكل متغيرات الدراسة. }
$$

r- حساب معاملات الارتباط بين عبارات كل محور ومجموع درجات المحور لحساب صدق

$$
\text { محتوى الاستبيان. }
$$

r- معامل ألفا كرونباخ، واختبار التجزئة النصفية باستخدام معادلتي سييرمان - بروان، وجتمان لحساب

$$
\text { ثبات أدوات الدراسة. }
$$

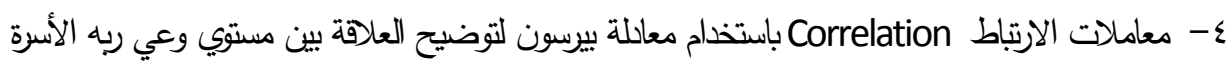

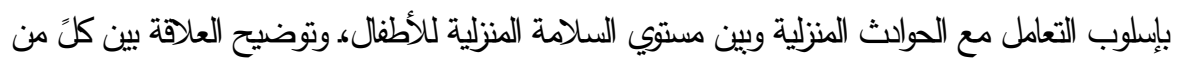




$$
\text { مجلة الاقتصاد المنزليـ مجلد مr- العدد الر ابع ـ 10 • بم }
$$

مستوي وعي ربه الأسرة بإسلوب التعامل مع الحوادث الهنزليةو مستوي السلامة النتزلية للأطفال وبين كلً من حجم الأسرة وعدد سنوات الزواج ومستوي الدخل الشهري للأسرة. 0- اختبار(ت) T test للوقوف على دلالة الفروق بين متوسطات درجات كلَ من (ربات

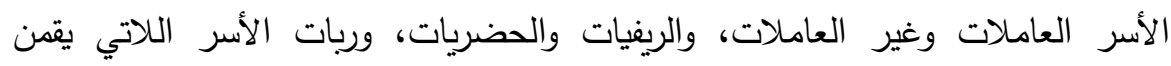
بمسكن ملك و إيجار ) في كلٍ من مستوي وعيهن بإسلوب التعامل مع الحوادث المنزلية ومستوي السلامة المنزلية للأطفال.

צ- تحليل التباين ANOVA)Analysis of Variance في اتجاه واحد لمعرفة دلالة الفروق بين متوسطات درجات ربات الأسر في مستوي وعيهن بكلً من إسلوب التعامل مع الحوادث

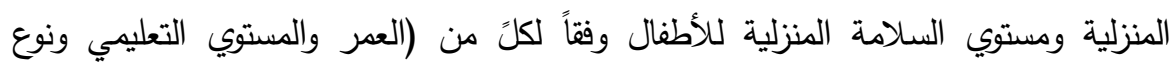
الوظيفة لكل من الزوج والزوجة ونوع المسكن). وفى حالة وجود فروق تم تطبيق اختبار Tukey

\section{نـنائج الدراسة المبيدانبة}

\section{أولا: وصف عينـة الدراستة}

فيما يلي وصف لعينة الدراسة الميدانية والتي بلغت . . ــ ربة أسرة تم اختيارهن بطريقة مقصودة، ويوضح ذلك الجداول من (V) إلى (T آ ) توضح ذلك.

جدول (v) التوزيع النسبي لعينة الدراسة وفقاً لمحل الإقامة

\begin{tabular}{|c|c|c|c|c|}
\hline المئوية & العلد & \multicolumn{2}{|c|}{ محل الإقامة } & r \\
\hline rI & $T r \varepsilon$ & محافظة الطائف & \multirow{3}{*}{ حضر } & \\
\hline 11.0 & $\leqslant 7$ & المدينة المنورة & & 1 \\
\hline V.o & $r$. & مكة المكرمة & & \\
\hline 0. & $r \ldots$ & \multicolumn{2}{|c|}{ المجموع } & \\
\hline $1 Y .0$ & 0. & الخرمة & \multirow{4}{*}{ ريف } & \multirow{4}{*}{ r } \\
\hline $0 . r$ & YI & رنية & & \\
\hline $1 . .1$ & $\varepsilon r$ & تربة & & \\
\hline r1.0 & ^ฯ & المويه & & \\
\hline
\end{tabular}


مجلة الاقتصاد المنزليـ مجلد 0rـ العدد الرابع ـ 10 • بrم

\begin{tabular}{|c|c|c|}
\hline 0 . & $r \ldots$ & المجموع \\
\hline $1 \ldots$ & $\varepsilon \ldots$ & العينة الكلية \\
\hline
\end{tabular}

يتبين من جدول (V): أن العينة الكلية للدراسة تبلغ ( . . ) ربة أسرة ، مأخوذة من

حضر وريف المملكة العربية السعودية بالمناصفة .

r- مئات العمر لرب وربة الأسرة:

جدول (^) التوزيع النسبي لعينة الدراسة وفقاً لفئات العمر لرب و ربة الأسرة

\begin{tabular}{|c|c|c|c|c|}
\hline \multicolumn{2}{|c|}{ ربة الأسرة } & \multicolumn{2}{|c|}{ رب الأسرة } & \multirow{2}{*}{ فئات العمر } \\
\hline النسبة المئوية & العلد & النسبة المئوية & العدد & \\
\hline$Y \varepsilon . \Lambda$ & 99 & $\Lambda .0$ & $r \varepsilon$ & من · זسنة وحتى أقل من · r سنة \\
\hline $10 . r$ & 71 & $r \cdot r$ & $\Lambda 1$ & من · ب سنة وحتى آقل من · ؛ سنة \\
\hline 09 & YYE & $07 . r$ & YYO & من ؛ وحتى ألقل من · ه سنة \\
\hline$\varepsilon$ & 17 & 10 & 7. & أ • سنة فأكثر \\
\hline $1 \cdots$ & $\varepsilon \cdots$ & $1 \ldots$ & $\varepsilon \cdots$ & المجموع \\
\hline
\end{tabular}

يتبين مـن جدول (^): أن أعلي نسبة بفئات العمر لكلٍ من رب و ربـة الأسرة بالعينـة الكلية

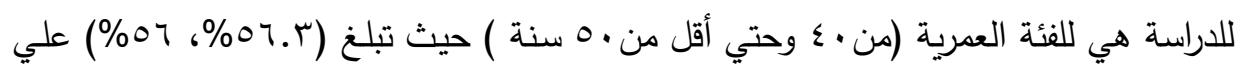

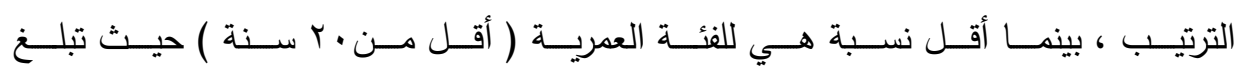
(صفر \%،صفر \%) علي الترتيب. "ب - مجم الأسرة : جدول (9) التوزيع النسبي لعينة الاراسة وفقاً لحجم الأسرة

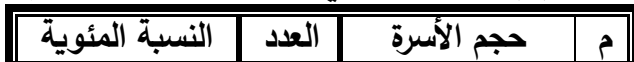


مجلة الاقتصاد المنزليـ مجلد مبـ العدد الرابع ـ 10 • ب م

\begin{tabular}{|c|c|c|c|}
\hline 1.0 & re & من r إلي ع أفراد & 1 \\
\hline rT.o & $1 \% \varepsilon$ & من • إلي 1 آَقراد & $r$ \\
\hline $0 \wedge$ & PRY & من V آَفراد فَأكثر & $r$ \\
\hline $1 \ldots$ & $\varepsilon \ldots$ & المجموع & \\
\hline
\end{tabular}

يتبين مسن جدول (9): أن أعلي نسبة بفئات حجم الأسرة للعينة الكلية للدراسة هي للفئة

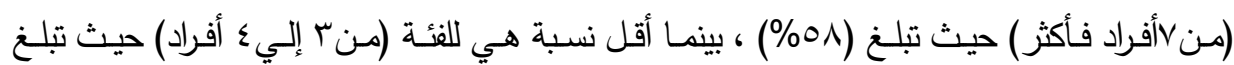

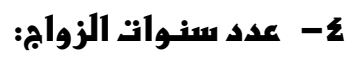

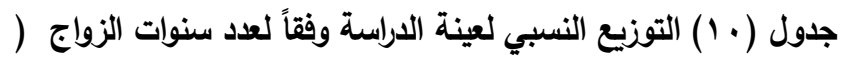

\begin{tabular}{|c|c|c|c|}
\hline النسبة المئوية & العدد & عدد سنوات الزواج & מ \\
\hline$\wedge$ & $\overline{M r}$ & آقل من • سنوات & 1 \\
\hline- & - & من • وحتى آقل من · اسنوات & $r$ \\
\hline IY.A & 01 & من · ا وحتى آقل من • اسنة & $r$ \\
\hline 17.0 & 79 & من 10 وحتى آقل من · זسنة & $\varepsilon$ \\
\hline 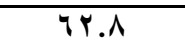 & YOI & • باسنة فأكثر & 0 \\
\hline $1 \ldots$ & $\varepsilon \cdots$ & المجموع & \\
\hline
\end{tabular}

يتبين من جدول (• (1): أن أعلي نسبة بفئات عدد سنوات الزواج للعينة الكلية للدراسة هي

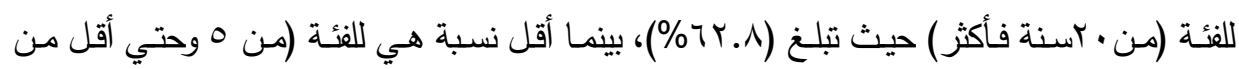

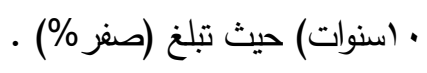

0

جدول (11) التوزيع النسبي لعينة الدراسة وفقاً لنوع و طبيعة السكن

\begin{tabular}{|c|c|c|c|c|c|c|c|}
\hline النسبة المئوية & العدد & طبيعة السكن & م & النسبة المئوية & العدد & نوع السكن & م \\
\hline AY.O & $r r$. & ملك & $T$ & $r \varepsilon .0$ & $1 \%$ & شقة & $T$ \\
\hline $1 V .0$ & V. & إيجار & $r$ & $r \cdot .0$ & TYY & دوز & $r$ \\
\hline- & - & لادي الأهل & $r$ & ro & $1 \leq$. & فيلا & $r$ \\
\hline $1 \ldots$ & $\varepsilon \ldots$ & المجموع & & $1 \ldots$ & $\varepsilon \ldots$ & مجموع & \\
\hline
\end{tabular}

يتبين مسن جدول (1 1): أن أعلي نسبة بنوع السكن للعينة الكلية للدراسـة هي (لسـاكني

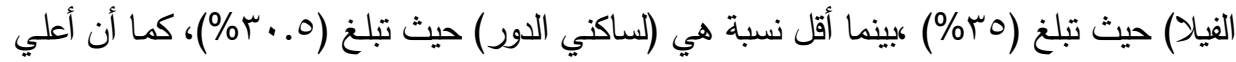

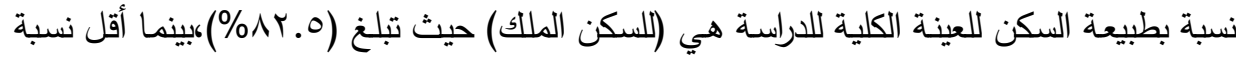

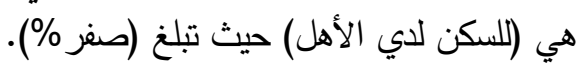

1 - نوع الوظيفة لرب و ربة الأسرة : 
مجلة الاقتصاد المنزليـ مجلد Or ـ العدد الرابع - 10 • بم

جدول (r r ) التوزيع النسبي لعينة الدراسة وفقاً لنوع وظيفة رب وربة الأسرة

\begin{tabular}{|c|c|c|c|c|}
\hline \multicolumn{2}{|c|}{ ربة الأسرة } & \multicolumn{2}{|c|}{ رب الأسرة } & \multirow[t]{2}{*}{ الوظيفة } \\
\hline النسبة المئوية & العدد & النسبة المئوية & العدد & \\
\hline IY.A & 01 & $\leq 7$ & $1 \wedge \varepsilon$ & وظيفة حكومية \\
\hline $7 . r$ & ro & r..० & 1.7 & أعمال حرة \\
\hline- & - & $1 . .0$ & $\leq r$ & متقاعد \\
\hline \multirow[t]{2}{*}{11} & TY & - & - & بلون عمل \\
\hline & & IV & 71 & متوفي \\
\hline $1 \ldots$ & $\varepsilon \ldots$ & $1 \ldots$ & $\varepsilon \ldots$ & |المجموع \\
\hline
\end{tabular}

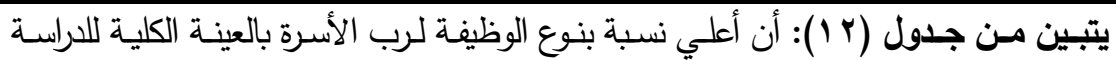

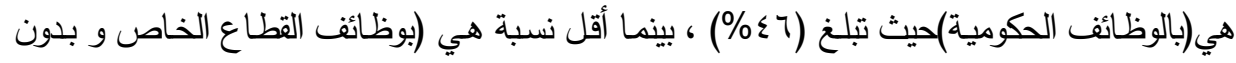
عمل) حيث تبلغ (صفر \%،صفر \%) علي الترتيب، كما أن أعلي نسبة بنوع الوظيفة لربة الأسرة بالعينة

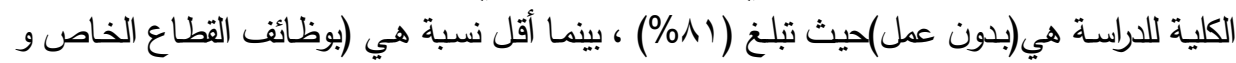

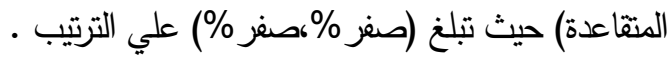

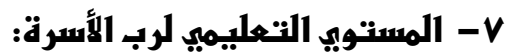

جدول (r ا ) التوزيع النسبي لعينة الاراسة وفقاً للمستوي التعليمي لرب و ربة الأسرة (

\begin{tabular}{|c|c|c|c|c|}
\hline \multicolumn{2}{|c|}{ ربة الأسرة } & \multicolumn{2}{|c|}{ رب الأسرة } & \multirow[t]{2}{*}{ المستوى التعليمى } \\
\hline النسبة المئوية & العدد & النسبة المئوية & العد & \\
\hline$£ . \Lambda$ & 19 & IV.O & $v$. & لا يجيد القراءة والكتابة \\
\hline$\varepsilon \cdot . r$ & 171 & 9.0 & $r \Lambda$ & حاصل على الابتدائية \\
\hline IV & 71 & r.. & 14 & حاصل على الثهادة المتوسطة \\
\hline 11.1 & $\leqslant V$ & 19 & $\sqrt{ } 4$ & حاصل على الثانوية العامة \\
\hline r..r & 1.0 & rr.o & ir. & حاصل على مؤهل جامعي \\
\hline $1 \cdots$ & $\varepsilon \ldots$ & $1 \cdots$ & $\varepsilon \ldots$ & المجموع \\
\hline
\end{tabular}

يتبين من جدول (T (1): أن أعلي نسبة بالمستوي التعليمي لرب الأسرة بالعينة الكلية للدراسة

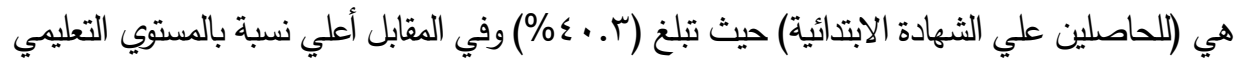

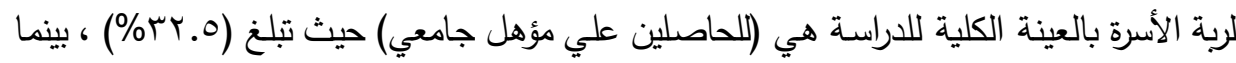

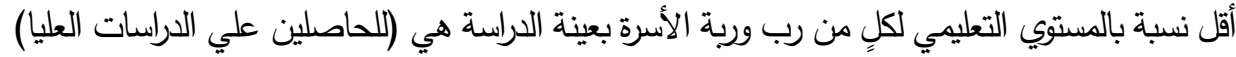

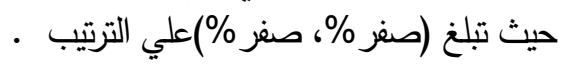

1- فئات الدخل الشهرى للأسرة 
مجلة الاقتصاد المنزليـ مجلد OY ـ العدد الرابع - 10 • ب م

جدول (ء 1) التوزيع النسبي لعينة الاراسة وفقاً لفئات لاخل الثهري للأسرة

\begin{tabular}{|c|c|c|c|}
\hline النسبة المئوية & العلد & فئات الاخل الثهري للأسرة & م \\
\hline $1 Y .0$ & 0 . & أقل من . . . ب ريال & 1 \\
\hline 10 & 7. & 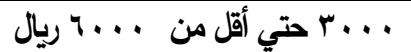 & $r$ \\
\hline$r 0 . r$ & 1.1 & . . . . حتي أقل من ...9 ريال & $r$ \\
\hline 19.1 & Vq & 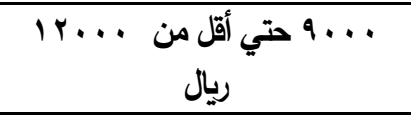 & $\varepsilon$ \\
\hline ro & $1 \ldots$ & 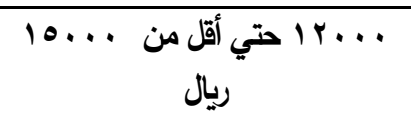 & 0 \\
\hline Y.० & 1. & . . . . 1 اريال فأكثر & 9 \\
\hline $1 \ldots$ & $\varepsilon \ldots$ & 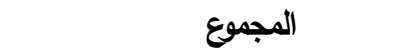 & \\
\hline
\end{tabular}

يتبين من جدول (ء 1): أن أعلي نسبة بفئات الدخل الثـهري للأسرة للعينة الكلية للدراسة

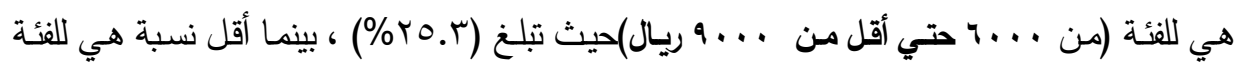

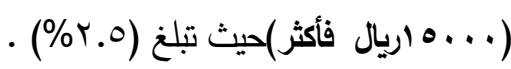

9- التوزيـع النسبي لعينـة ربـات الأسـر وفقاً لمستوي وعيهن بإسلوب التعامـل مـع الحـوادث المنزلية:

جلول (0 1 ) توزيع أفراد عينة ربات الأسر وفقاً لمستوي وعيهن بإسلوب التعامل مع الحوابث المنزلية بمحوريه

\begin{tabular}{|c|c|c|c|c|c|c|}
\hline \multicolumn{2}{|c|}{ 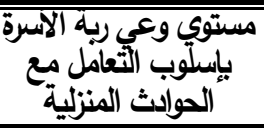 } & \multicolumn{2}{|c|}{ فم مي إسلوبت التعامل الأسرة } & \multicolumn{2}{|c|}{ 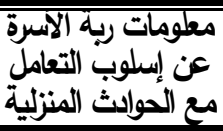 } & \multirow[t]{2}{*}{ المحاور } \\
\hline$\%$ & عدد & $\%$ & عدد & $\%$ & عدد & \\
\hline ir & OY & rq.1 & 119 & rq & 119 & منخفض \\
\hline 00 & YY. & $0 V .0$ & rr. & 01.1 & $r \cdot V$ & متوسط \\
\hline rr & IYA & IY.A & 01 & $19 . r$ & VV & مرتفع \\
\hline \multicolumn{2}{|c|}{$1 \leqslant 9.0 \mathrm{~V}$} & \multicolumn{2}{|c|}{$v 0.79$} & \multicolumn{2}{|c|}{$V 4.91$} & المتوسط \\
\hline \multicolumn{2}{|c|}{7.17} & \multicolumn{2}{|c|}{ r.q. } & \multicolumn{2}{|c|}{$r .9 r$} & الانحراف المعياري \\
\hline $1 \cdots$ & $\varepsilon \cdots$ & $1 \ldots$ & $\varepsilon \cdots$ & $1 \cdots$ & $\varepsilon \cdots$ & المجموع \\
\hline
\end{tabular}

يتبين مسن جدول (ه 1) : أن أعلي نسبة لربات الأسر في مستوي الوعي بمحوري

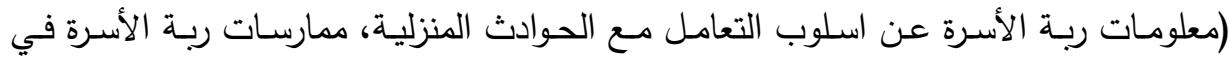

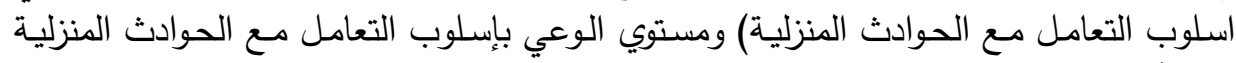

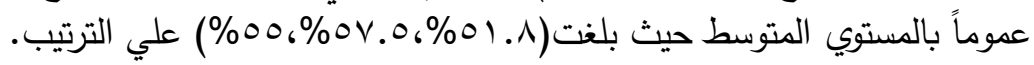




$$
\text { مجلة الاقتصاد المنزلي- مجلد مr- العدد الر ابع - 10 • بم }
$$

• - التوزيع النسبي لعينة ربات الأسر وفقاً لمستوي السلامة المنزلية للأطفال : جلول (ه ا ) توزيع أفراد عينة ربات الأسر وفقاً لمستوي السلامة المنزلية للأطفال بمحاوره الأربعة

\begin{tabular}{|c|c|c|c|c|c|c|c|c|c|c|}
\hline \multicolumn{2}{|c|}{ المنزليةي للأطفال } & \multicolumn{2}{|c|}{ 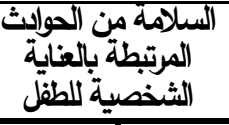 } & \multicolumn{2}{|c|}{ المرتبطة بالمواد الكيمة الحواثيائية } & \multicolumn{2}{|c|}{ 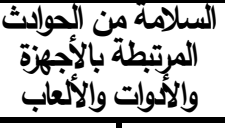 } & \multicolumn{2}{|c|}{ 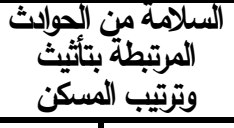 } & المحاور \\
\hline$\%$ & عد & $\%$ & عدد & $\%$ & عد & $\%$ & عد & $\%$ & علد & مستوي \\
\hline rV.o & 10. & $\mathrm{~V}$ & rA & $1 \wedge . \Lambda$ & Vo & $\$ 1.0$ & 179 & $r 0.0$ & $1 \cdot r$ & منخفض \\
\hline$\varepsilon \varepsilon . \Gamma$ & IVV & $M 1.0$ & $1 Y 7$ & $0 \leqslant . \Lambda$ & Y19 & Y1.0 & Aт & ro.r & 1.1 & متوسط \\
\hline IA.r & $V r$ & 71.0 & $r \leq Y$ & Y7.0 & 1.7 & $r v$ & $1 \leqslant \Lambda$ & $\leqslant 9 . \%$ & $19 V$ & مرتفع \\
\hline \multicolumn{2}{|c|}{$111 . . \varepsilon$} & \multicolumn{2}{|c|}{ FV.74 } & \multicolumn{2}{|c|}{ rV.TA } & \multicolumn{2}{|c|}{ rq.rq } & \multicolumn{2}{|c|}{ Y^. $\varepsilon \varepsilon$} & المتوسط \\
\hline \multicolumn{2}{|c|}{ 7. } & \multicolumn{2}{|c|}{ Y.. r } & \multicolumn{2}{|c|}{ r... 9} & \multicolumn{2}{|c|}{ Y.MT } & \multicolumn{2}{|c|}{1.71} & الانحراف المعياري \\
\hline $1 \ldots$ & $\varepsilon \ldots$ & $1 \ldots$ & $\varepsilon \ldots$ & $1 \ldots$ & $\varepsilon \ldots$ & $1 \ldots$ & $\varepsilon \ldots$ & $1 \cdots$ & $\varepsilon \ldots$ & المجموع \\
\hline
\end{tabular}

يتين من جدول (17) أن أعلي نسبة لربات الأسر بمحوري (السلامة من الحوادث المرتبطة

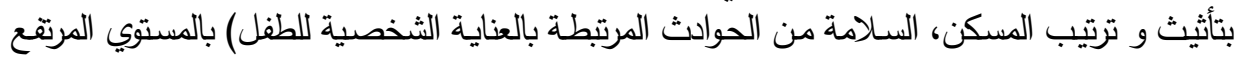

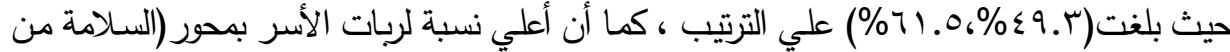

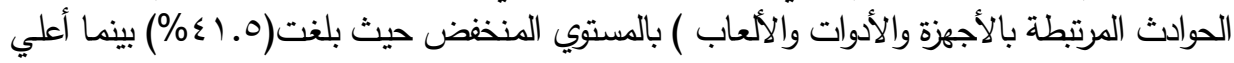

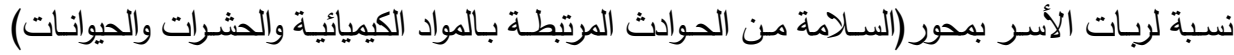

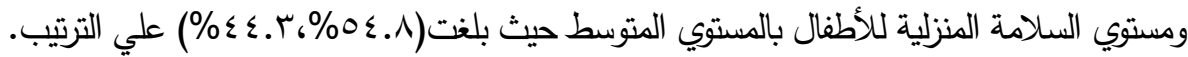

\section{ثانبياً: 1انـنائج في ضوء فروض الدراسة}

\section{1- - تنتائج الفرض الأول}

ينص الفرض الأول على أنه: " لا توجد علاقة ارتباطية ذات دلالة إحصائية بين مستوي وعي ربه الأسرة بإسلوب التعامل مع الحوادث المنزلية وبين مستوي السلامة المنزلية للأطفال ". وللتحقق من صحة الفرض إحصائيا تم حساب معاملات الارتباط باستخدام معادلة بيرسون بين مستوي وعي ربه الأسرة بإسلوب التعامل مع الحوادث المنزلية وبين مستوي السلامة المنزلية للأطفال ، ويوضح ذلك الجدول (IV): - 
مجلة الاقتصاد المنزليـ مجلد 0بـ العدد الرابع ـ 10 • بم

جلول (IV): معاملات الازتباطبين مستوي وعي ربه الأسرة بإسلوب التعامل مع الحواثث الهنزلية وبين مستوي السلامة المنزلية للأطفال

\begin{tabular}{|c|c|c|c|c|c|}
\hline السلأمنزية & 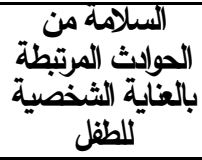 & 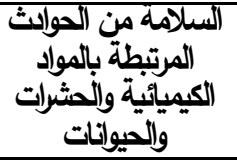 & 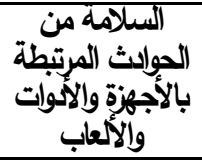 & 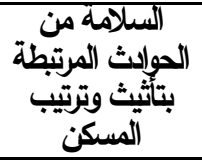 & المتغيرات \\
\hline $\begin{array}{l}* * * \\
\text { •rY }\end{array}$ & $\begin{array}{l}* * * \\
\text {. YYI }\end{array}$ & $. .7 r-$ & $\begin{array}{l}* * * \\
.109\end{array}$ & $\begin{array}{l}* * * \\
\bullet . \leqslant 19\end{array}$ & 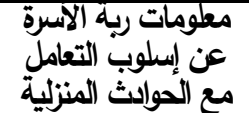 \\
\hline $\begin{array}{l}\text { **** } \\
. r \wedge r\end{array}$ & $\begin{array}{l}* * * \\
. .090\end{array}$ & $\begin{array}{l}* * * \\
\bullet r \cdot r\end{array}$ & $\begin{array}{l}* * * \\
. . Y 70\end{array}$ & $\begin{array}{c}* \\
.111\end{array}$ & في إسلوب التعامل الأسرة \\
\hline $\begin{array}{l}* * * * \\
. . r v .\end{array}$ & $\begin{array}{l}* * * \\
.0 .1\end{array}$ & $\cdots \wedge 0$ & $\begin{array}{l}* * * \\
\text { •.r }\end{array}$ & $\begin{array}{l}* * * \\
* . r Y V\end{array}$ & 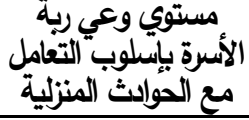 \\
\hline
\end{tabular}

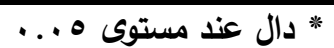

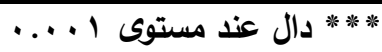

$$
\text { يتبين من جدول (IV) ما يلي : . }
$$

• وجود علاقة ارتباطية موجبة بين معلومات ربة الأسرة عن إسلوب التعامل مع الحوادث المنزلية وكل من السلامة من الحوادث المرتبطة بتأثثث وترتيب المسكن ، والسلامة من الحوادث المرتبطة بالأجهزة والأدوات والألعـاب ، والسـلامة مـن الحـوادث المرتبطة بالعنايـة الشخصية للطفل ، ومستوي السـلامة

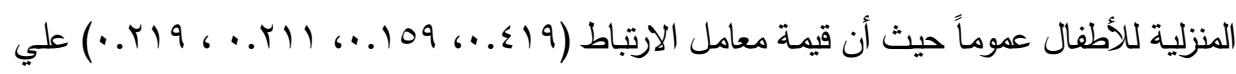
الترتيب للعينة الكلية للدراسة وهي قيم دالة احصائياً عند مستوي دلالة (1 . . .) ، بينما لا توجد علاقة ارتباطية بين معلومات ربة الأسرة عن إسلوب التعامل مع الحوادث المنزلية وبين السلامة من الحوادث المرتبطة بالمواد الكيميائية والحشرات والحيوانات حيث كانت قيمة معامل الارتباط با ب . . . وهـى قيمة غير دالة إحصائيا . • وجود علاقة ارتباطية موجبة بين ممارسات ربة الأسرة عن إسلوب التعامل مع الحوادث المنزلية وكل

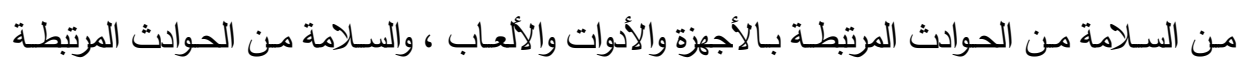
بالمواد الكيميائية والحشـرات والحيوانـات، والسـلامة مـن الحوادث المرتبطة بالعنايـة الشخصية للطفل ،

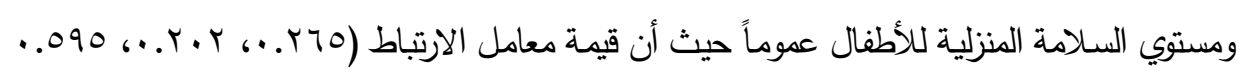

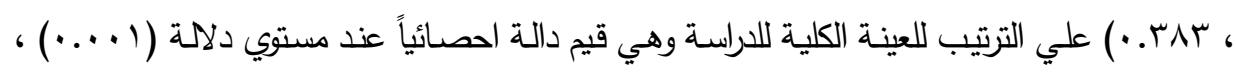
بينما توجد علاقة ارتباطية بين ممارسات ربـة الأسرة عن إسلوب التعامل مـع الحوادث المنزلية وبين 


$$
\text { مجلة الاقتصاد المنزلي- مجلد هبـ العدد الرابع ـ } 10 \text { • بم }
$$

السلامة من الحوادث المرتبطة بتأثيث وترتيب المسكن حيث كانت قيمة معامل الارتباط ا 11 . . وهى قيمة دالة إحصائيا عند مستوى دلالة ه ـ. . . • وجود علاقة ارتباطية موجبة بين وعى ربة الأسرة عن إسلوب التعامل مع الحوادث المنزلية وكل من السـلامة من الحوادث المرتبطة بتأثيث وترتيب المسكن ، والسـلامة مـن الحوادث المرتبطة بـالأجهزة والأدوات والألعـاب ، والسـلامة مـن الحوادث المرتبطـة بالعنايـة الشخصية للطفل ، ومستوي السـلامة

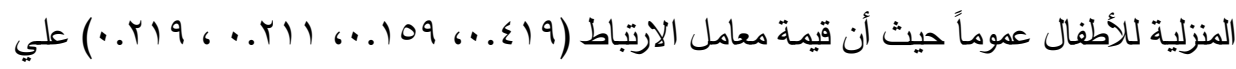
الترتيب للعينة الكلية للدراسة وهي قيم دالة احصائياً عند مستوي دلالة (1 . . .) ، بينما لا توجد علاقة ارتباطية بين وعي ربة الأسرة عن إسلوب التعامل مع الحوادث المنزلية السلامة من الحوادث المرتبطة بالمواد الكيميائية والحشرات والحيوانات حيث كانت قيمة معامل الارتباط با ج . . . وهى قيمة غير دالة • إحصائيا نستخلص ممـا سبق أنـه توجد علاقة ارتباطيه موجبة عند مستوي دلالة (1 . . . ) بين مستوي وعي ربـه الأسـرة بإسـلوب التعامـل مـع الحـوادث المنزليـة وبين مسـتوي السـلامة المنزليـة للأطفال. وبذلك يتحقق عدم صحة الفرض الأول.

\section{r- بـنائج الفرض الثناني}

ينص الفرض الثاني على أنه: "لا توجد علاقة ارتباطية ذات دلالة إحصائية بين مستوي وعي ربه الأسرة بإسلوب التعامل مع الحوادث المنزلية وبين كلً من حجم الأسرة وعدد سنوات الزواج ومستوي الاخل الثهري للأسرة".

وللتحقق من صحة الفرض إحصائيا تم حساب معاملات الارتباط باستخدام معادلة بيرسون بين مستوي وعي ربه الأسرة بإسلوب التعامل مع الحوادث المنزلية وبين كلً من حجم الأسرة وعدد سنوات الزواج ومستوي الدخل الشهري للأسرة ، ويوضح ذللك الجدول (1 I): -

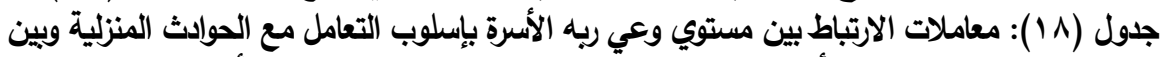

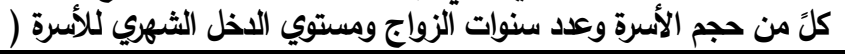

\begin{tabular}{|c|c|c|c|}
\hline مستوي الألخل الثهري & عد سنوات الزواج & 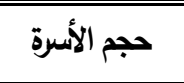 & المتغيرات \\
\hline$* * * . . \leqslant 00-$ & ****. & ****.YY. - & معلومات ربه الأسرة عن إسلويب التعامل \\
\hline ****.ro, - & $* * * \ldots \wedge r-$ & $* * . .1 \leq r-$ & ممارسات ربه الاسرة في إبلوية ألتعامل \\
\hline
\end{tabular}


مجلة الاقتصاد المنزليـ مجلد هبـ العدد الر ابع ـ 10 • بrم

\begin{tabular}{|c|c|c|c|}
\hline$* * * . . \leqslant 90-$ & ****.rVq - & ***..YYr - & مستوي وعي ربيه الأسرة بإسلوب التعامل \\
\hline
\end{tabular}

كل القيم داله عند مستوى ال....

يتبين من جلول (1 1 ) وجود علاقة ارتباطية سالبة بين معلومات ربة الأسرة عن إسلوب التعامل مع الهع

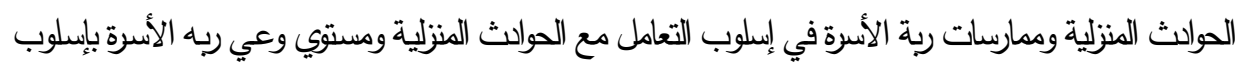
التعامل مع الحوادث المنزلية عموماً وبين كلً من حجم الأسرة وعلد سنوات الزواج ومستوي الدخل الثهري للأسرة

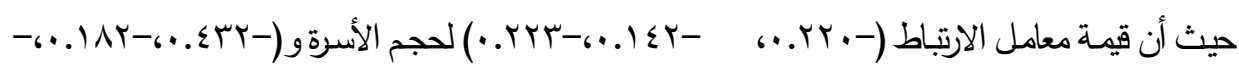

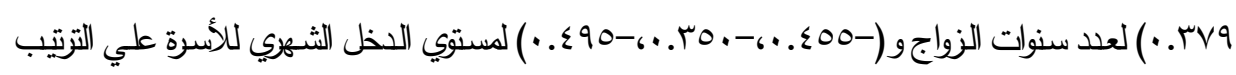

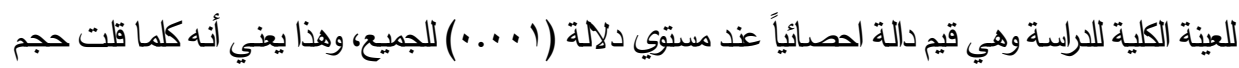

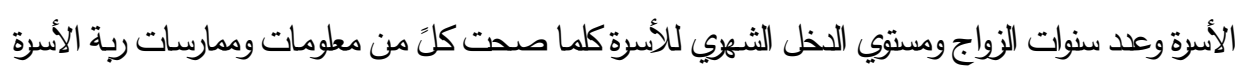
نحو إسلوب التعامل مع الحوادث المنزلية و إنتع مستوي وعي ربه الأسرة بإسلوب التعامل مع الحوادث المنزلية .

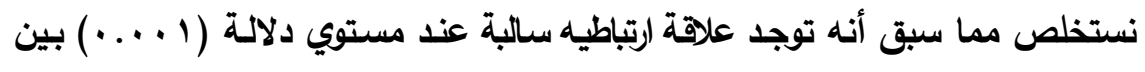
مستوي وعي ربه الأسرة بإسلوب التعامل مع الحوادث المنزلية وبين كلً من حجم الأسرة وعدد سنوات الزواج ومستوي الاخل الثهري للأسرة. وبذلك يتحقق عدم صحة الفرض الثران الثاني.

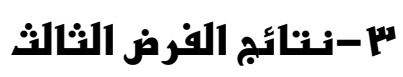

ينص الفرض الثالث على أنه: "لا توجد علاقة ارتباطية ذات دلالة إحصائية بين مستوي السلامة المنزلية للأطفال وبين كلً من حجم الأسرة وعدد سنوات الزواج ومستوي الاخل

$$
\text { الثهري للأسرة". }
$$

وللتحقق من صحة الفرض إحصائيا تم حساب معاملات الارتباط باستخدام معادلة بيرسون

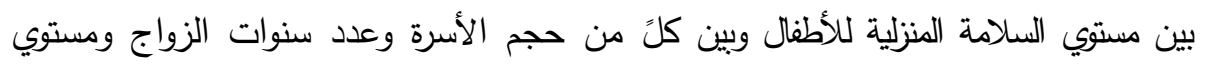
الدخل الشهري للأسرة ، ويوضح ذلك الجدول (9 1 (1): جدول (9 1): معاملات الارتباط بين مستوي السلامة المنزلية للأطفال وبين كلً من حجم الأسرة وعدد سنوات الزواج ومستوي النخل الثهري للأسرة

\begin{tabular}{|c|c|c|c|}
\hline الثهتوي للأسرة & علد سنوات & حجم الأسرة & المتغيرات \\
\hline$\cdots 9 v-$ & $. .1 .1-$ & $\cdots r \wedge-$ & السلاهة من الحواثث المرتبطة بتأثيث وترتيب المسكن \\
\hline$\ldots r r-$ & ..11 ${ }^{*}$ & $\ldots \leqslant 4-$ & السلامة من الحوادث المرتبطة بالأجهزة والأوات والألعاب \\
\hline. .11 & $\therefore \wedge \Gamma^{\top}-$ & $\cdots+r-$ & السلامهة من الحوإث المرتبطة بالمواد الكيميائية وإلحشرات \\
\hline
\end{tabular}


مجلة الاقتصاد المنزليـ مجلد 0rـ العدد الرابع - 10 • بم

\begin{tabular}{|c|c|c|c|}
\hline & & & والحيوانات \\
\hline $\begin{array}{c}* * * \\
. . Y 99-\end{array}$ & $\begin{array}{c}* * * \\
.00 \leqslant-\end{array}$ & 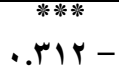 & السلامة من الحواثث المرتبطة بالعناية الثخصية للطفل \\
\hline$\cdots V \varepsilon-$ & $\begin{array}{c}\text { **** } \\
\text {. . YVY - }\end{array}$ & ..11.- & مستوي السلامة المنزلية للأطفال \\
\hline
\end{tabular}

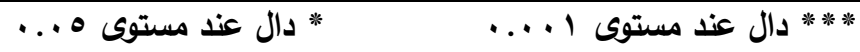

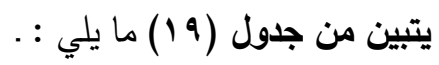

• وجـود علاقـة ارتباطية سـالبة بين حجم الأسـرة وبين مستوي وعـي ربـات الأسـر بمحور

السلامة من الحوادث المرتبطة بالعناية الشخصية للطفل والسلامة المنزلية للأطفال عموماً حيث أن

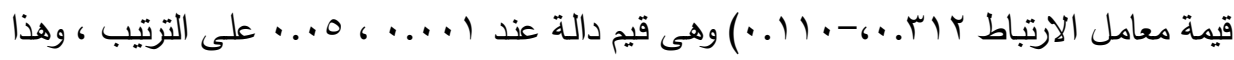
يعني أنه كلما قلت حجم الأسرة إرتقع مستوي وعي ربـه الأسرة محور السـلامة من الحوادث المرتبطة بالعناية الثخصية للطفل والسلامة المنزلية للأطفال عموماً. بينما لاتوجد علاقة ارتباطية بين حجم الأسرة وكل من محور السلامة من الحوادث المرتبطة بتأثثث وترتيب المسكن ، والسلامة من الحوادث المرتبطـة بـالأجهزة والأدوات والألعـاب ، السـلامة مـن الحوادث المرتبطـة بـالمواد الكيميائيـة والحشـرات والحيوانات .

• وجود علاقة ارتباطية سـالبة بين عدد سنوات الزواج وبين مستوي وعي ربات الأسـر

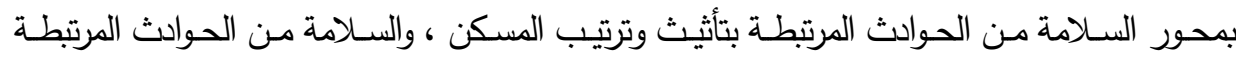

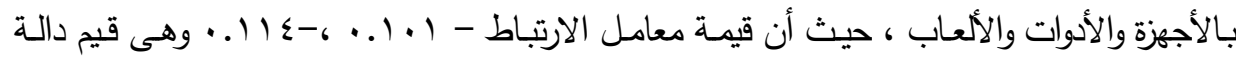
عند ه . . ، وأيضا وجود علاقة ارتباطية سالبة بين عدد سنوات الزواج وبين مستوي وعي ربات

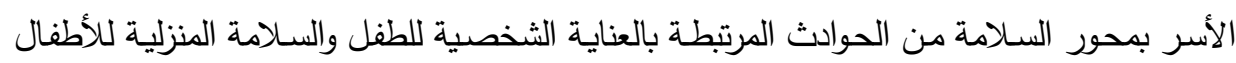

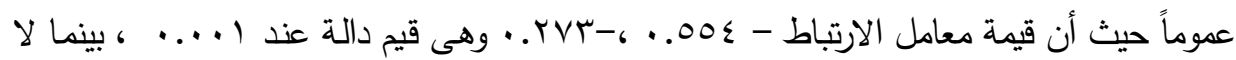
توجد علاقـة ارتباطية بين عدد سـوات الزواج وبنـت محورالسـلامة مـن الحـوادث المرتبطـة بـالمواد الكيميائية والحشرات والحيوانات .

• وجود علاقة ارتباطية سـالبة بين مستوي الـخل الشـهري للأسرة وبين مستوي وعي ربات

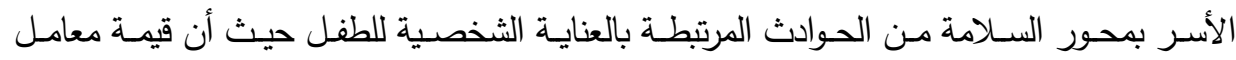
الارتباط - 99 9. . وهى قيمة دالة عند ا . .. . . . بينما لاتوجد علاقة ارتباطية بين مستوي الاخل الثهري للأسرة وكل من محور السلامة من الحوادث المرتبطة بتأثيث وترتيب المسكن ، والسلامة من

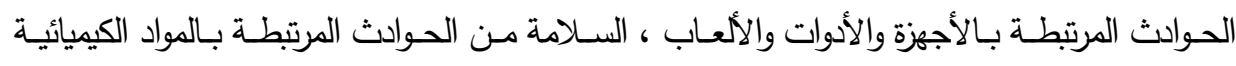
والحشرات والحيوانات والسلامة المنزلية للأطفال عموماً.

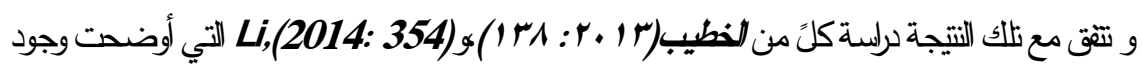
تباين ذات دلالة احصائية بين ربـات الأسر في التعرض للحواثث المنزليةوفقاً لحجم الأسرةو عدد سنوات للزواج 


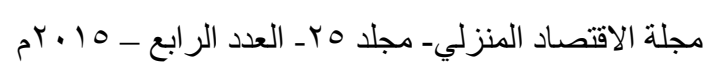

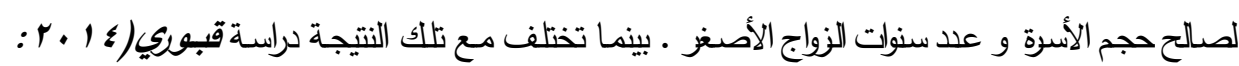

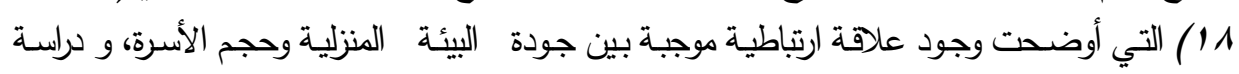

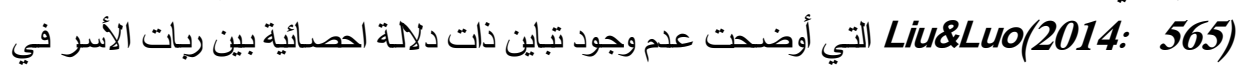
مستوي التعرض للحواثث المنزلية وققاً لعدد سنوات الزواج •

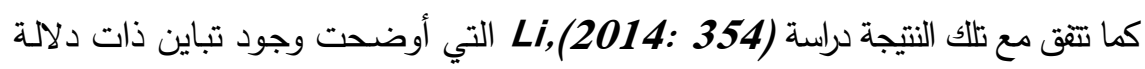

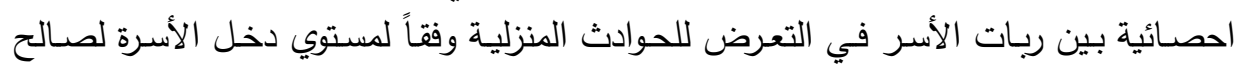

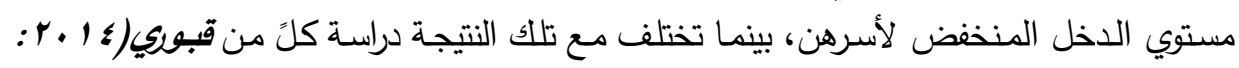

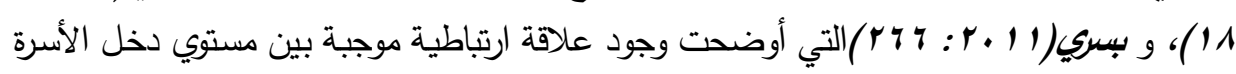

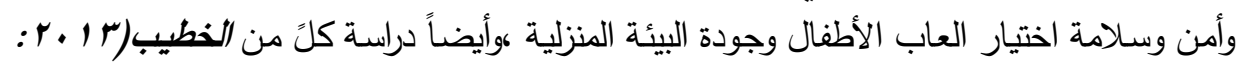

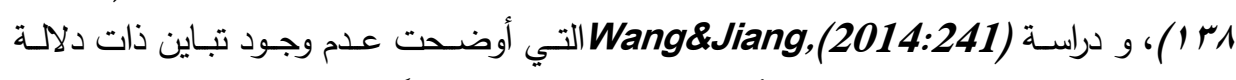
احصائية بين ربات الأسر في تعرض أطفالهن للحوادث المنزلية وفقاً لمستوي دخل الأسرة.

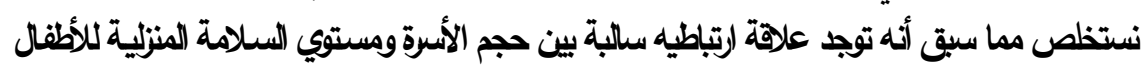

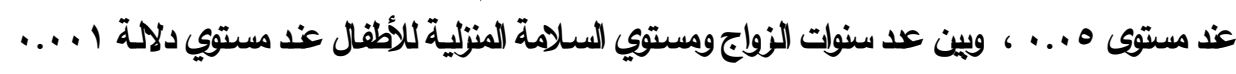

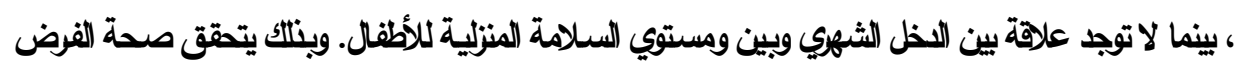

الثلث جزئيا .

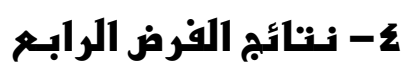

ينص الفرض الرابع على أنه: " لا توجد فروق ذات دلالة إحصائية بين ربات الأسر

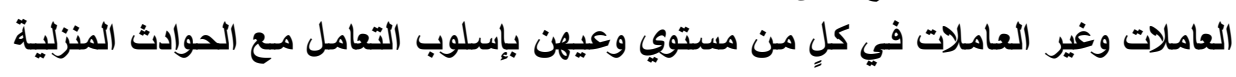

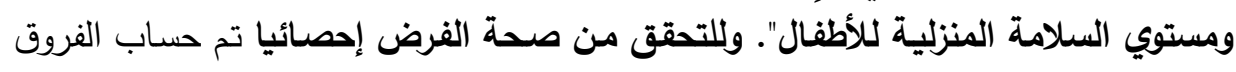

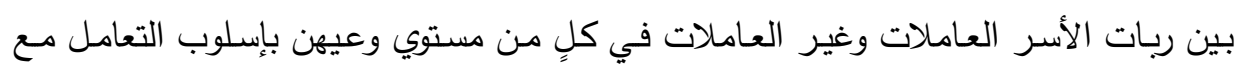

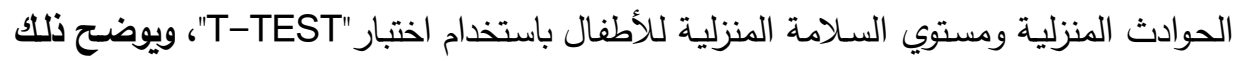

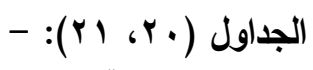

\begin{tabular}{|c|c|c|c|c|c|c|c|c|}
\hline \multirow{2}{*}{ مستوي الدلالة } & \multirow{2}{*}{ قيمة ت } & \multirow{2}{*}{ 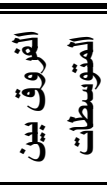 } & \multicolumn{2}{|c|}{ 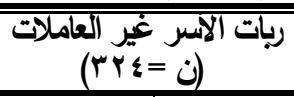 } & \multicolumn{2}{|c|}{ 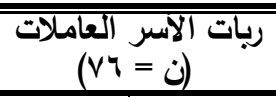 } & \multirow[t]{2}{*}{ البيان } & \multirow[b]{2}{*}{ المحاور } \\
\hline & & & الالمعراف & المستوسط & الانعراري & المتابي & & \\
\hline
\end{tabular}

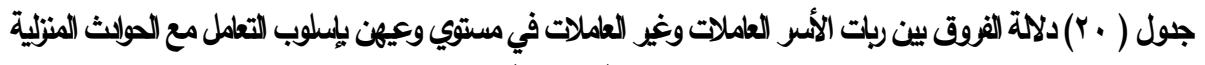


مجلة الاقتصاد المنزليـ مجلد هبـ العدد الرابع ـ 10 • ب م

\begin{tabular}{|c|c|c|c|c|c|c|c|}
\hline$\cdots \cdot 1$ & $r . . r$. & O.Y. & r.7V & VY.qY & $1 . r v$ & VA.I r & معلومات ربه الأسرة عن إسلويب \\
\hline$\cdots+1$ & $\varepsilon .00$ & 1.87 & r.Vr & $V \varepsilon . Y \varepsilon$ & $\varepsilon .+7$ & $V 0.99$ & مارسات \\
\hline$\cdots+1$ & $0 . V 7$ & 7.90 & $7.7 Y$ & $1 \leq V .17$ & $\varepsilon .99$ & $10 \leqslant .11$ & 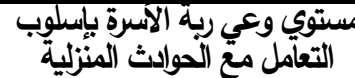 \\
\hline
\end{tabular}

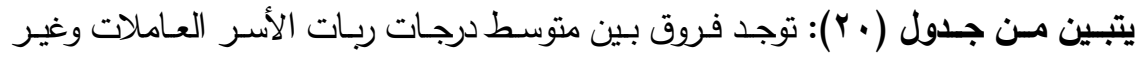

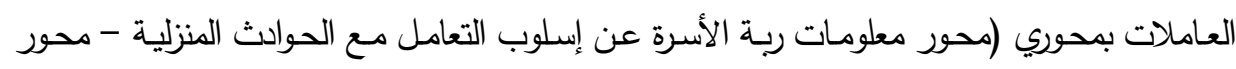

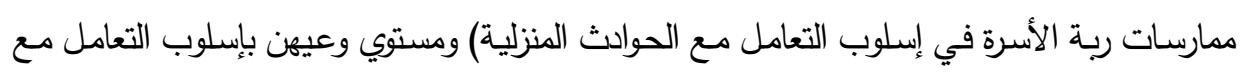

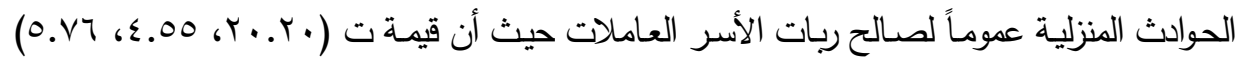

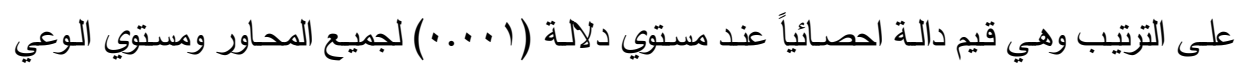
بإسلوب التعامل مع الحوادث المنزلية عموماً.

جول ( ب (Y) دلالة الفروق بين ربات الأسر العاملات وغير العاملات في مستوي السلامة المنزلية للأطفال بمحاورها

\begin{tabular}{|c|c|c|c|c|c|c|c|}
\hline \multirow{2}{*}{ مستوي الالالة } & \multirow{2}{*}{ قيمة ت } & \multirow{2}{*}{ 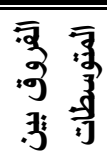 } & \multicolumn{2}{|c|}{ 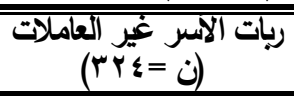 } & \multicolumn{2}{|c|}{$\begin{array}{c}\text { ربات الأسر العاملات (V7) } \\
\text { (V7) }\end{array}$} & \multirow[t]{2}{*}{ البيان } \\
\hline & & & المعياري & المستبطيط & الالمعياري & الحستبيط & \\
\hline$\cdots \cdot 1$ & V.7V & $1.1 \%$ & 1.20 & rA.Yr & .99 & rq.r & الستلأيثة من الحوايث المرتبطة \\
\hline 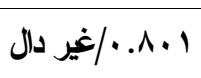 &.$r o$ & $\cdots 1$ & $r . \varepsilon r$ & rq. r $\varepsilon$ & $1 . \wedge 9$ & rq.rr & السالأحهزة من الأحواتث والألعاب المرتبطة \\
\hline$\cdots+1$ & Y.19 &. .01 & Y.. E & YV.YI & $r . \cdot q$ & rV.Vq & 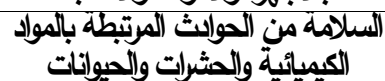 \\
\hline 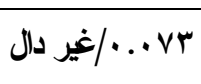 & $1 . \Lambda$. & . & Y.11 & rv. $0 q$ & $1 . Y \varepsilon$ & rv.qr & السلاماية من الحوالثة للطفلزبطة \\
\hline$\ldots 1$ & 1.77 & r.11 & T.Ar & IIr.rV & r.vi & | וצ.r & مستوي السلامة المنزلية للأطفال \\
\hline
\end{tabular}

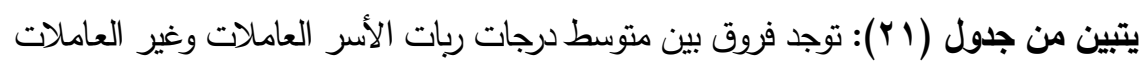

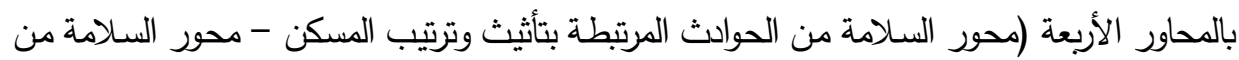

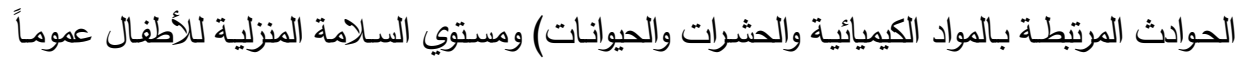

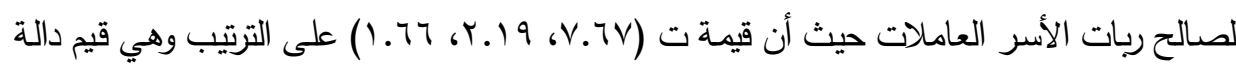

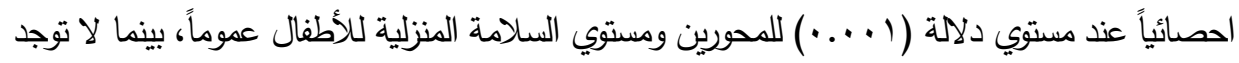
فروق بين متوسط درجات ربات الأسر العاملات وغير العاملات بمحوري (محور السلامة من الحوادث لـاثل 


$$
\text { مجلة الاقتصاد المنزليـ مجلد مبـ العدد الرابع - } 10 \text { • ب م }
$$

المرتبطة بالأجهزة والأدوات والألعاب - محور السلامة من الحوادث المرتبطة بالعناية الشخصية للطفل)

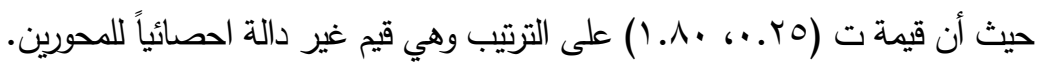

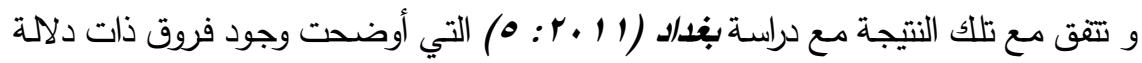

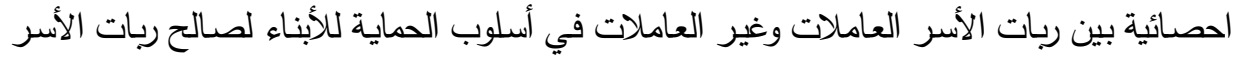

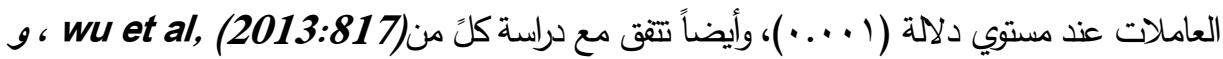

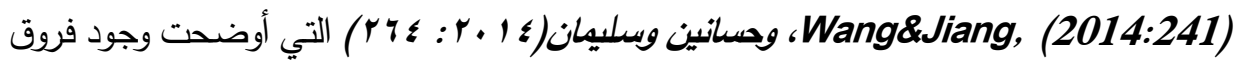

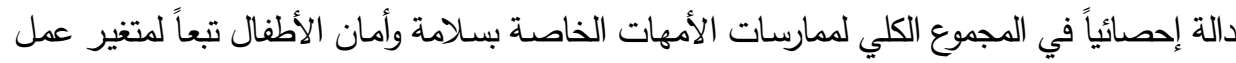

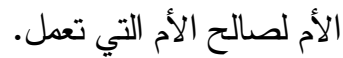

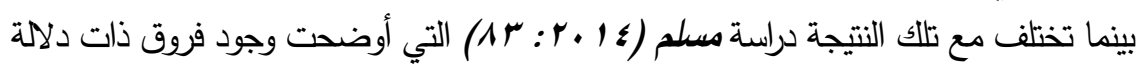

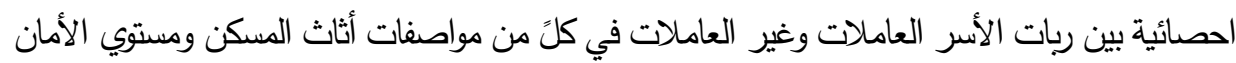

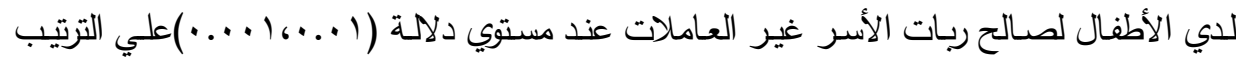

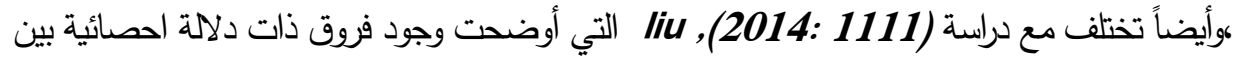
ربات الأسر العاملات وغير العاملات في التدابير الوقائية للأطفال ضد المخاطر لصالح رجيات الأسر

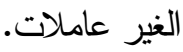

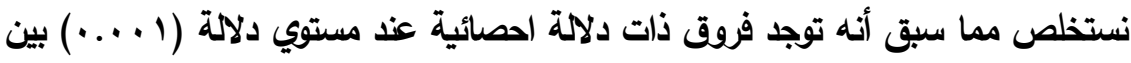

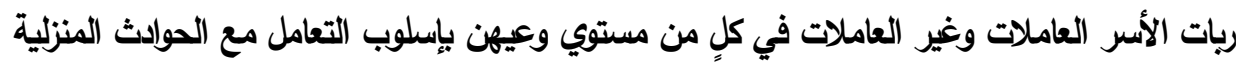

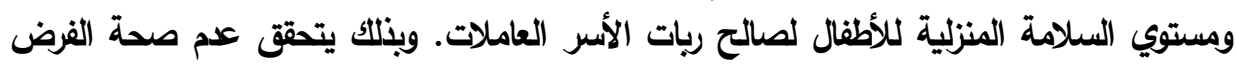

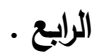

\section{0}

ينص الفرض الخامس على أنـه: " لا توجد فروق ذات دلالـة إحصائية بين ربـات الأسر الحضريات والريفيات في كلٍ من مستوي وعيهن بإسلوب التعامل مـع الحوادث المنزلية

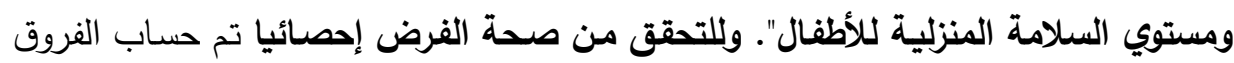

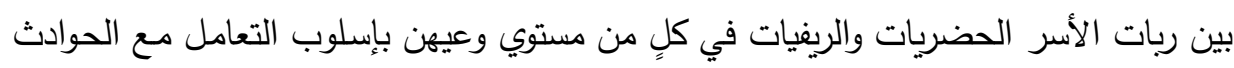

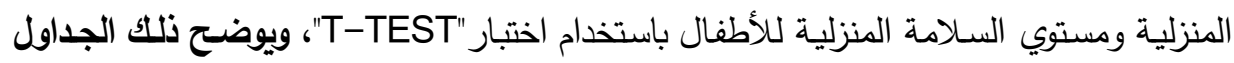
جدول (Yr) دلالة الفروق بين بات بات الأسر الحضريات والريفيات في مستوي وعيهن بإسلوب التعامل مع الحوادث المنزلية بمحوريه والريفيه 
مجلة الاقتصاد المنزليـ مجلد هبـ العدد الرابع ـ 10 • ب م

\begin{tabular}{|c|c|c|c|c|c|c|c|}
\hline \multirow{2}{*}{ مستوي الدلالة } & \multirow{2}{*}{ قيمة ت } & \multirow{2}{*}{ 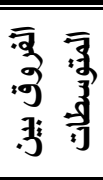 } & \multicolumn{2}{|c|}{ 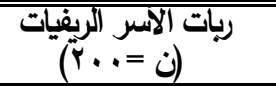 } & \multicolumn{2}{|c|}{ 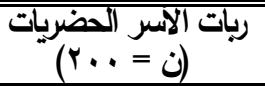 } & \multirow[t]{2}{*}{ البيان } \\
\hline & & & الالمعراف & المتابي & الالمعراف & المسابي & \\
\hline 9 ا ^. ·/غير دال & .rr & $\ldots 9$ & r.tr & VT.AV & E.rT & VT.94 & 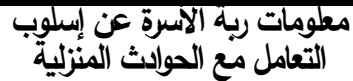 \\
\hline 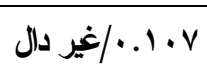 & $1.7 r$ & . & r.l. & vo.ro & $0 . .9$ & $v 0.91$ & ممارسات ربّه الآسرة فَي إبليلوب \\
\hline 1هץ . ·/غير دال & $1.1 \pi$ &.$V r$ & E.Y૫ & $|\leqslant q . r|$ & V.9Y & $1 \leqslant 9.9 \pi$ & 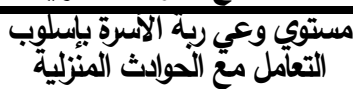 \\
\hline
\end{tabular}

يتبين من جدول (Yr): لا توجد فروق بين متوسط درجات ربات الأسر الحضريات

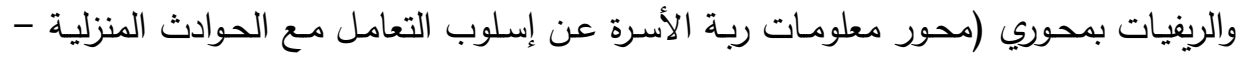

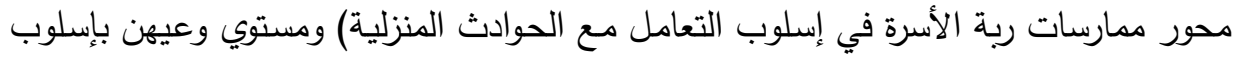

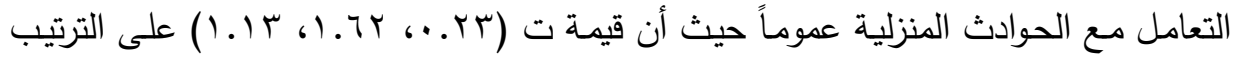

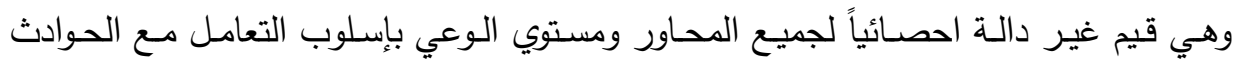

جدول (Y Y) دلالة الفروق بين ربات الأسر الحضريات والريفيات في مستوي السلامة المنزلية

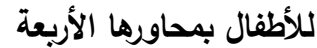

\begin{tabular}{|c|c|c|c|c|c|c|c|}
\hline \multirow{2}{*}{ مستوي الدلالة } & \multirow{2}{*}{ قيمة ت } & \multirow{2}{*}{ 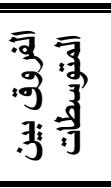 } & \multicolumn{2}{|c|}{ 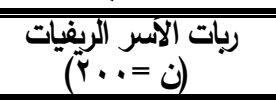 } & \multicolumn{2}{|c|}{ 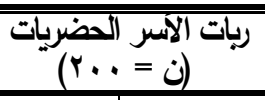 } & \multirow[t]{2}{*}{ البيان } \\
\hline & & & المعياري & الصتوسطي & المعياري & المتوسطي & \\
\hline$\cdots \cdot 1$ & $0.0 Y-$ & $\cdot \wedge 9-$ &..$\wedge \wedge$ & 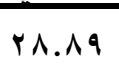 & r.lr & $r v .99$ & ألستأميثة من الحوإثت المرتبطة \\
\hline$\cdots 1$ & r.ro- & $\cdot v \vee-$ & r.rr & Y9.7ะ & r.YA & YA.Av & 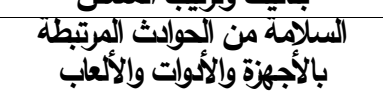 \\
\hline$\cdots 1$ & $7.74-$ & I.rY- & 1.00 & YA.rะ & r. . . & $r v . . r$ & 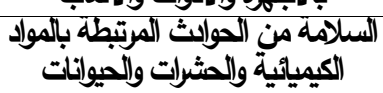 \\
\hline$\cdots 1$ & $1.17-$ & $. r r-$ & $1 . . \varepsilon$ & rV.Ar & Y.१^ & $r v .01$ & السلالامهة من الحضابثة المثرتبطه \\
\hline$\cdots 1$ & $0 . r_{4-}$ & r.rq- & s.1T & $11 \leq .79$ & V. 10 & 111.49 & مستوي السلامة المنزلية للأطفال \\
\hline
\end{tabular}

يتبـين مـن جـدول (rr): توجد فروق بين متوسط درجات ربـات الأسـر الحضـريات

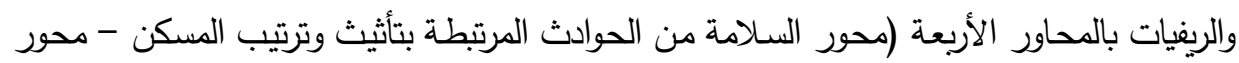

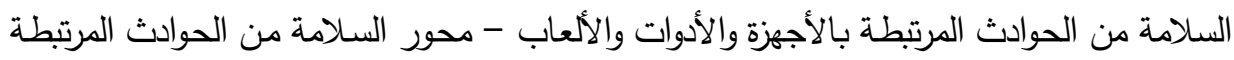
بالمواد الكيميائية والحشرات والحيوانات - محور السلامة من الحوادث المرتبطة بالعناية الثخصية 


$$
\text { مجلة الاقتصاد المنزلي- مجلد مr- العدد الرابع - } 10 \text { • rم }
$$

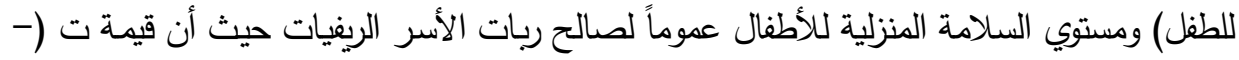

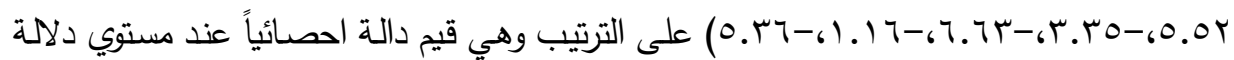

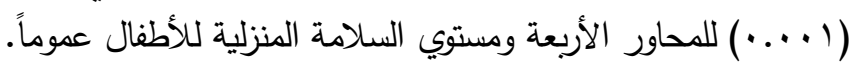

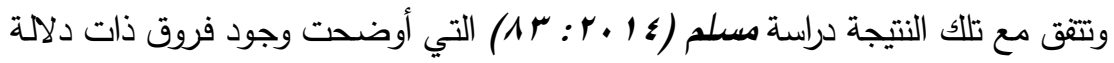

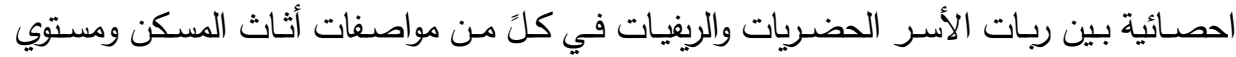

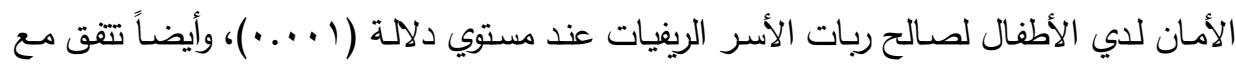

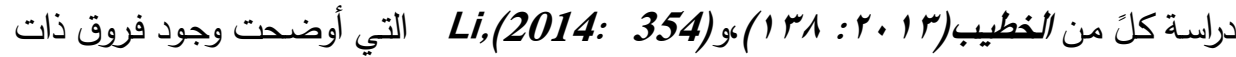

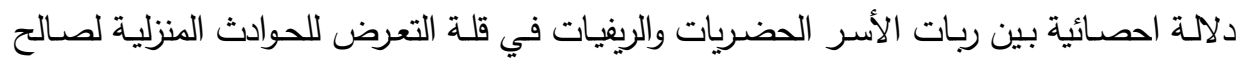

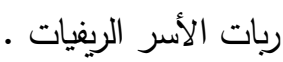

نستخلص مما سبق أنه لا توجد فروق ذات دلالة إحصائية بين ربات الأسر الحضريات

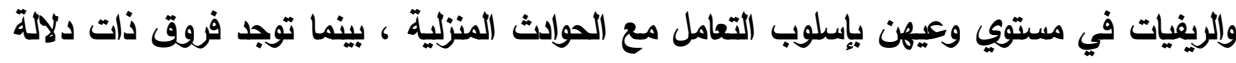

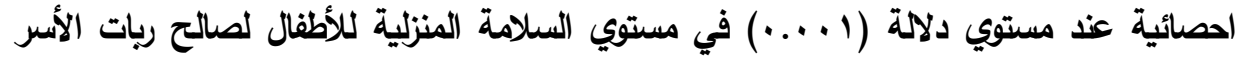
الريفيات. وبذلك يتحقى عدم صحة الفرض الخامس جزئياً .

\section{1}

ينص الفرض السـادس على أنها: " لا توجد فروق ذات دلالـة إحصائية بين ربات الأسر في كلٍ من مستوي وعيهن بإسلوب التعامل مـع الحوادث المنزلية ومستوي السـلامة المنزليـة للأطفـال وفقاً لطبيعة المسكن ". وللتحقق من صـحة الفرض إحصـائيا تم حساب

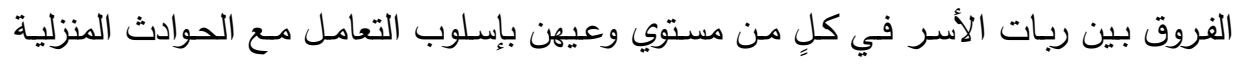

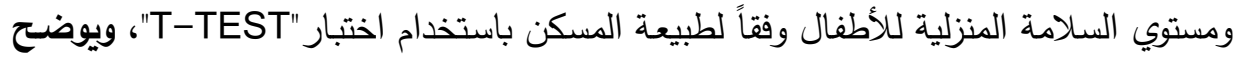

$$
\text { ذلك الجداول ( }
$$

\begin{tabular}{|c|c|c|c|c|c|c|c|}
\hline \multirow{2}{*}{ مستوي } & \multirow{2}{*}{ قيمة ت } & \multirow{2}{*}{ 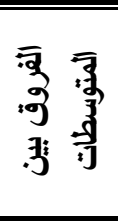 } & \multicolumn{2}{|c|}{ 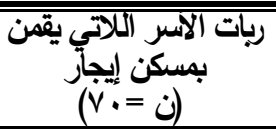 } & \multicolumn{2}{|c|}{ ربات الآسكر اللالتي يقمن } & \multirow[t]{2}{*}{ البيان } \\
\hline & & & المعياري & الحسابي & الالحيرافي & الحسابي & \\
\hline$\cdots \cdots 1$ & $1 . v r-$ & $\cdot . \wedge \cdot-$ & $r . \varepsilon r$ & $V \varepsilon . \Delta V$ & $\varepsilon . . r$ & Vr.VV & معلومات ببه الآسرة عن إبلوية \\
\hline
\end{tabular}

جدول (؟ Y) دلالة الفروق بين ربات الأسر في مستوي وعيهن بإسلوب التعامل مع الحوادث المنزلية 
مجلة الاقتصاد المنزليـ مجلد 0Yـ العدد الرابع - 10 • بم

\begin{tabular}{|c|c|c|c|c|c|c|c|}
\hline$\cdots \cdots 1$ & 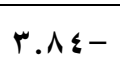 & $1.9 \leq-$ & $r . \varepsilon V$ & VV.YY & 7.91 & Vo.ru & ممارسات ربة الأسرة في إسلويّب \\
\hline$\cdots+1$ & r.rl- & Y.V $\varepsilon-$ & $0 . \varepsilon r$ & $101.1 \mathrm{r}$ & $7 . \leqslant 0$ & $1 \leqslant 9 . .9$ & 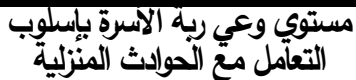 \\
\hline
\end{tabular}

يتبين من جدول (؟ Y): توجد فروق بين متوسط درجات ربات الأسر اللاتي يقمن بمسكن ملك واللاتي يقهـن بمسكن إيجـار بمحوري (محسور معلومـات ربـة الأسـرة عـن إسـلوب التعامل مــع الحوادث المنزلية - محور ممارسـات ربـة الأسرة في إسلوب التعامل مـع الحوادث المنزلية) ومستوي وعيهن بإسلوب التعامل مع الحوادث المنزلية عموماً لصالح ربات الأسر اللاتي يقمن بمسكن إيجار

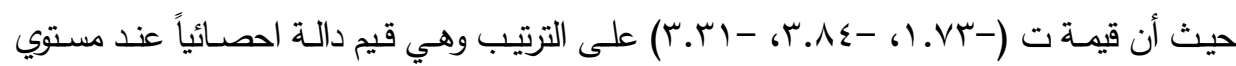
دلالة (1 ( . . •) لجميع المحاور ومستوي الوعي بإسلوب التعامل مع الحوادث المنزلية عموماً.

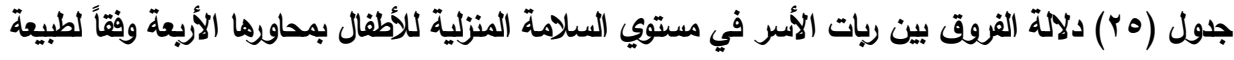

\begin{tabular}{|c|c|c|c|c|c|c|c|}
\hline \multirow{2}{*}{ مستوي } & \multirow{2}{*}{ قيمة ت ت ق ق ق } & \multirow{2}{*}{ 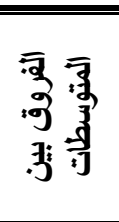 } & \multicolumn{2}{|c|}{ 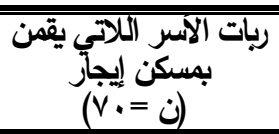 } & \multicolumn{2}{|c|}{ ربات الأسكر اللاتي يقمن ملت } & \multirow{2}{*}{ المحاور } \\
\hline & & & الاتحراف & المتوسطب & المعيازي & المستوسطي & \\
\hline$\cdots+1$ & $\varepsilon .9-$ & $\cdot . \wedge 9-$ & 1.71 & rq.1V & 1.77 & 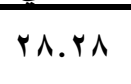 & السلامه من الحوالث (المرتبطة بتاثيث \\
\hline$\cdots+1$ & $7 . \diamond \wedge-$ & $1 . \varepsilon Y-$ & $1 . \varepsilon r$ & $r \cdot . \leqslant r$ & Y.\&। & rq.. & السالأمهة من والألحوات والألماب المرتبطة \\
\hline$\cdots \cdot 1$ & $V .90-$ & Y.10- & r.. 9 & rq. $\{7$ & 1.19 & YV.MI & السلامه مني الحوإتث المرتبطات بالمواد \\
\hline$\cdots \cdot 1$ & $1 \cdot \ldots \leqslant-$ & Y. $\{q-$ & 1.04 & Yq.VI & 1.10 & rv.rr & 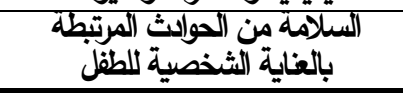 \\
\hline$\cdots \cdot 1$ & $1 \cdot . \wedge \cdot-$ & $7.90-$ & $\varepsilon .7 r$ & $11 \wedge . V V$ & $7 .+1$ & $111 . \wedge r$ & مستوي السلامة المنزلية للأطفال \\
\hline
\end{tabular}

يتبين من جدول (†) (ب): توجد فروق بين متوسط درجات ربات الأسر اللاتي يقمن بمسكن ملك واللاتي يقمن بمسكن إيجار بالمحاور الأربعة (محور السلامة من الحوادث المرتبطة بتأثثيث وترتيب المسكن - محور السـلامة من الحوادث المرتبطة بالأجهزة والأدوات والألعاب - محور السـلامة من الحوادث المرتبطة بالمواد الكيميائية والحشرات والحيوانات - محور السلامة من الحوادث المرتبطة بالعناية الثخصية للطفل) ومستوي السـلامة المنزلية للأطفال عموماً لصالح ربات الأسر اللاتي يقمن بمسكن

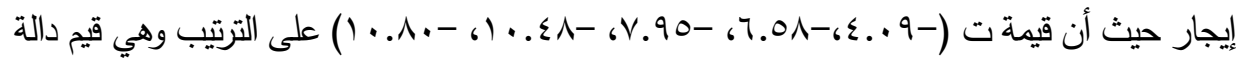
احصائياً عند مستوي دلالة (1 . . . ) للمحاور الأربعة ومستوي السلامة المنزلية للأطفال عموماً. 


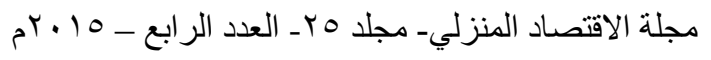

نستخلص مما سبق أنه توجد فروق ذات دلالة إحصائية عذ مستوي دلالة ( ( . . ) بين

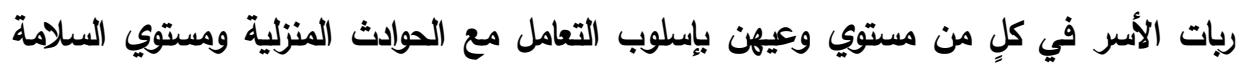
المنزلية للأطفال وفقاً لطبيعة المسكن لصالح ربات الأسر اللاتي يقمن بمسكن إيجار . وبذلك يتحقق لئق علم صحة الفرض السادس.

\section{V- نـنائج الفرض السابـو}

ينص الفرض السابع على أنه: " لا يوجد تباين دال احصائياً في مستوي وعي ربات الأسر النر

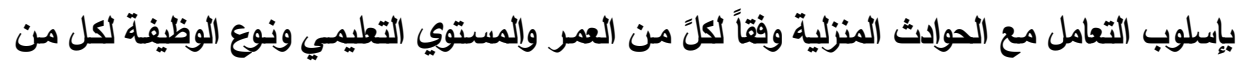
الزوج والزوجة ونوع المسكن". وللتحقق من صحة الفرض إحصائياً استخدم اختبار تحليل التباين في اتجاه واحد "One Way Anova " للكثف عن التباين في مستوي وعي ربات الأسر بإسلوب التعامل

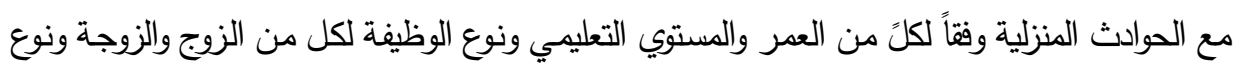

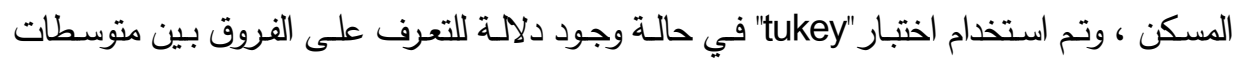

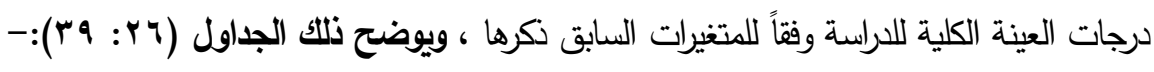

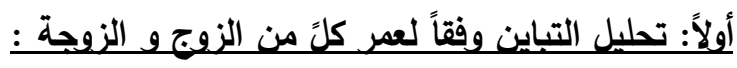
أ- تحليل التباين في مستوي وعي ريات الأسر بإسلوب التعامل مع الحوادث المنزلية وفقاً لاختلاف أعمار أزوجهن.

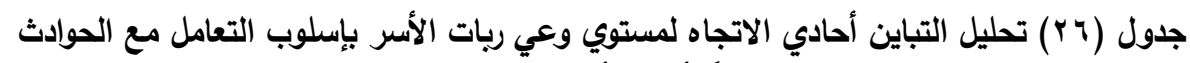

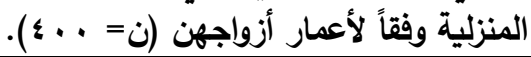

\begin{tabular}{|c|c|c|c|c|c|c|}
\hline مستوى الدلالة & قيمة ف & متوسط المربعات & لرجات الحرية & مجموع المربعات & مصادر التباين & المحاور \\
\hline$\because \cdots 1$ & 17.99 & $\begin{array}{l}r Y Y \wedge I \mid \\
I r . \wedge \leq q\end{array}$ & $\begin{array}{c}r \\
r q q \\
r q q\end{array}$ & $\begin{array}{l}\text { Ұ४.EYY } \\
0 \& \Lambda \& . Y Y \Lambda \\
710 Y . V 7 .\end{array}$ & داخل المجموعات المجوعات & مع مع إبلوماتِ بِّة التعامل \\
\hline$\because \cdots 1$ & $1 V . V \varepsilon$ & $\begin{array}{l}r r q . V . q \\
\text { ir.oir }\end{array}$ & $\begin{array}{l}r \\
r q 9 \\
r q 9\end{array}$ & $\begin{array}{l}819.119 \\
070.981 \\
7.79 .87 .\end{array}$ & داخل المجموعات المجوعات & 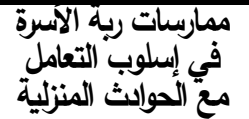 \\
\hline$\because \cdots 1$ & $10 . \Lambda r$ & $\begin{array}{l}0 V 0.91 \mathrm{~V} \\
\mathrm{rq.} \$ 10\end{array}$ & $\begin{array}{l}r \\
r q 9 \\
r q 9\end{array}$ & $\begin{array}{l}\text { IVYV.VOI } \\
1 \leq \varepsilon Y . Y \wedge q \\
191 \leq \Lambda . . \varepsilon .\end{array}$ & 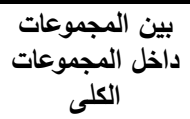 & 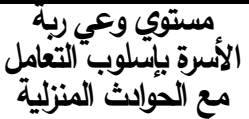 \\
\hline
\end{tabular}

يتبين من جدول (†r): وجود تباين دال احصائياً في مستوي وعي ربات الأسر

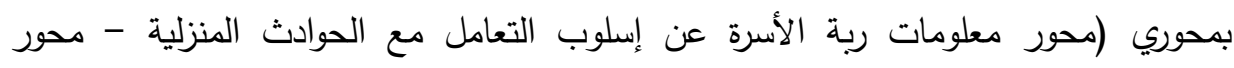




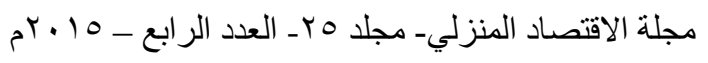

ممارسات ربة الأسرة في إسلوب التعامل مع الحوادث المنزلية) ومستوي وعيهن بإسلوب التعامل

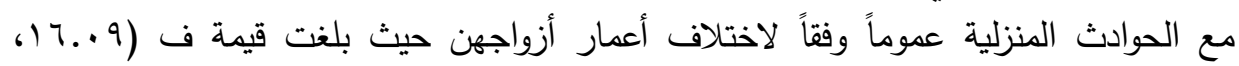

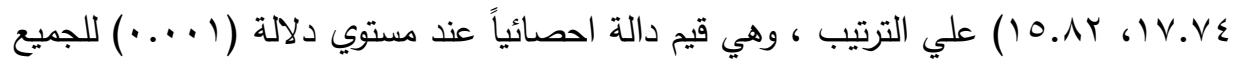
، بما يعني تأثر مستوي وعي ربات الأسر بإسلوب التعامل مع الحوادث المنزلية دالية بمحوريه وفقاً لاختلاف أعمار أزواجهن.

جلول (rV) متوسط درجات الوعي لربات الأسر بإسلوب التعامل مع الحوادث المنزلية وفقاً لأعمار أزواجهن الأن

\begin{tabular}{|c|c|c|c|}
\hline 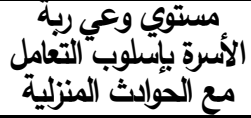 & 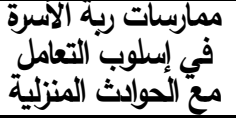 & مع مع إسلوبت بلّة التعالمبل & المتوسطات الحسابية للاتجاه \\
\hline - & - & - & |أقل من · باسنة. \\
\hline 100.70 & $\mathrm{V9..}$ & 74.70 & من · rاسنة وحتى أقل من · ب سنة. \\
\hline $1 \leq V .79$ & 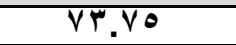 & $V \Psi .9 \xi$ & من · r سنة وحتى أقل من · ؛ سنة. \\
\hline $1 \leqslant 1.9 \mathrm{~V}$ & $\mathrm{~V} 0.99$ & VY.91 & من · ؛ وحتى أقل من · 8 سنة . \\
\hline $10 \cdot .9$ & $v 0 . \cdot 1$ & $V \bullet . \wedge Y$ & 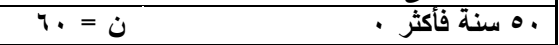 \\
\hline
\end{tabular}

وبتطبيق اختبارtukey يكشف جدول (YV): أن أعلي متوسط لدرجات ربات الأسر

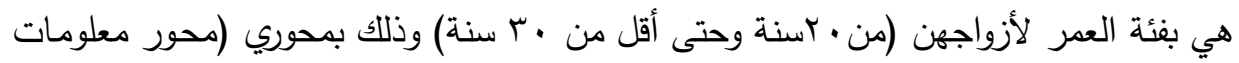

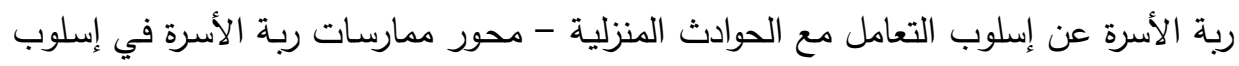

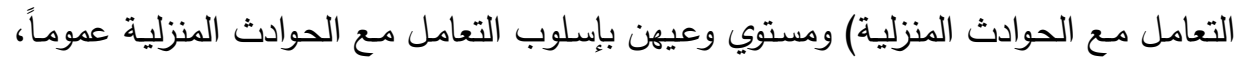

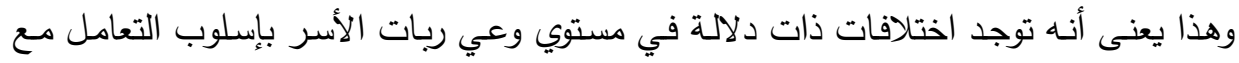

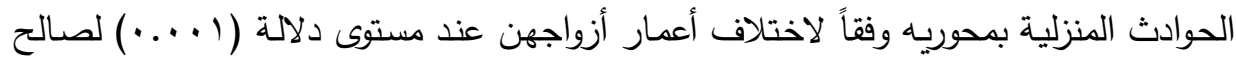
فئة العمر لأزواجهن (من • rاسنة وحتى أقل من · ب سنة).

ب- تحليل التباين في مستوي وعي ربات الأسر بإسلوب التعامل مع الحوادث المنزلية وفقاً لاختلاف أعمارهن.

جدول (r^) تحليل التباين أحادي الاتجاه لمستوي وعي ربات الأسر بإسلوب التعامل مع الحوادث

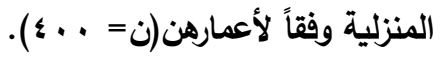

\begin{tabular}{|c|c|c|c|c|c|c|}
\hline مستوى الدلالة & قيمة ف & متوسط المربعات & الحرية & مجموع المربعات & مصادر التباين & المحاور \\
\hline$\because \cdots 1$ & $\wedge \wedge . \leqslant 7$ & $\begin{array}{l}A r Y . q \leq 0 \\
q . r \cdot r\end{array}$ & $\begin{array}{l}r \\
r q q \\
r q q\end{array}$ & $\begin{array}{l}r \leq \neg \wedge . \wedge r q \\
r q \wedge r . q Y \varepsilon \\
\nearrow 1 \circ Y . \vee q .\end{array}$ & دين المجموعات المجموعات & معلومات ربة الأسرة عن إلتعامل مع الحوادث \\
\hline
\end{tabular}


مجلة الاقتصاد المنزلي- مجلد مr- العدد الرابع - 10 • بم

\begin{tabular}{|c|c|c|c|c|c|c|}
\hline & & & & & الكلى & المنزلية \\
\hline$\because \cdots 1$ & $1 \wedge . \vee \wedge$ & $\begin{array}{l}r 01.9 \leqslant r \\
1 r .819\end{array}$ & $\begin{array}{l}r \\
r q q \\
r q q\end{array}$ & $\begin{array}{l}\text { Vo0.Ar. } \\
0 \% 1 r .9 T . \\
7.79 . V 7 .\end{array}$ & $\begin{array}{l}\text { داخل المجموعات } \\
\text { المجمعات }\end{array}$ & $\begin{array}{c}\text { إسلوب التعامل مع الحوادية الأسرة في } \\
\text { المنزلية }\end{array}$ \\
\hline$\because \cdots 1$ & $0 \leqslant . \leqslant Y$ & $\begin{array}{l}10 V 1 . r q . \\
r \wedge . \wedge V \leq\end{array}$ & $\begin{array}{l}r \\
r q q \\
r q q\end{array}$ & $\begin{array}{l}\varepsilon v 1 r . \wedge v 1 \\
11 \leq r \leq .179 \\
171 \leqslant 1 . \cdot \varepsilon .\end{array}$ & $\begin{array}{l}\text { داخل المجموعات } \\
\text { المجوعات }\end{array}$ & بإسلوب التعامل مع الحوادث رية الأسرة \\
\hline
\end{tabular}

يتبين من جدول (^^): وجود تباين دال احصائياً في مستوي وعي ربات الأسر بمحوري (محور معلومات ربة الأسرة عن إسلوب التعامل مع الحوادث المنزلية - محور

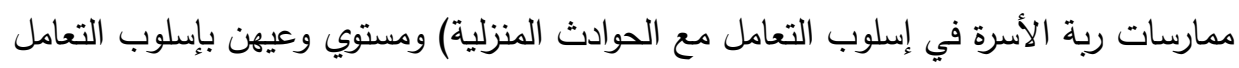

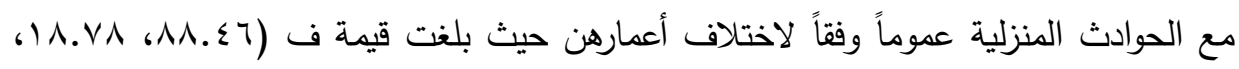

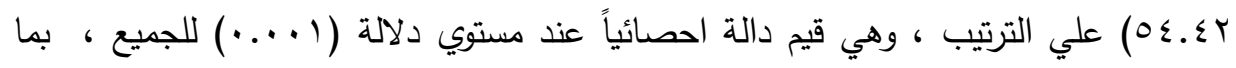
يعني تأثر مستوي وعي ربات الأسر بإسلوب التعامل مع الحوادث المنزلية بمحوريه وفقاً التأياً لاختلاف أعمارهن.

جدول (9 ؟) متوسط درجات الوعي لربات الأسر بإسلوب التعامل مع الحوادث المنزلية وفقاً لأعمارهن . ( $)$

\begin{tabular}{|c|c|c|c|}
\hline مستوي وعي ربة الأسرة & ممارسات ربة الأسرة في & إسلوب التعامل مع الحواثث & المتوسطات الحسابية للاتجاه \\
\hline $1 \leq Y . \cdot \theta$ & VY.Vo & 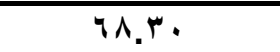 & من ·اسنة وحتى أقل من ·r سنة. \\
\hline 101.9 & $V 0 . \cdot r$ & $V \varepsilon . r V$ & 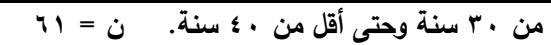 \\
\hline $10 \cdot . \leqslant 0$ & $V V^{2} \cdot V 4$ & $v 0.99$ & من · ؛ وحتى أقل من ·• سنة . \\
\hline $10 V . .$. & $11 .$. & V.... & • • م سنة فأكثر . \\
\hline
\end{tabular}

وبتطبيق اختبارtukey يكشف جلول (9 Y): أن أعلي متوسط لدرجات ربات الأسر هي بفئة

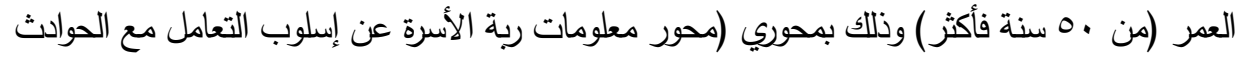

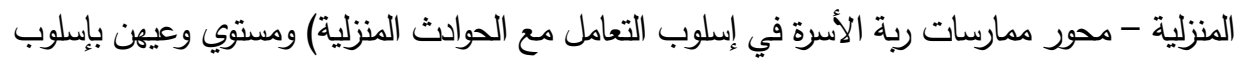




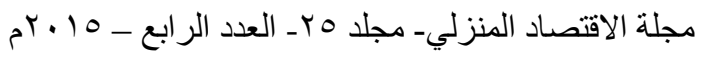

التعامل مع الحوادث المنزلية عموماً، وهذا يعنى أنه توجد اختلافات ذات دلالة في مستوي وعي ربات

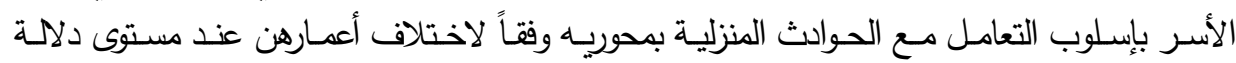

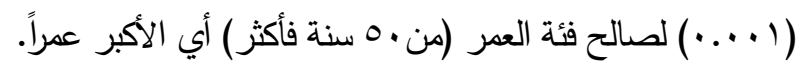

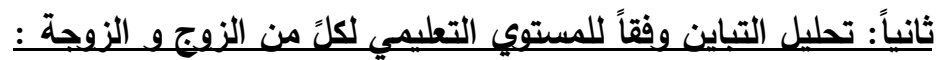

أ- تحليل التباين في مستوي وعي ربات الأسر بإسلوب التعامل مع الحوابث المنزلية وفقاً للمستوي التعليمي

لأنولجهن.

جدول ( • ب) تحليل التباين أحادي الاتجاه لمستوي وعي ربات الأسر بإسلوب التعامل مع الحوادث

المنزلية وفقاً للمستوي التعليمي لأزواجهن (ن = ل . . ؛).

\begin{tabular}{|c|c|c|c|c|c|c|}
\hline مستوى الدلالة & قيمة ف & متوسط المربعات & لرجات الحرية & مجموع المربعات & مصادر التباين & المحاور \\
\hline$\because \cdots 1$ & Y. I. & $\begin{array}{l}\text { Yr.rov } \\
\text { IO }\end{array}$ & $\begin{array}{l}r \\
r q v \\
r q q\end{array}$ & $\begin{array}{l}7 \leq .010 \\
7.11 . Y \leq 0 \\
710 Y . V 7 .\end{array}$ & 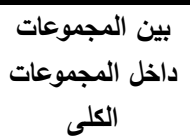 & 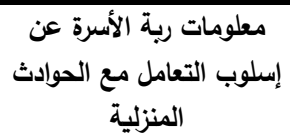 \\
\hline$\because \cdots 1$ & I \&.V & $\begin{array}{l}Y .9 .797 \\
1 \leq . Y r r\end{array}$ & $\begin{array}{l}r \\
r q v \\
r q q\end{array}$ & $\begin{array}{l}819.49 \% \\
070.091 \\
7.79 .87 .\end{array}$ & $\begin{array}{c}\text { داخل المجموعات المجموعات } \\
\text { الكلى }\end{array}$ & 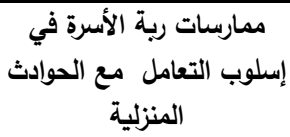 \\
\hline$\because \cdots 1$ & 9.11 & $\begin{array}{c}r o . r q . \\
r \wedge . q 1 .\end{array}$ & $\begin{array}{l}r \\
r q v \\
r q q\end{array}$ & $\begin{array}{l}V . V \Lambda . \\
10 \leq \varepsilon V . Y q . \\
171 \leq \Lambda .8 .\end{array}$ & 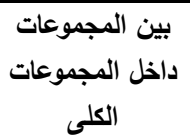 & بإسلوب التعامل مع الحوادث رية الأسرة \\
\hline
\end{tabular}

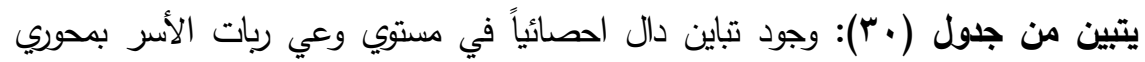
(محور معلومات ربة الأسرة عن إسلوب التعامل مع الحوادث المنزلية - محور ممارسات ربية دائ الأسرة في

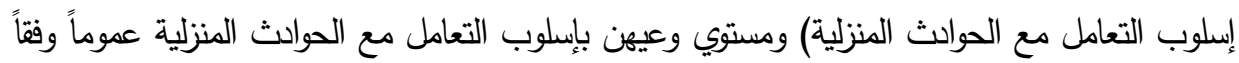

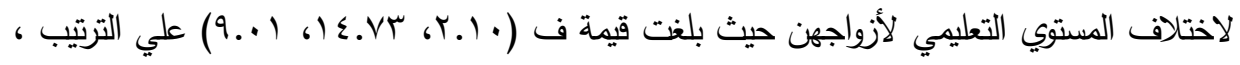

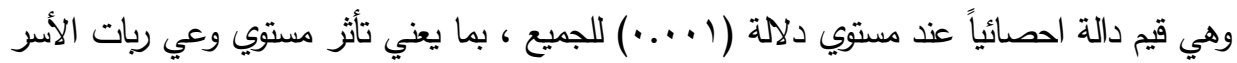
بإسلوب التعامل مع الحوادث المنزلية بمحوريه وفقاً لاختلاف المستوي التعليمي لأزواجهن.

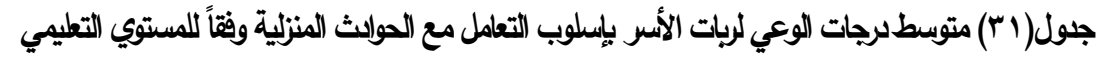
لأزواجهن(ن) = . + ؟).

\begin{tabular}{|c|c|c|c|}
\hline مع الأسرة بإسلوب وعي التعامل & مع ممارسات ربة الأسرة & مع مع إسلوب التعات ربة الأسرة & المستوي التعليمي للزوج \\
\hline $1 \leqslant \Lambda . Y \leqslant$ & $V \leqslant .97$ & Vr.YA & $1 \cdot 1=0$ \\
\hline 101.17 & V..9. & $V \varepsilon, Y V$ & ن \\
\hline
\end{tabular}


مجلة الاقتصاد المنزليـ مجلد مبـ العدد الرابع _ 10 • بrم

\begin{tabular}{|l|l|l|ll||}
\hline $1 \leq \Lambda .79$ & $V \varepsilon . V$. & $V Y .99$ & $1 r \cdot=0$ \\
\hline
\end{tabular}

وبتطييق اختبارtukey يكثف جدول ( آ⿱ إ): أن أعلي متوسط لدرجات ربات الأسر هي

بالمستوي التعليمي المتوسط لأزواجهن وذلك بمحوري (محور معلومات ربة الأسرة عن إسلوب التعامل

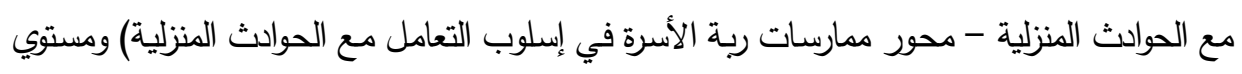

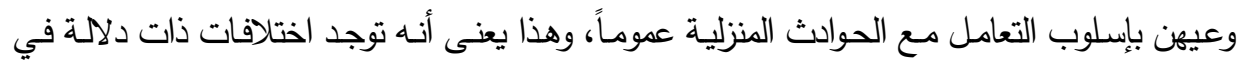

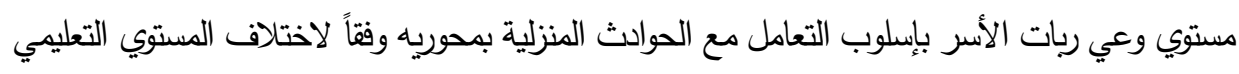
لأزواجهن عند مستوى دلالة ( ( .... ) لصالح المستوي التعليمي المتوسط لأزواجهن.

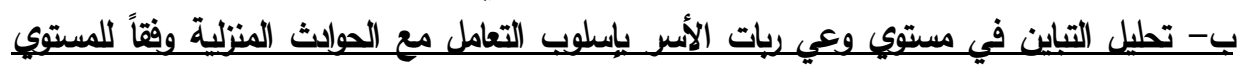
(التعليمي لُهن.

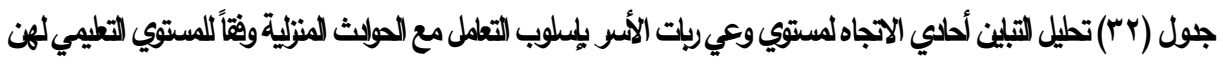

\begin{tabular}{|c|c|c|c|c|c|c|}
\hline مستوى الدلالة & قيمة ف & متوسط المربعات & لرجات الحرية & مجموع المربعات & مصادر التباين & المحاور \\
\hline$\because \cdots 1$ & $17 . \cdot V$ & $\begin{array}{l}r . r \Delta V \\
1 \leq . r r \Lambda\end{array}$ & $\begin{array}{c}r \\
\text { rqv } \\
\text { rqq }\end{array}$ & $\begin{array}{l}\varepsilon 7 . . V 1 \leq \\
079 \% .8 \leq 7 \\
710 Y . V 7 .\end{array}$ & داخل المجموعات المجوعات & معلومات ربة الأسرة عن إسلوب التعامل مع \\
\hline$\because \cdots 1$ & $\leqslant 0 . \wedge 0$ & $\begin{array}{l}079 . \leq 1 \leq \\
1 Y . \leqslant 4 .\end{array}$ & $\begin{array}{c}r \\
\text { rqv } \\
\text { rqq }\end{array}$ & $\begin{array}{l}11 \% \wedge . \wedge r V \\
89 \% . .9 \% r \\
7.79 . \vee 7 .\end{array}$ & داخل المجموعات المجوعات & ممارسات ربة الأسرة في \\
\hline$\because \cdots 1$ & $r \leqslant .07$ & $\begin{array}{l}1 \wedge \wedge .91 Y \\
r .19 \mathrm{~V}\end{array}$ & $\begin{array}{c}r \\
\text { rqv } \\
\text { rqq }\end{array}$ & 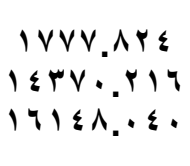 & داخل المجموعات المجوعات & مستوي وعي ربة الأسرة \\
\hline
\end{tabular}

يتبين من جدول (rr): وجود تباين دال احصائياً في مستوي وعي ربات الأسر بمحوري (محور معلومات ربة الأسرة عن إسلوب التعامل مع الحوادث المنزلية - محور ممارسات ربة دية الأسرة

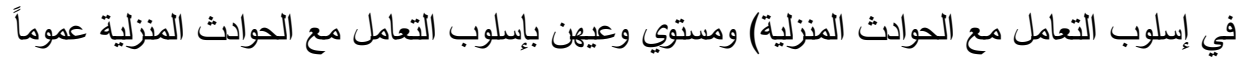

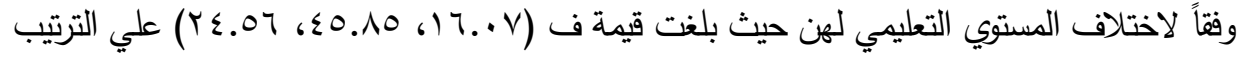

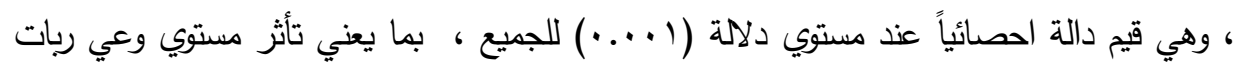

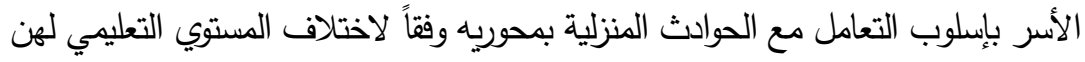




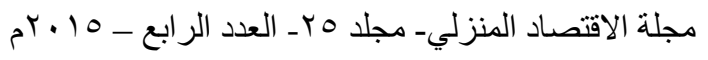

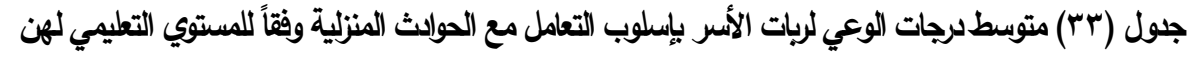
با.

\begin{tabular}{|c|c|c|c|}
\hline مستوي وعي ربة الأسرة & مع مع إسبات ربة الأسرة & مع مع إسلوب التعات ربة الأسرة & طات الحسابية للاتجاه \\
\hline $1 \leqslant 7.9 \leqslant$ & VT.T & VY.YA & $11 .=0$ \\
\hline $1 \leqslant \Lambda .7 \leqslant$ & $V \varepsilon .74$ & $V \varepsilon . r Y$ & ن \\
\hline 101.19 & $V V . \varepsilon \Lambda$ & $v_{0}, \ldots$ & $1.0=0$ \\
\hline
\end{tabular}

وبتطبيق اختبارtukey يكثف جدول (rr): أن متوسط درجات ربات الأسر يتدرج تصاعلياً

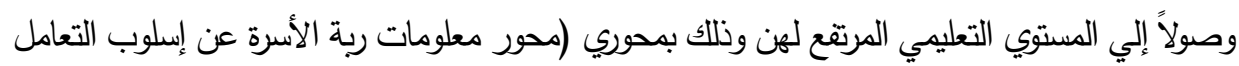

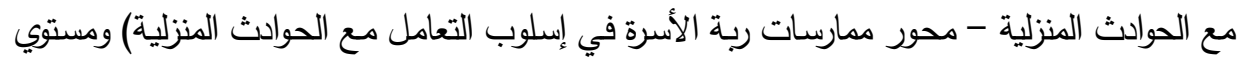

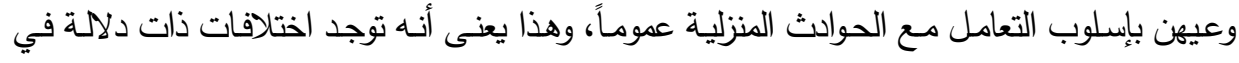

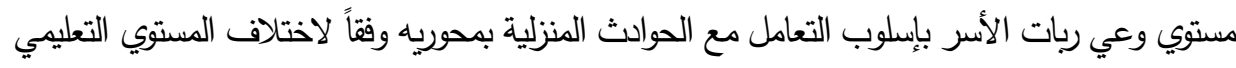

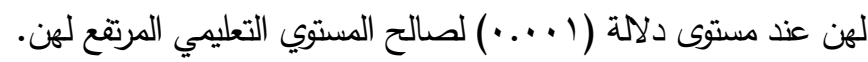

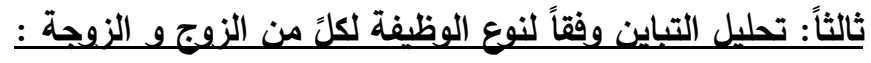

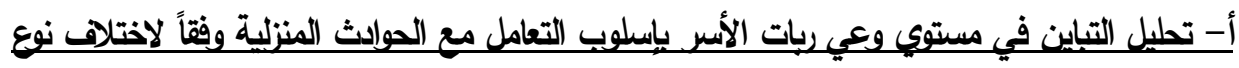
الوظيفة لأزولجهن.

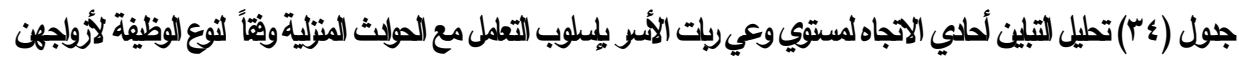

\begin{tabular}{|c|c|c|c|c|c|c|}
\hline \multicolumn{7}{|c|}{ (4) } \\
\hline مستوى الدلالة & قيمة ف & متوسط المربعات & درجات الحرية & مجموع المربعات & مصادر التباين & المحاور \\
\hline$\because \cdots 1$ & ro.rv & $\begin{array}{l}\varepsilon r r . . \leqslant \leq q \\
\mid r . r o \leqslant\end{array}$ & $\begin{array}{l}r \\
\text { raq } \\
\text { raq }\end{array}$ & $\begin{array}{l}1 r \ldots . r \leqslant 4 \\
\varepsilon \wedge 0 r . \leqslant 1 \leqslant \\
110 r . v 4 .\end{array}$ & 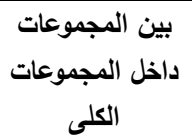 & 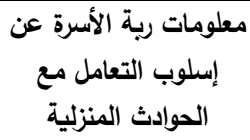 \\
\hline$\because \cdots 1$ & ro.9r & $\begin{array}{l}r r r . .0 V \\
\mid r . A i r\end{array}$ & $\begin{array}{l}r \\
r a q \\
r 99\end{array}$ & $\begin{array}{l}997.1 \times 1 \\
0.07 .019 \\
9.99 .07 .\end{array}$ & $\begin{array}{l}\text { داخل المجموعات المجوعات } \\
\text { الكلى }\end{array}$ & إسلوب التعامل ميعة الأسرة في \\
\hline$\because \cdots 1$ & $r r . \leqslant 0$ & $\begin{array}{l}\text { I.AN.rV. } \\
\text { rY.orr }\end{array}$ & $\begin{array}{l}r \\
r a q \\
r 99\end{array}$ & 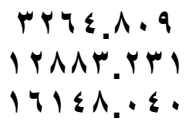 & داخل المجموعات & مستوي وعي رية الأسرة \\
\hline
\end{tabular}




$$
\text { مجلة الاقتصاد المنزليـ مجلد مrــ العدد الرابع ـ } 10 \text { • بم }
$$

يتبين من جدول (؟؟): وجود تباين دال احصائياً في مستوي وعي ربات الأسر بمحوري

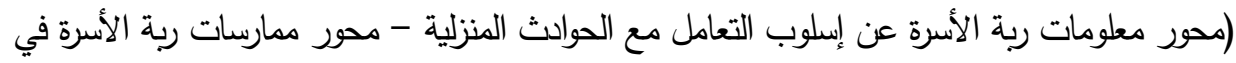

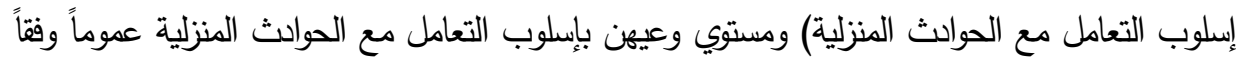

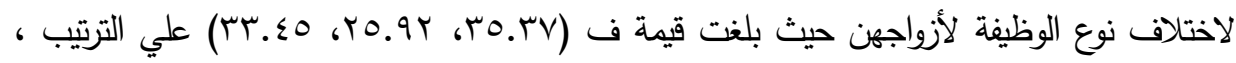

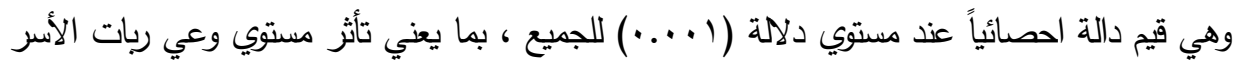
بإسلوب التعامل مع الحوادث المنزلية بمحوريه وفقاً لاختلاف نوع الوظيفة لأزواجهن.

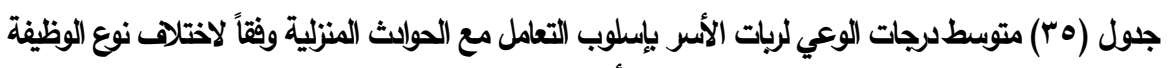
لأزواجهن

\begin{tabular}{|c|c|c|c|c|}
\hline 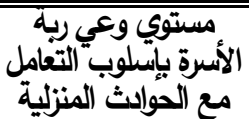 & 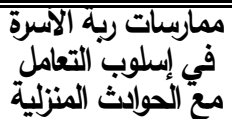 & مع مع إسلوبت بلة التعاملي & المتوسطات الحسابية للاتجاه & نوع وظيفة الزوج \\
\hline $1 \leq \Lambda . r 0$ & VT.9I & VY.TV & $1 \wedge \varepsilon=\dot{0}$ & وظيفة حكومية . \\
\hline 100.10 & $\nabla \wedge .0$. & VV.To & $1.7=\dot{0}$ & أعمال حرة . \\
\hline $1 \leqslant V .0$. & $V 0.91$ & $V \varepsilon .0 \wedge$ & $\varepsilon r=\dot{U}$ & 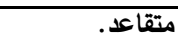 \\
\hline $1 \leqslant \Lambda . \leqslant \Lambda$ & $V \varepsilon .1$. & $V T . \leqslant 1$ & $7 \wedge=\dot{ن}$ & متوفي. \\
\hline
\end{tabular}

وبتطبيق اختبارtukey يكثف جدول (ror): أن أعلي متوسط لدرجات ربات الأسر هي بنوع الوظيفة لأزواجهن (أعمال حرة) يليها (المتقاعد) يليها (المتوفي)ثم في النهاية(الحكومية)

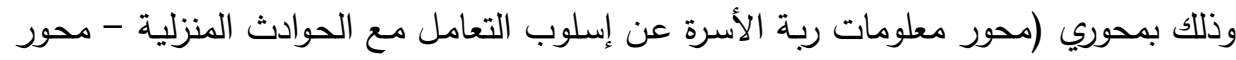
ممارسات ربة الأسرة في إسلوب التعامل مع الحوادث المنزلية) ومستوي وعيهن بإسلوب التعاب التعامل

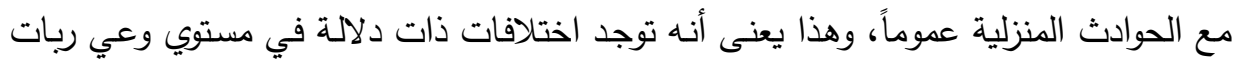

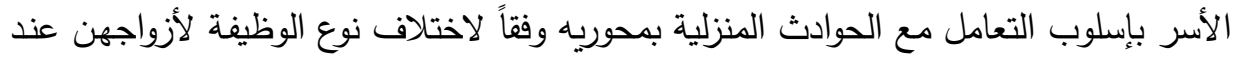
مستوى دلالة ( ( . . . ) لصالح نوع الوظيفة لأزواجهن (أعمال حرة).

ب- تحليل التباين في مستوي وعي ربات الأسر باسيلوب التعامل مع الحوادث المنزلية وفقاً لنوع الوظيفة لهن. 


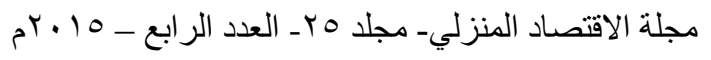

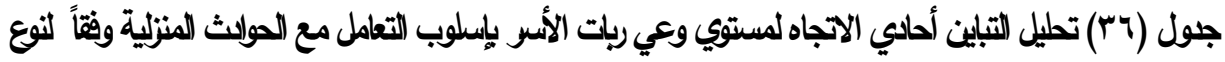
الوظيفة لهن (ن= - . ؟).

\begin{tabular}{|c|c|c|c|c|c|c|}
\hline مستوى & قيمة ف & متوسط المربعات & لرجات الحرية & مجموع المربعات & مصادر التباين & المحاور \\
\hline$\because \cdots 1$ & 11.71 & $\begin{array}{c}\wedge 9 \neg . \wedge \text { Y० } \\
1 . .9 \wedge .\end{array}$ & $\begin{array}{l}r \\
r q v \\
r q q\end{array}$ & $\begin{array}{l}1894.70 . \\
8409.11 . \\
7104.87 .\end{array}$ & داخل المجموعات المجموعات & معلومات ربة الأسرة عن إسلوب التعامل مع \\
\hline$\because \cdots 1$ & $r 7.7 r$ & $\begin{array}{l}r \Delta \Lambda . \Lambda \cdot \Lambda \\
|r . \leqslant \Lambda|\end{array}$ & $\begin{array}{l}r \\
r q v \\
r q q\end{array}$ & $\begin{array}{l}V 1 V .710 \\
0 \% 0 Y .1 \leq 0 \\
7.79 .87 .\end{array}$ & داخل المجموعات المجموعات & ممارسات ربة الأسرة في \\
\hline$\because \cdots 1$ & Y..VI & $\begin{array}{l}90 V . \leqslant 79 \\
r 0 . \wedge 0 r\end{array}$ & $\begin{array}{l}r \\
r q v \\
r q q\end{array}$ & $\begin{array}{l}191 \leq .9 \mu v \\
1 \leq 4 \% .1 . \% \\
191 \leq 1 . . \varepsilon .\end{array}$ & بين المجموعات المجموعات & مستوي وعي ربة الأسرة \\
\hline
\end{tabular}

يتبين من جلول (Tr): وجود تباين دال احصائياً في مستوي وعي ربات الأسر بمحوري

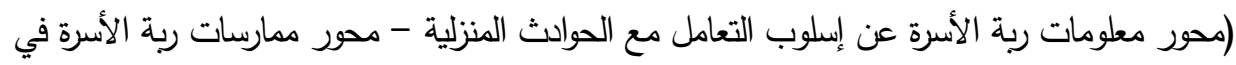

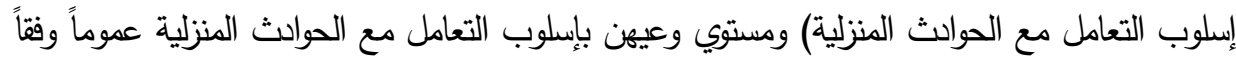

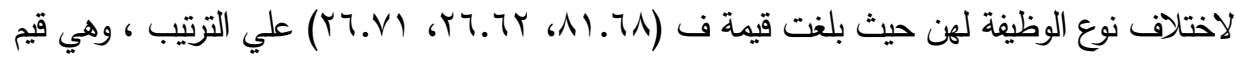

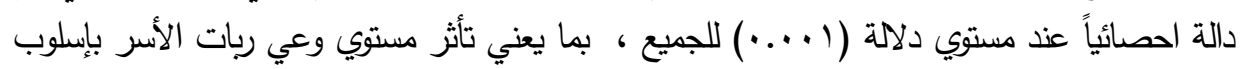
التعامل مع الحوادث المنزلية بمحوريه وفقاً لاختلاف نوع الوظيفة لهن لهن. جلول (rv) متوسط درجات الوعي لربات الأسر بإسلوب التعامل مع الحوإث المنزلية وفقاً لنوع الوظيفة لهن

\begin{tabular}{|c|c|c|c|}
\hline مستوب الأسرة بإسلوب التعامل رعبة & ممارسات ربة الأسرة & مع معلومات ربة الأسرة & المتوسطات الحسابية للاتجاه \\
\hline $1 \leq 9.09$ & 80.99 & VV.Y. & وظيفة حكومية \\
\hline 101 & $\vee \wedge . .$. & $\Lambda \cdot \ldots$ & أعمال حرة . \\
\hline $1 \leq 1.94$ & VY.Rq & VY.qY & $r r \leq=\dot{U}$ \\
\hline
\end{tabular}

وبتطبيق اختبارtukey يكثف جدول (rV): أن أعلي متوسط لدرجات ربات الأسر هي بنوع

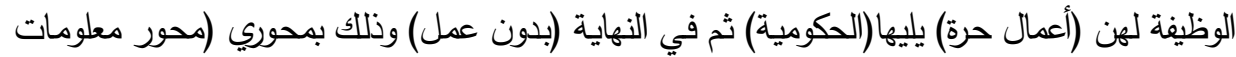
ربة الأسرة عن إسلوب التعامل مع الحوادث المنزلية - محور ممارسات ربة الأسرة في إسلوب التعائ التعامل 


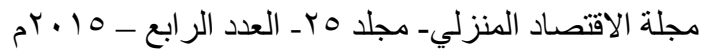

مع الحوادث المنزلية) ومستوي وعيهن بإسلوب التعامل مع الحوادث المنزلية عموماً، وهذا يعنى أنه توجد

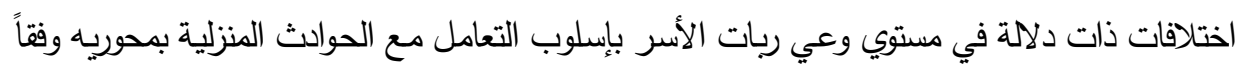
لاختلاف نوع الوظيفة لهن عند مستوى دلالة ( ( . ...)لصالح نوع الوظيفة لهن العابعال أعمال حرة). رايعاً: تحليل التباين وفقاً لنوع المسكن:

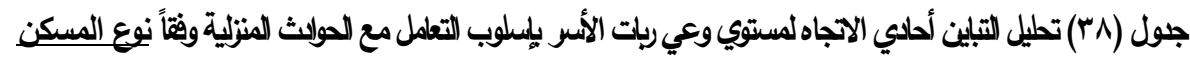

\begin{tabular}{|c|c|c|c|c|c|c|}
\hline مستوى الدلالة & قيمة ف & متوسط المربعات & الحرية & مجموع المربعات & مصادر التباين & المحاور \\
\hline$\because \cdots 1$ & $\begin{array}{c}\Lambda r . V \\
\Lambda\end{array}$ & $\begin{array}{l}q .0 .4 \wedge 1 \\
1 . .9 r v\end{array}$ & $\begin{array}{l}r \\
r q v \\
r q q\end{array}$ & $\begin{array}{l}111 . .87 \% \\
84 \varepsilon 1.99 V \\
710 \% .87 .\end{array}$ & داخل المجموعات المجوعات & معلومات ربة الأسرة عن \\
\hline$\because \cdots 1$ & 1.9 & $\begin{array}{l}17.11 \varepsilon \\
10.5 .1\end{array}$ & $\begin{array}{l}r \\
r q v \\
r q q\end{array}$ & $\begin{array}{l}\text { YY.YYA } \\
7 . \text { YV.OYY } \\
7.79 . V 7 .\end{array}$ & داخل المجموعات المجموعات & ممارسات ربة الأسرة في \\
\hline$\because \cdots 1$ & $\begin{array}{c}r_{1} \\
\varepsilon\end{array}$ & $\begin{array}{l}11.7 .19 \\
10.99\end{array}$ & $\begin{array}{l}r \\
r q v \\
r q q\end{array}$ & 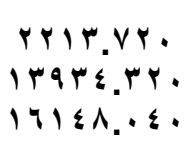 & داخل المجموعات المجموعات & مستوي وعي ربة الأسرة \\
\hline
\end{tabular}

يتبين من جلول (^^): وجود تباين دال احصائياً في مستوي وعي ربات الأسر بمحوري

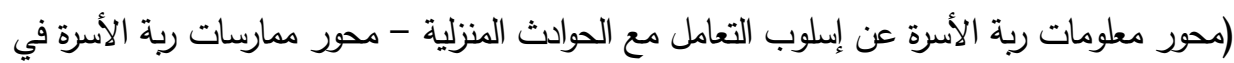

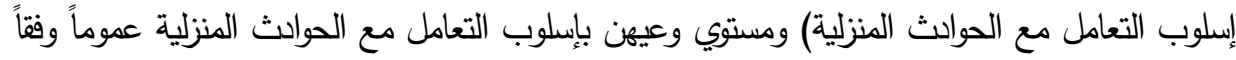

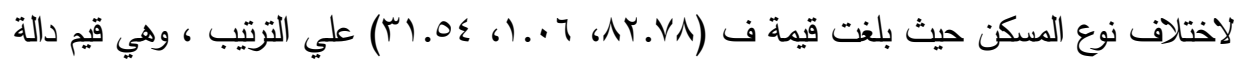

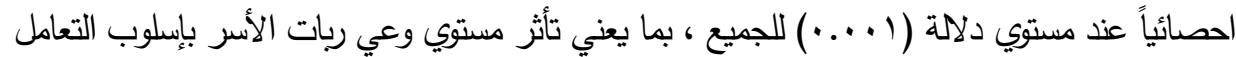
مع الحواثث المنزلية بمحوريه وفقاً لاختلاف نوع المسكن.

جدول (ج) متوسط درجات الوعي لربات الأسر بإسلوب التعامل مع الحوادث المنزلية وفقاً لنوع المسكن

\begin{tabular}{|c|c|c|c|c|}
\hline 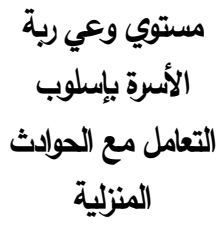 & مع مع إسلوبات ربة الأسرة & مع مع إسلومات ربة الأسرة & لاتجاه & نوع المسكن \\
\hline $1 \leq \Lambda . \% \wedge$ & Vo.vo & VY.TY & $\mid r \Lambda=\dot{~}$ & شقة \\
\hline $1 \leq V . r$. & Vo. Yo & $V Y_{.} \cdot 7$ & U & دور \\
\hline IOY.VY & $v 0.9 T$ & 17.89 & ن = = & فيلا \\
\hline
\end{tabular}




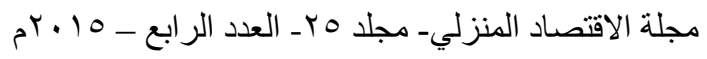

وبتطبيق اختبارtukey يكثف جدول (q⿳): أن أعلي متوسط لدرجات ربات الأسر هي بنوع

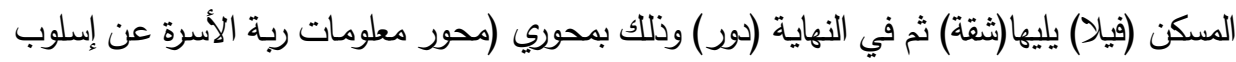
التعامل مع الحوادث المنزلية - محور ممارسات ربة الأسرة في إسلوب التعامل مع الحوادث التهاثل المنزلية)

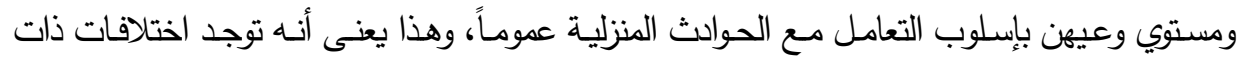

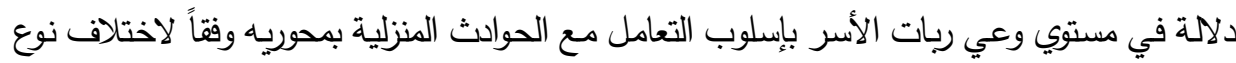
المسكن عند مستوى دلالة (1 ( ...) لصالح نوع المسكن (فيلا).

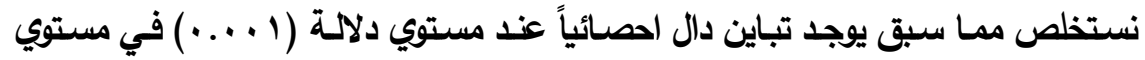

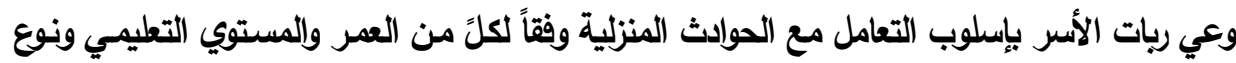

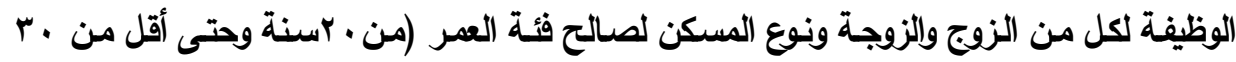

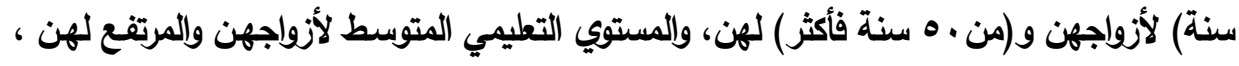

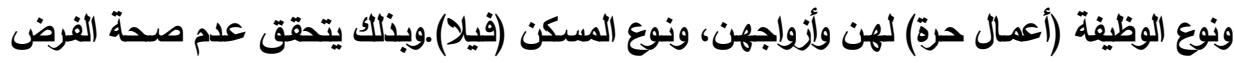

السابع.

\section{1- م-نتائج الفُرض الثنامن}

ينص الفرض الثامن على أنها: "لا يوجد تباين دال احصائياً في مستوي السـلامة المنزلية

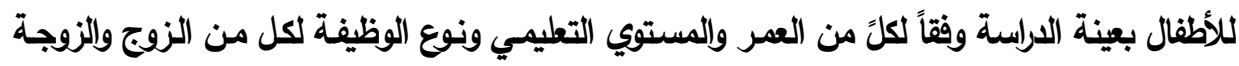

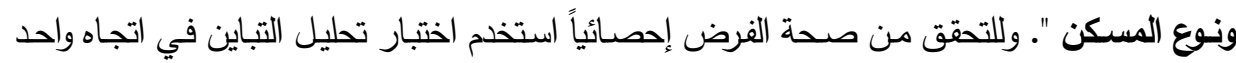
"One Way Anova"

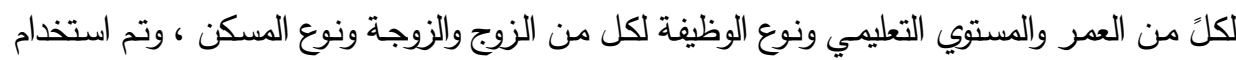

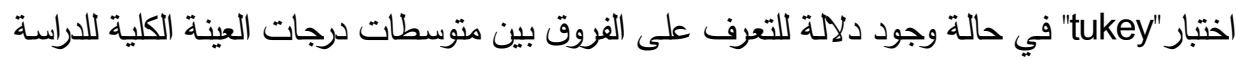

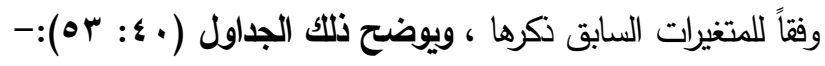

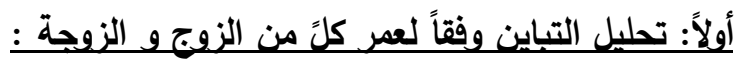

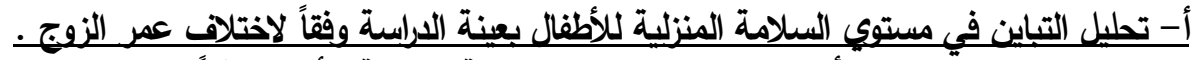

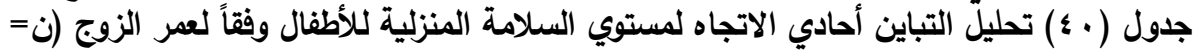
. (

\begin{tabular}{|c|c|c|c|c|c|c|}
\hline مستوى الدلالة & قيمة ف & متوسط المربعات & درجات الحرية & مجموع المربعات & مصادر التباين & المحاور \\
\hline$\because \cdots 1$ & $\wedge \wedge . \wedge \Lambda$ & $\begin{array}{l}\varepsilon V . \otimes A \\
r . \& q r\end{array}$ & $\begin{array}{l}r y \\
r 9 q \\
r 99\end{array}$ & $\begin{array}{l}I \leqslant 1 . I V Y \\
q \wedge V . Y Y 0 \\
11 Y \Lambda .4 V\end{array}$ & داخل المجموعات & المرتبطة بتأثيث وترتيث المواتث \\
\hline
\end{tabular}


مجلة الاقتصاد المنزليـ مجلد هبـ العدد الرابع ـ 10 • ب م

\begin{tabular}{|c|c|c|c|c|c|c|}
\hline$\because \cdots 1$ & $\varepsilon \cdot . \leqslant \wedge$ & $\begin{array}{l}179 . . \leqslant \leq V \\
\varepsilon .119\end{array}$ & $\begin{array}{l}r \\
r q q \\
r q q\end{array}$ & $\begin{array}{l}0.1 .4 \leq 1 \\
1708.7 \leq 9 \\
1170.99 .\end{array}$ & داخل المجموعات المجوعات & 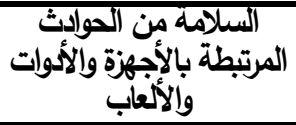 \\
\hline$\because \cdots 1$ & $1 \wedge .0 V$ & $\begin{array}{l}\text { VI.0 } \\
\text { Y.A. }\end{array}$ & $\begin{array}{l}r \\
r q 9 \\
r q 9\end{array}$ & $\begin{array}{l}\text { YIE.7 } \\
10 Y 0.99 V \\
1 V \varepsilon . .7 V 1\end{array}$ & داخل المجموعات المجوعات & المرتبطة بالمواد الكيميائية الحواتية \\
\hline$\because \cdots 1$ & $\checkmark \wedge . \% q$ & $\begin{array}{l}\text { IAV.AYr } \\
r . V \leqslant V\end{array}$ & $\begin{array}{l}r \\
r q 9 \\
r q 9\end{array}$ & $\begin{array}{l}074.874 \\
1.18 .971 \\
1701.841\end{array}$ & بين المجموعات المجموعات & 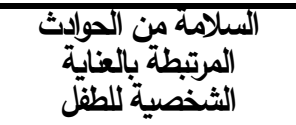 \\
\hline$\because \cdots 1$ & $\approx 1.9 \mathrm{~V}$ & $\begin{array}{l}\text { IrqV.q10 } \\
r .949\end{array}$ & $\begin{array}{l}r \\
r q q \\
r q 9\end{array}$ & 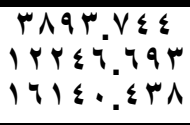 & $\begin{array}{l}\text { داخل المجموعات المجوعات } \\
\text { الكلى }\end{array}$ & مستوي السيلامة المنزلية \\
\hline
\end{tabular}

يتبين من جدول (•؛): وجود تباين دال احصائياً في مستوي وعي ربات الأسر بالمحاور

الأربعة(محور السلامة من الحوادث المرتبطة بتأثيث وترتيب المسكن - محور السلامة من الحوادث

المرتبطة بالأجهزة والأدوات والألعاب - محور السلامة من الحوادث المرتبطة بالمواد الكيميائية

والحشرات والحيوانات - محور السلامة من الحوادث المرتبطة بالعناية الثخصية للطفل) والسلامة

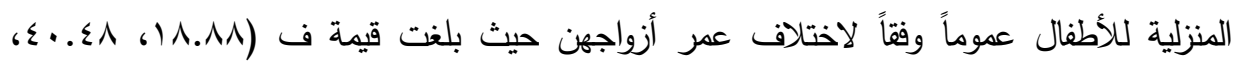

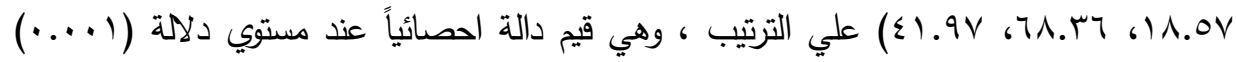

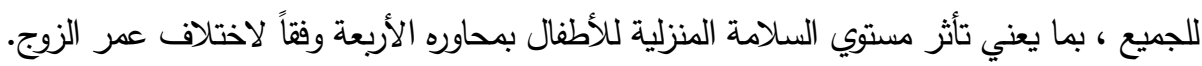

جدول ( إ) متوسط درجات الوعي لربات الأسر بالسلامة المنزلية للأطفال وفقاً لعمر أزواجهن

\begin{tabular}{|c|c|c|c|c|c|}
\hline اللمنلاهية & 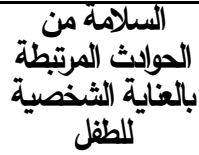 & 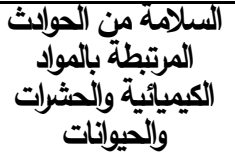 & بالأجهزية والألمرتبطة & 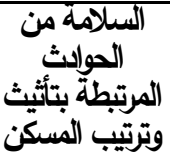 & لتجاه \\
\hline $117 . Y \varepsilon$ & $r \cdot . r q$ & rN. MO & $r \cdot . r 0$ & YN.VV & 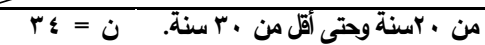 \\
\hline $11 \pi .4 \lambda$ & YN.YY & YV.OT & $Y 1.10$ & $Y \Lambda_{.}{ }^{\top}$ & من · · سنة وحتى أقلى من · ؛ سنة. \\
\hline $11 \leqslant .44$ & PV. 79 & TV.9T & $r \cdot . \cdot r$ & TN. $7 \mathrm{~V}$ & من · ؛ وحتى أقل من · 0 سنة \\
\hline $1 \cdot 0.1$. & YO. $\leqslant Y$ & $Y 4 .{ }^{Y} Y$ & YV.YV & YV.1. & . 0 سنة فأكثر \\
\hline
\end{tabular}

وبتطيق اختبارtukey يكثف جلول (1 ؛): أن أعلي متوسط لدرجات ربات الأسر هي بفئة

العر لأزواجهن (من • rانة وحتى أقل من · ب سنة) وذلك بالمحاور الأربعة(محور السلامة من الحوادث

المرتبطة بتأثيث وترتيب المسكن - محور السلامة من الحوادث المرتبطة بالأجهزة والأدوات والألعاب -

محور السلامة من الحوادث المرتبطة بالمواد الكيميائية والحشرات والحيوانات - محور السلامة من الحوادث

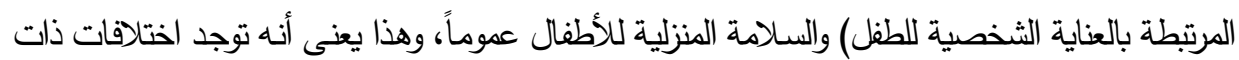




$$
\text { مجلة الاقتصاد المنزليـ مجلد Or ـ العدد الر ابع ـ } 10 \text { • بم }
$$

دلالمة في مستوي وعي ربات الأسـر بالسـلاهة المنزلية للأطفال بمحاوره الأربعة وفقاً لاختلاف أعمار

أزواجهن عند مستوى دلالة (1 ....) لصالح فئة العمر لأزواجهن (من • باسنة وحتى أقل من • بـ سنة).

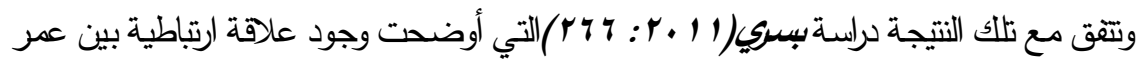

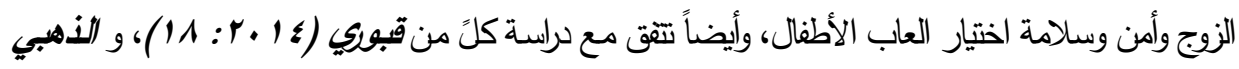

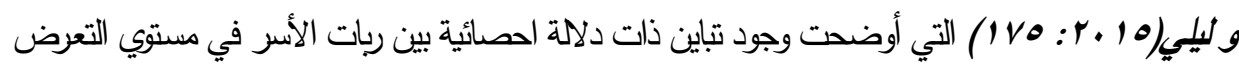

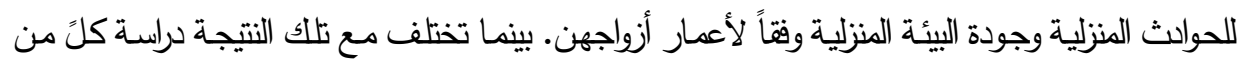
Wang\&Jiang,(2014:241) و Li,(2014: 354) التي أوضحت علم وجود تباين ذات دلالة احصائية بين ربات الأسر في مستوي التعرض للحوادث المنزلية وفقاً لأعمار أزواجهن.

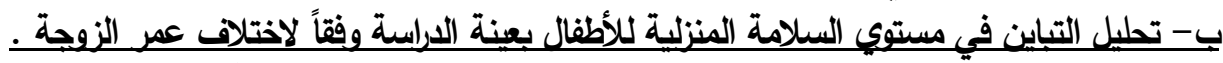

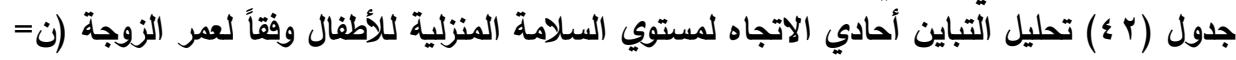

\begin{tabular}{|c|c|c|c|c|c|c|}
\hline مستوى الدالة & قيمة ف & متوسط المربعات & الحرية & مجموع المربعات & مصادر التباين & المحاور \\
\hline$\because \cdots 1$ & $01 . \mu \wedge$ & $\begin{array}{c}1.0 .494 \\
r .01\end{array}$ & $\begin{array}{l}r \\
r 99 \\
r 99\end{array}$ & 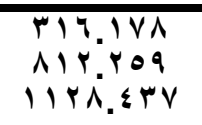 & داخل المجموعات المجموعات & المرتبطة بتأثتيث وترتيب الحوإث \\
\hline$\because \cdots 1$ & $9 . r q$ & $\begin{array}{c}\varepsilon V . \wedge Y q \\
0 . i \cdot V\end{array}$ & $\begin{array}{l}r \\
r a q \\
r 99\end{array}$ & $\begin{array}{l}1 \leq r . \varepsilon V 9 \\
Y . Y Y .011 \\
Y 170.99 .\end{array}$ & داخل المجموعات المجموعات & 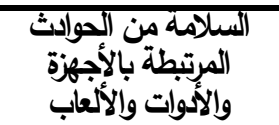 \\
\hline$\because \cdots 1$ & $1 \varepsilon . \cdot V$ & $\begin{array}{l}00 . \Lambda V \varepsilon \\
\text { r.qVY }\end{array}$ & $\begin{array}{l}r \\
r a q \\
r 99\end{array}$ & 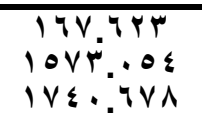 & داخل المجموعات المجمعات & المرتبطة بالمواد من الكيميائية \\
\hline$\because \cdots 1$ & rV. I & $\begin{array}{l}q 0 . r .1 \\
r . \leq \leq 1\end{array}$ & $\begin{array}{l}r \\
r 99 \\
r 99\end{array}$ & $\begin{array}{l}r \wedge 0.9 . \varepsilon \\
1790.04 \varepsilon \\
1701.541\end{array}$ & داخل المجموعات المجموعات & 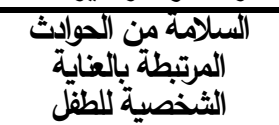 \\
\hline$\because \cdots 1$ & YV.11 & 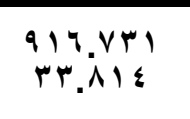 & $\begin{array}{l}r \\
\text { maq } \\
r 99\end{array}$ & $\begin{array}{l}r v 0 \cdot .19 \leq \\
1749 \cdot .4 \leq \varepsilon \\
171 \leq . .84\end{array}$ & داخل المجموعات المجوعات & مستوي السيلامة المنزلية \\
\hline
\end{tabular}

يتبين من جلول (r \&): وجود تباين دال احصائياً في مستوي وعي ربات الأسر بالدحاور الأربعة(محور السلامة من الحوادث المرتبطة بتأثيث وترتيب المسكن - محور السلامة من الحوادث المرتبطة بالأجهزة والأدوات والألعاب - محور السلامة من الحوادث المرتبطة بالمواد الكيميائية

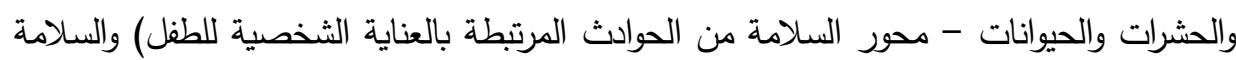

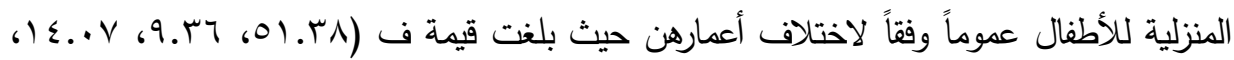




$$
\text { مجلة الاقتصاد المنزلي- مجلد مr- العدد الر ابع - 10 • بم }
$$

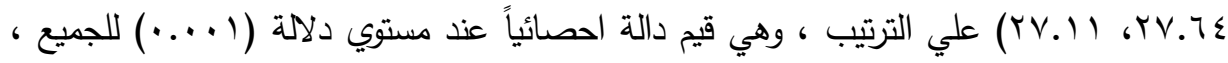
بما يعني تأثر مستوي السلامة المنزلية للأطفال بمحاوره الأربعة وفقاً لاختلاف عمر الزوجة.

جدول (T \&) متوسط درجات الوعي لربات الأسر بالسلامة المنزلية للأطفال وفقاً لأعمارهن (ن= . (

\begin{tabular}{|c|c|c|c|c|c|}
\hline اللأطنالية & بالعناية الثخلاثلة المزتبة منة & 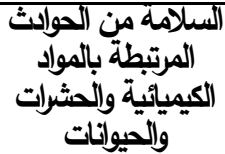 & 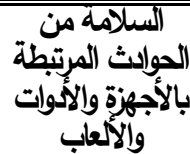 & 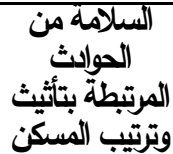 & لات الحسابية للاتجاه \\
\hline 117.17 & rq.1T & $r \wedge .71$ & r9.7. & rq. ri & 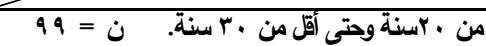 \\
\hline $11 \% .17$ & rV..O & Y7.0V & Yq. & Y.09 & من · r سنة وحتى أقل من · ؛ سنة. \\
\hline $1 \cdot 1.17$ & RV.tT & YV.TT & YN.0 & Yর.V. & 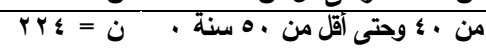 \\
\hline $1.9 . \cdot$ & YV... & YV... & ү^... & YV... & • منة فأكثر من \\
\hline
\end{tabular}

وبتطبيق اختبارtukey يكثف جدول (r ؛): أن أعلي متوسط لدرجات ربات الأسر هي بفئة

العمر (من • rسنة وحتى أقل من ·r سنة) وذلك بالمحاور الأربعة(محور السلامة من الحوادث المرتبطة

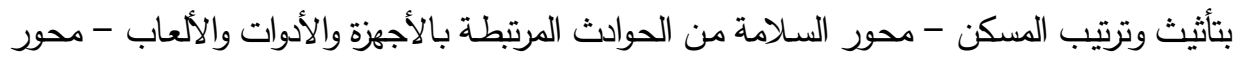
السلامة من الحوادث المرتبطة بالمواد الكيميائية والحشرات والحيوانات - محور السلامة من الحوادث

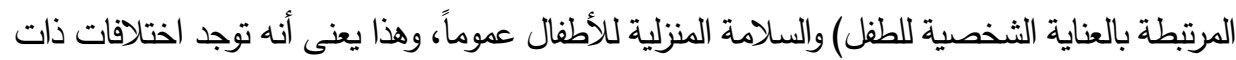
دلالة في مستوي وعي ربات الأسر بالسلامة المنزلية للأطفال بمحاوره الأربعة وفقاً لاختلاف أعمارهن

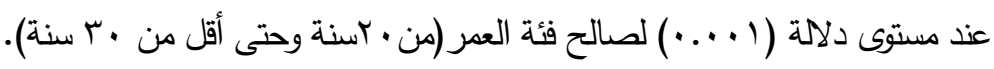

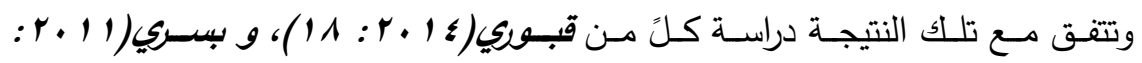

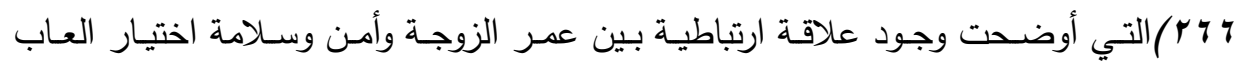

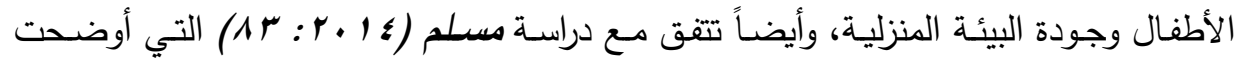

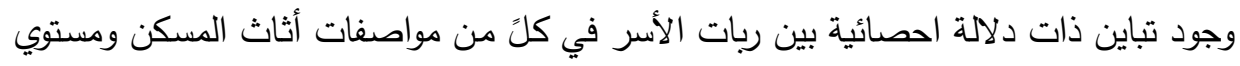

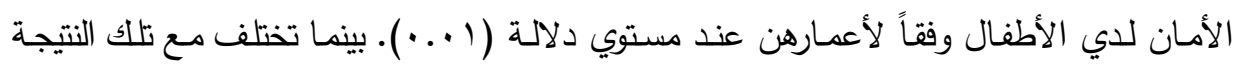
دراسة كلً من (2014:241),Wang\&Jiang)، و Li,(2014: 354) التي أوضحت عدم وجود تباين ذات دلالة احصائية بين ربات الأسر في مستوي التعرض للحوادث المنزلية وفقاً لأعمارهن.

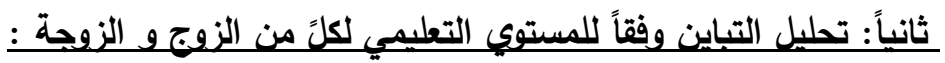
أ- تحليل التباين في مستوي السلامة المنزلية للأطفال بعينة الداسة وفينقاً لاختلاف المستوي التعليمي للزوج . تحلئ 


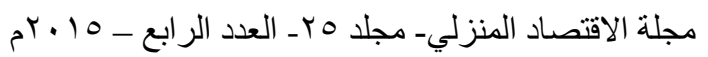

جلول ( ؛ ؛) تحليل التباين أحادي الاتجاه لمستوي السلامة المنزلية للأطفال وفقاً للمستوي التعليمي للزوج

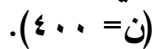

\begin{tabular}{|c|c|c|c|c|c|c|}
\hline مستوى الدلالة & قيمة ف & متوسط المربعات & الدرية & مجموع المربعات & مصادر التباين & المحاور \\
\hline$\because \cdots 1$ & $\varepsilon r . \leqslant 7$ & r & $\begin{array}{l}\text { r } \\
\text { mav } \\
\text { raq }\end{array}$ & $\begin{array}{l}r+r .79 r \\
9 r 0 . V \leq 0 \\
11 r i . \leqslant r V\end{array}$ & داخلين المجموعات المجلى & المرتبطة بتأثيثيث وترتيب الموادث \\
\hline$\because \cdots 1$ & 11.1. & $\begin{array}{l}7.10 . \\
0.10 .\end{array}$ & $\begin{array}{l}r \\
r q v \\
r q q\end{array}$ & $\begin{array}{l}T Y 1.0 .1 \\
r . \leq 8.819 \\
\text { ri } 90.99 .\end{array}$ & دآبل المجموعات المجلى & المرتبطة بالألجهزة والأدوات \\
\hline$\because \cdots 1$ & $r q .9 r$ & $\begin{array}{l}11 \varepsilon .0 \leq 9 \\
\text { ril. }\end{array}$ & $\begin{array}{l}r \\
r a v \\
r a q\end{array}$ & $\begin{array}{l}r r \Lambda .9 V \\
101 Y .0 \Lambda . \\
1 V \varepsilon . .9 V \Lambda\end{array}$ & داخلين المجموعات المجلى & المرتبطة بالمواد الكوادياثية \\
\hline$\because \cdots 1$ & 7.19 & $\begin{array}{l}r \varepsilon .97 r \\
\varepsilon .9 \varepsilon\end{array}$ & $\begin{array}{l}r \\
\text { rav } \\
\text { raq }\end{array}$ & $\begin{array}{l}89.9 Y V \\
17.1 .011 \\
1701.841\end{array}$ & داخل المجموعات المجلى & 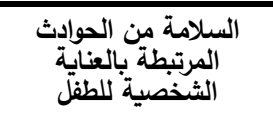 \\
\hline$\because \cdots 1$ & $Y \leqslant .0 \wedge$ & $\begin{array}{l}1 \wedge 9.101 \\
r 9.1 \vee V\end{array}$ & $\begin{array}{l}r \\
\text { rav } \\
\text { raq }\end{array}$ & 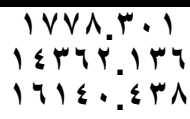 & داخل المجموعات المجلى & مستوي السلالامة المنزلية \\
\hline
\end{tabular}

يتبين من جلول (؟ ؛): وجود تباين دال احصائياً في مستوي وعي ربات الأسر بالمحاور

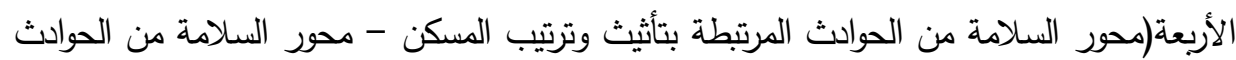

المرتبطة بالأجهزة والأدوات والألعاب - محور السلامة من الحوادث المرتبطة بالمواد الكيميائية

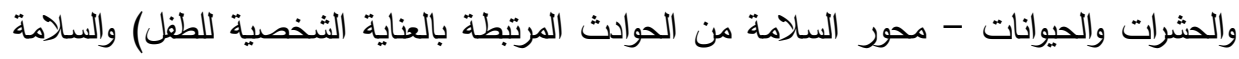

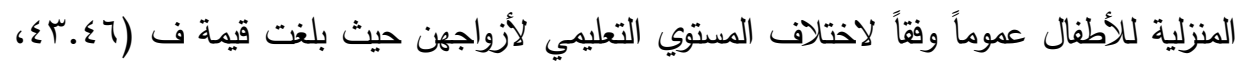

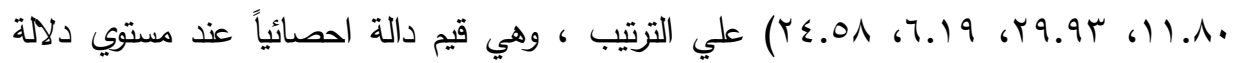

(1.... للجميع ، بما يعني تأثر مستوي السلامة المنزلية للأطفال بمحاوره الأربعة وفقاً لاختلاف

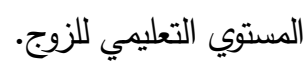

جلول (0 ؛) متوسط درجات الوعي لربات الأسر بالسلاهة المنزلية للأطفال وفقاً للمستوي التعليمي لأزواجهن

\begin{tabular}{|c|c|c|c|c|c|}
\hline السلامتية & 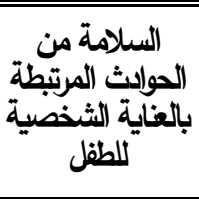 & 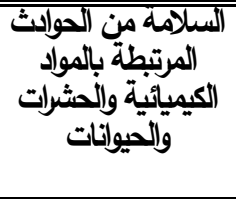 & 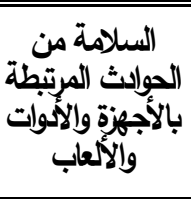 & 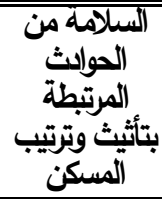 & \\
\hline & TV.Th & T7.10 & 07 & TV.TA & $1 \cdot \Lambda=\dot{0}$ \\
\hline $11 Y .01$ & TV.V. & YV.\&. & र9.1 & Yर.VV & ن \\
\hline 110.1. & r^.ाI & T^.VY & rq.91 & $T 1.99$ & ن \\
\hline
\end{tabular}




$$
\text { مجلة الاقتصاد المنزليـ مجلد Or ـ العدد الر ابع ـ } 0 \text { • ب م }
$$

وبتطبيق اختبارtukey يكشـف جدول (0 ؛): أن متوسط درجات ربات الأسـر

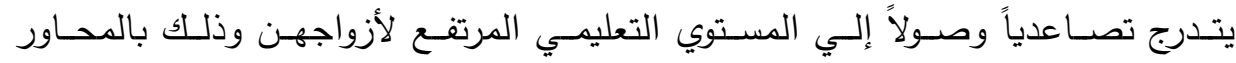

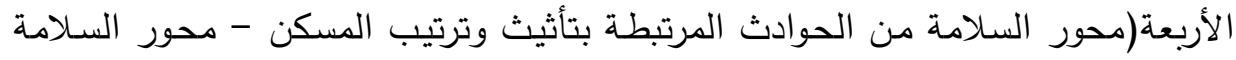

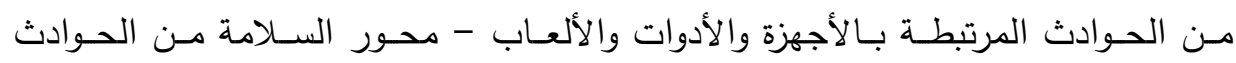
المرتبطة بالمواد الكيميائية والحشرات والحيوانات - محور السلامة من الحوادث المرتبطة

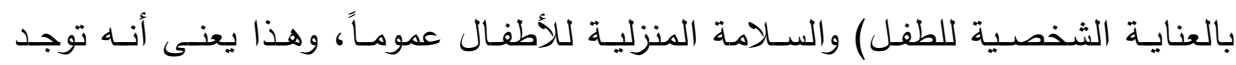
اختلافات ذات دلالـة في مستوي وعي ربات الأسر بالسـلامة المنزلية للأطفال بمحاوره

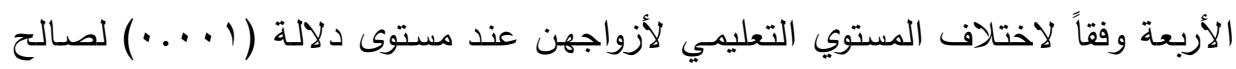
المستوي التعليمي المرتفع لأزواجهن.

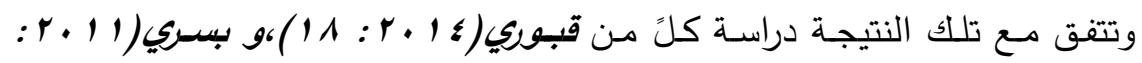
rا r r/التي أوضحت وجود علاقة ارتباطية بين مستوي تعليم الزوج وأمن وسلامة اختيار

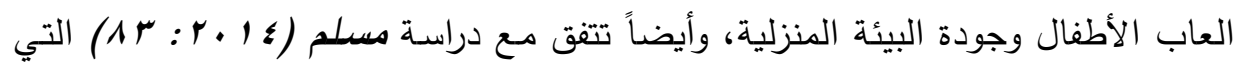

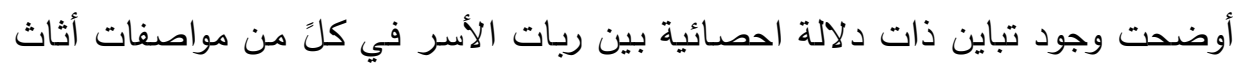

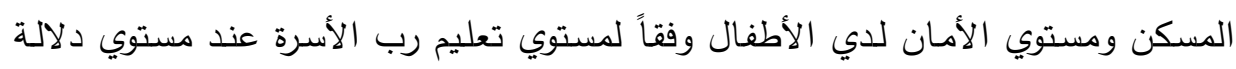

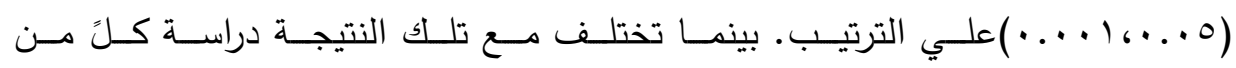
Liu\&Luo(2014: 565) Wang\&Jiang,(2014:241) وجود تباين ذات دلالة احصائية بين ربات الأسر في مستوي التعرض للحوادث المنزلية وفقاً لمستوي تعليم أزواجهن. ب- تحليل التباين في مستوي السلامة المنزلية للأطفال بعينة الدراسة وفقاً لاختلاف المستوي التعليمي للزوجة تولئ

جلول ("َّ ؟) تحليل التباين أحادي الاتجاه لمستوي السلامة المنزلية للأطفال وفقاً للمستوي التطليمي للزوجة (ن=

\begin{tabular}{|c|c|c|c|c|c|c|}
\hline مستوى الدلالة & قيمة ف & متوسط المربعات & الحرجات & مجموع المربعات & مصادر التباين & المحاور \\
\hline$\because \cdots 1$ & $\Lambda . Y 4$ & $\begin{array}{l}Y Y .0 \leqslant V \\
\text { Y.VYQ }\end{array}$ & $\begin{array}{l}r \\
r q y \\
r a q\end{array}$ & 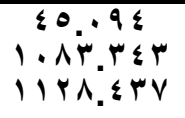 & داخل المجموعات & المرتبطة بتأثيثن وتروتيب الموادث \\
\hline$\because \cdots 1$ & rr.ru & $\begin{array}{l}\text { lo0.7A. } \\
\text { \&.TVY }\end{array}$ & $\begin{array}{l}r \\
r q v \\
r q q\end{array}$ & $\begin{array}{l}M 11 . r 9 . \\
1108.74 . \\
\text { M190.99. }\end{array}$ & داخل المجموعات & 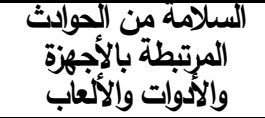 \\
\hline
\end{tabular}


مجلة الاقتصاد المنزليـ مجلد هبـ العدد الرابع ـ 10 • ب م

\begin{tabular}{|c|c|c|c|c|c|c|}
\hline$\because \cdots 1$ & ro.vV & $\begin{array}{c}\text { IrY.Avo } \\
r . V i 0\end{array}$ & $\begin{array}{l}r \\
r q v \\
r q q\end{array}$ & $\begin{array}{l}r q 0 . V \leq 9 \\
1 \leq 8 \leq .9 r \wedge \\
1 V \varepsilon . .7 V V\end{array}$ & داخل المجموعات المجمعات & 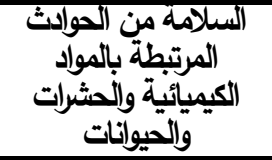 \\
\hline$\because \cdots 1$ & $\varepsilon . \mu$. & $\begin{array}{l}1 V .01 \varepsilon \\
\varepsilon . \cdot V Y\end{array}$ & $\begin{array}{l}r \\
r q v \\
r q q\end{array}$ & $\begin{array}{l}40.49 \\
1717.8 .9 \\
1701.841\end{array}$ & داخل المجموعات المجوعات & 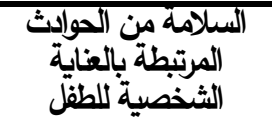 \\
\hline$\because \cdots 1$ & IT.rY & $\begin{array}{l}\varepsilon V 1 . \leqslant V . \\
r \wedge . \forall \wedge 1\end{array}$ & $\begin{array}{l}r \\
r q v \\
r q q\end{array}$ & $\begin{array}{l}9 \leq 4.9 \leq 8 \\
1019 V .89 V \\
171 \leq . .841\end{array}$ & داخل المجموعات المجوعات & مستوي السيلامة المنزلية \\
\hline
\end{tabular}

يتبين من جدول (ף ؛): وجود تباين دال احصائياً في مستوي وعي ربات الأسر

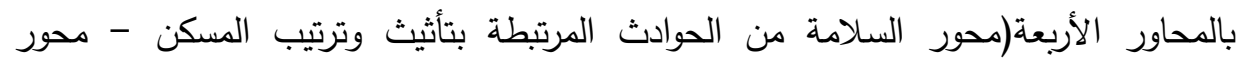

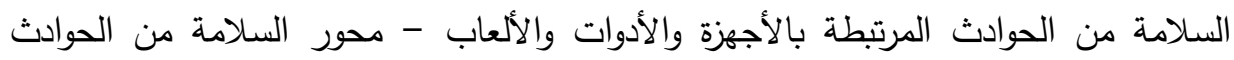

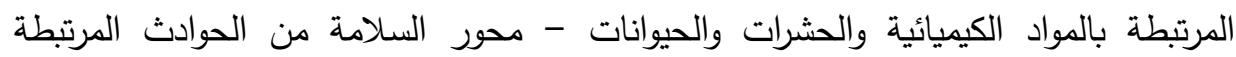

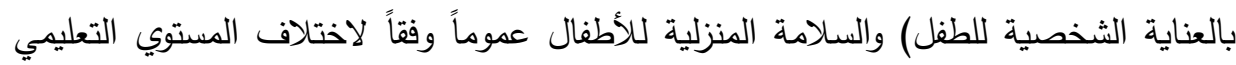

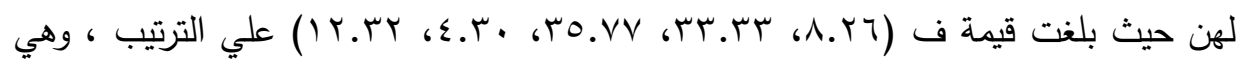

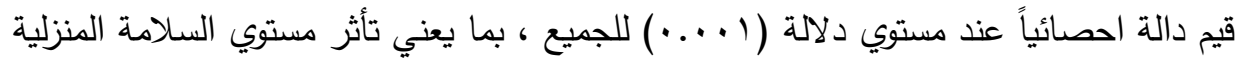

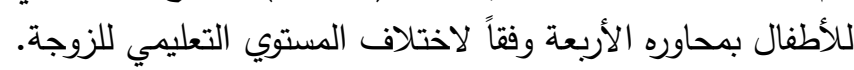

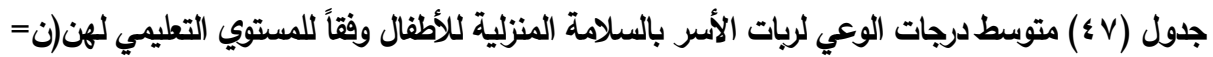
. ( $\varepsilon .$.

\begin{tabular}{|c|c|c|c|c|c|}
\hline المسلامتية & 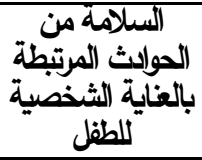 & 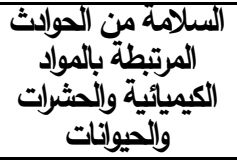 & 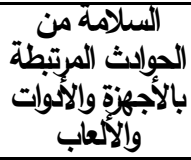 & 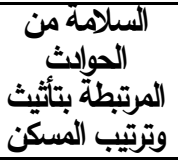 & كاه \\
\hline 111.17 & YV.YT & 79.70 & $r \Lambda .00$ & $r \Lambda . \cdot V$ & $1 \wedge=\dot{0}$ \\
\hline $110 . \varepsilon T$ & Tर. 9 & $r \Lambda . \Lambda T$ & $r \cdot .7 T$ & Tर.V7 & $110=\dot{0}$ \\
\hline $11 Y . \varepsilon \varepsilon$ & PV.79 & YV.07 & T1.9V & YA.VY & $1.0=\dot{0}$ \\
\hline
\end{tabular}

وبتطبيق اختبارtukey يكثـف جدول (V \&): أن أعلي متوسط لدرجات ربات الأسر هي

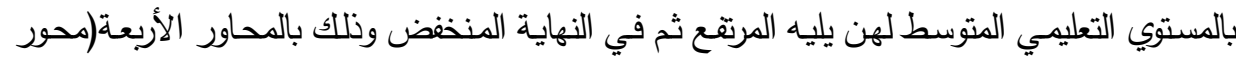

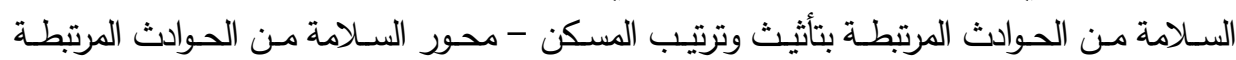

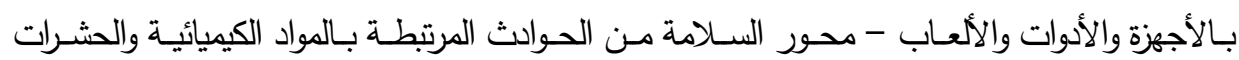
والحيوانـات - محسر السـلامة مـن الحوادث المرتبطـة بالعنايـة الثخصية للطفل) والسـلامة المنزليـة

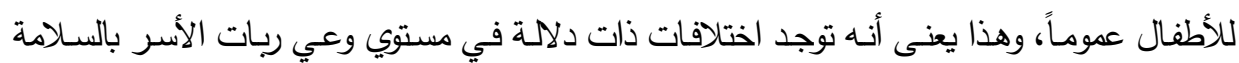




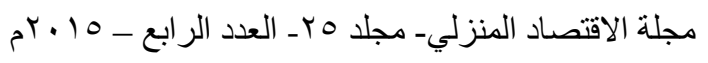

المنزلية للأطفال بمحاوره الأربعة وفقاً لاختلاف المستوي التعليمي لهن عند مستوى دلالة ( (....)

لصالح المستوي التعليمي المتوسط لهن.

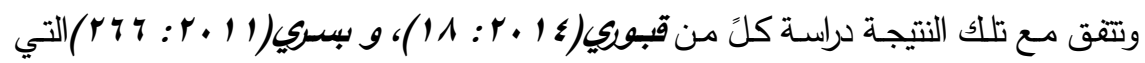

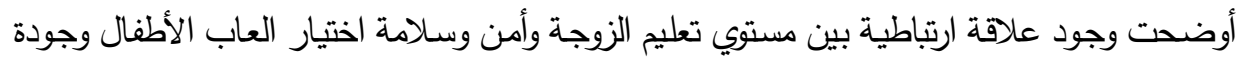

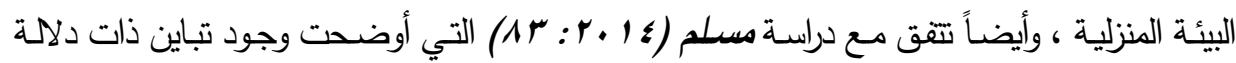

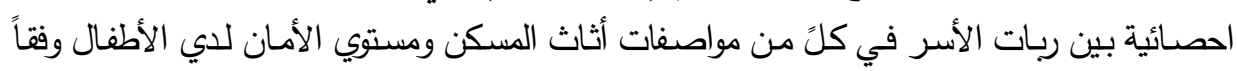

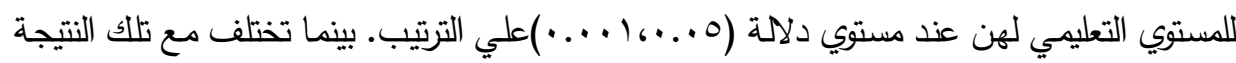
دراسة كلً من (2014:241), Wiu\&Luo(2014: 565) Wang\&Jiang (التي أوضحت عدم وجود تباين ذات دلالة احصائية بين ربات الأسر في مستوي التعرض للحوادث المنزلية وفقاً للمستوي التعليمي لهن.

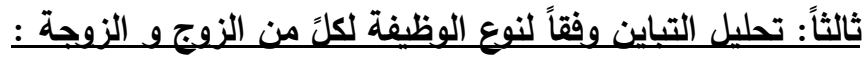

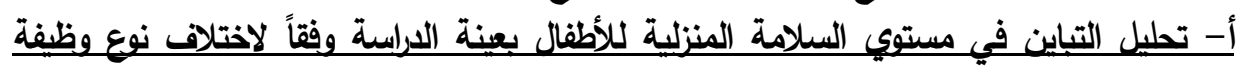
الزوج.

جدول (^^) تحليل التباين أحادي الاتجاه لمستوي السلامة المنزلية للأطفال وفقاً لنوع وظيفة الزوج (ن=

\begin{tabular}{|c|c|c|c|c|c|c|}
\hline مستوى الدلالة & قيمة ف & متوسط المربعات & الرجات & مجموع المربعات & مصادر التباين & المحاور \\
\hline$\because \cdots 1$ & Y.^o & $\begin{array}{l}V . q Y 0 \\
Y . V \wedge q\end{array}$ & $\begin{array}{l}\text { rq } \\
\text { rqq } \\
\text { rq9 }\end{array}$ & 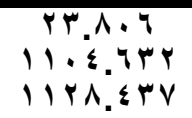 & داخل المجموعات & المرتبطة بتأثيثيث وترتيبث \\
\hline$\because \cdots 1$ & $1 \cdot . v \wedge$ & $\begin{array}{l}0 \leqslant .011 \\
0.0 \mathrm{~V}\end{array}$ & $\begin{array}{l}r \\
\text { rqq } \\
\text { rqq }\end{array}$ & $\begin{array}{l}17 r .000 \\
Y Y Y .540 \\
Y 170.99 .\end{array}$ & داخل المجموعات & 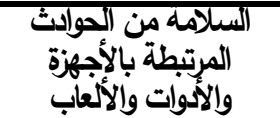 \\
\hline$\ldots$ & $1 . .9$. & $\begin{array}{l}\varepsilon \varepsilon .479 \\
\varepsilon .97\end{array}$ & $\begin{array}{l}r \\
r 9 q \\
r 99\end{array}$ & 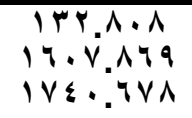 & داخل المجموعات & المرتبطة بالمواد من الكوايمياثية \\
\hline$\because \cdots 1$ & $r . .1 V$ & & $\begin{array}{l}r y \\
r 99 \\
r 99\end{array}$ & 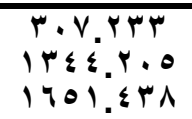 & داخل المجموعات & 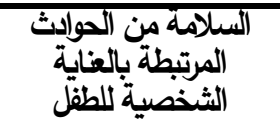 \\
\hline$\because \cdots 1$ & $11 . \mathrm{VV}$ & $\begin{array}{l}\varepsilon \varepsilon .01 v \\
r v . \& Y \mid\end{array}$ & $\begin{array}{l}\text { ru } \\
\text { rqq } \\
\text { rq9 }\end{array}$ & 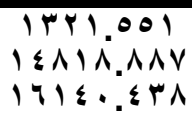 & داخل المجموعات & مستوي اللطيلامة المنزلية \\
\hline
\end{tabular}

يتبين من جلول (^^): وجود تباين دال احصائياً في مستوي وعي ربات الأسر بالمحاور

الأربعة(محور السلامة من الحوادث المرتبطة بتأثيث وترتيب المسكن - محور السلامة من الحوادث 


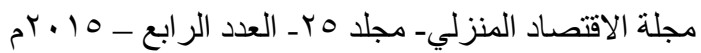

المرتبطة بالأجهزة والأدوات والألعاب - محور السلامة من الحوادث المرتبطة بالمواد الكيميائية والحشرات والحيوانات - محور السلامة من الحوادث المرتبطة بالعناية الثخصية للطفل) والسلامة

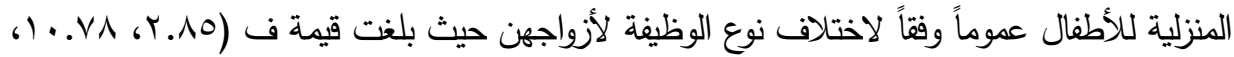

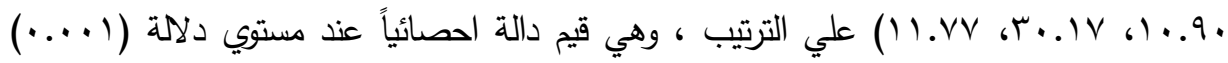

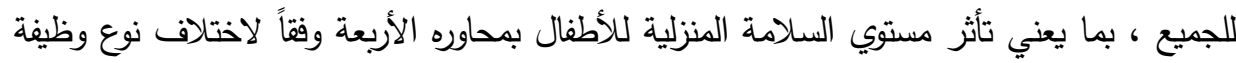
الزوج.

جدول (9 ؛) متوسط درجات الوعي لربات الأسر بالسلامة المنزلية للأطفال وفقاً لنوع الوظيفة لأزواجهن

\begin{tabular}{|c|c|c|c|c|c|}
\hline \multicolumn{6}{|c|}{ ( $)$ ( } \\
\hline المسلامتية & 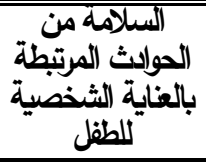 & 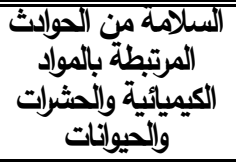 & 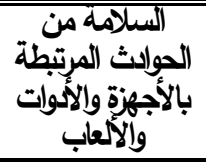 & 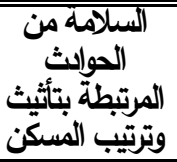 & \\
\hline$T 1 \varepsilon . v \lambda$ & Tर.०. & TA.YY & Pq.97 & T1. TY & وظيفة حكومية \\
\hline $111 . r 1$ & rV.TT & Y.. $\mathrm{NV}$ & YN.YO & YN.07 & $1.4=0$ \\
\hline $1.9 .4 \%$ & YO.Y & YV.Y \{ & Y9.1. & YV.VT & $\varepsilon r=\dot{U}$ \\
\hline $11 \leqslant .4$. & YV.qY & YV.VV & $r 9.71$ & $Y \wedge . \leqslant \varepsilon$ & $\because \Lambda=\dot{0}$ \\
\hline
\end{tabular}

وبتطبيق اختبارtukey يكثف جدول (9 ؛): أن أعلي متوسط لدرجات ربات الأسر هي بنوع

الوظيفة لأزواجهن (حكومية) وذلك بالمحاور الأربعة(محور السـلامة من الحوادث المرتبطة بتأثيث وترتيب المسكن - محور السلامة من الحوادث المرتبطة بالأجهزة والأدوات والألعاب - محور السلامة لهونة من الحوادث المرتبطة بالمواد الكيميائية والحشرات والحيوانات - محور السلامة من الحوادث المرتبطة بالعناية الثخصية للطفل) والسلامة المنزلية للأطفال عموماً، وهذا يعنى أنه توجد اختلافات ذات دلالهة

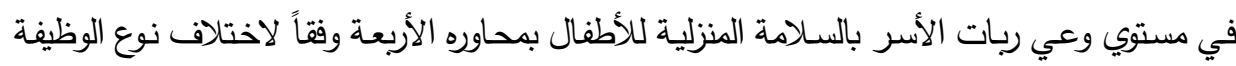
لأزواجهن عند مستوى دلالة ( ( .... لصالح نوع الوظيفة (حكومية) لأزواجهن.

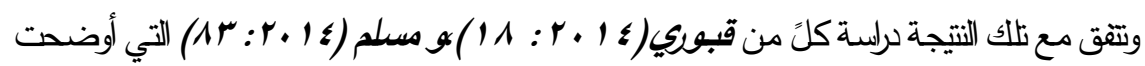

وجود تباين ذات دلالة احصائية بين ربات الأسر في كلًً من مواصفات أثاث المسكن ومستوي الأمان لدي الأطفال وققاً لنوع وظيفة أزارجهن.

ب- تحليل التباين في مستوي السلامة المنزلية للأطفال بعينة الدراسة وفقاً لاختلاف نوع وظيفة الزوجة.

جدول ( •ه) تحليل التباين أحادي الاتجاه لمستوي السلامة المنزلية للأطفال وفقاً لنوع وظيفة الزوجة (ن= .). 
مجلة الاقتصاد المنزليـ مجلد هبـ العدد الرابع ـ 10 • ب م

\begin{tabular}{|c|c|c|c|c|c|c|}
\hline مستوى الدلالة & قيمة ف & متوسط المربعات & الحرية & مجموع المربعات & مصادر التباين & المحاور \\
\hline$\because \cdots 1$ & rq. 1 & $\begin{array}{l}V_{1} .9 \leq r \\
r . \leq 1 .\end{array}$ & $\begin{array}{l}r \\
r a v \\
r a q\end{array}$ & $\begin{array}{l}1 \leq r . \wedge \wedge 0 \\
q \wedge \varepsilon .0 \Delta r \\
11 Y \Lambda . \leqslant r V\end{array}$ & 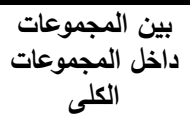 & المرتبطة بتأثيث الحوتث وترتيب \\
\hline$\because \cdots 1$ & rA. Ir & $\begin{array}{l}1 \% \varepsilon . r \wedge \varepsilon \\
\varepsilon . \vee \vee q\end{array}$ & $\begin{array}{l}r \\
r q v \\
r q q\end{array}$ & $\begin{array}{l}Y 7 \Lambda . V 9 \Lambda \\
1 \wedge 9 V . r Y r \\
Y 170.99 .\end{array}$ & داخل المجموعات المجوعات & السلامهة من الألحوالثة \\
\hline$\because \cdots 1$ & 0.17 & 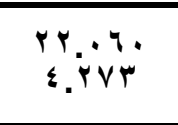 & $\begin{array}{l}r \\
r a v \\
r q 9\end{array}$ & $\begin{array}{l}\varepsilon \varepsilon .1 Y 1 \\
1794.00 V \\
1 V \varepsilon . .7 V V\end{array}$ & داخل المجموعات المجمات & المرتبطة بالمواد من الكيميائية \\
\hline$\because \cdots 1$ & 7.1. & $\begin{array}{l}r \varepsilon .7 Y r \\
\varepsilon . . Y Y\end{array}$ & $\begin{array}{l}r \\
\text { rav } \\
\text { raq }\end{array}$ & $\begin{array}{l}89 . Y \leqslant 0 \\
17.4 .19 \% \\
1701.841\end{array}$ & داخل المجموعات المجوعات & 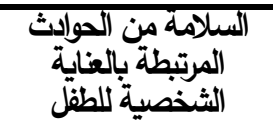 \\
\hline$\because \cdots 1$ & 0.01 & $\begin{array}{l}\text { Y } \\
r 9.199 \\
r 9.001\end{array}$ & $\begin{array}{l}r \\
r a v \\
r a q\end{array}$ & 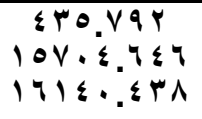 & 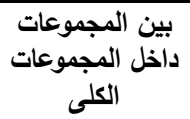 & مستوي السئلامة المنزلية \\
\hline
\end{tabular}

يتبين من جلول (·•): وجود تباين دال احصائياً في مستوي وعي ربات الأسر بالمحاور

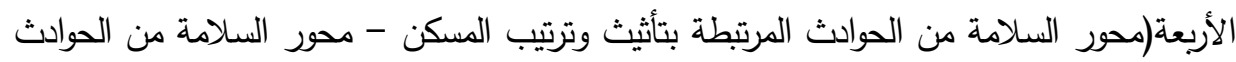

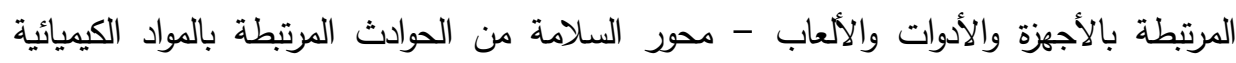

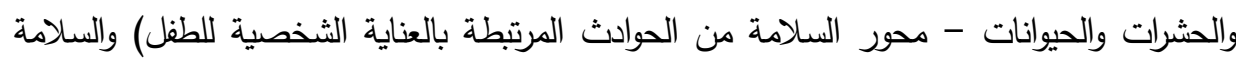

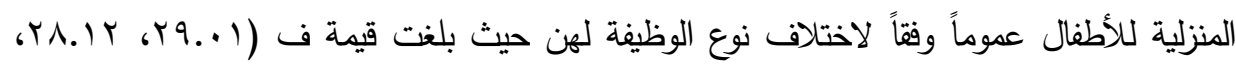

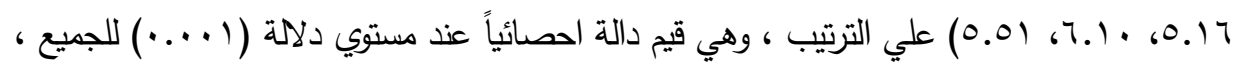

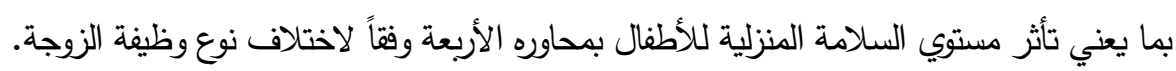

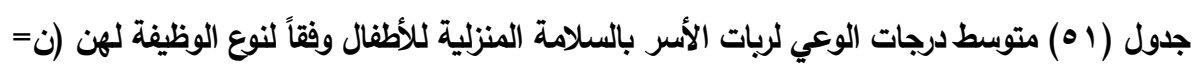

. (๕..

\begin{tabular}{|c|c|c|c|c|c|}
\hline المستويةي & بالعالية الثخلثة المرتبة منة & 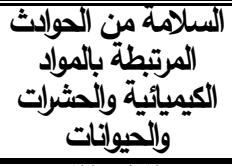 & 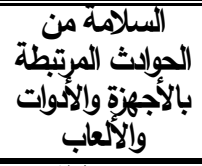 & 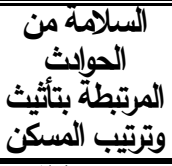 & اه \\
\hline TIY.YE & FV. \&I & rq.1Y & rA... & rی... & وظيفة حكومية \\
\hline $118 .$. & 19... & rA... & rY... & $r \cdot . \cdot$ & أعمال حرة . \\
\hline $11 Y .17$ & YV.7. & rV.Vq & $r q . Y \varepsilon$ & YA.YT & بدون عمل. \\
\hline
\end{tabular}

وبتطبيق اختبارtukey يكثف جدول (10): أن أعلي متوسط لدرجات ربات الأسر هي بنوع

الوظيفة (أعمال حرة) لهن وذلك بالمحاور الأربعة(محور السلامة من الحوادث المرتبطة بتأثيث وترتيب العيث 


$$
\text { مجلة الاقتصاد المنزلي- مجلد مr- العدد الرابع - } 10 \text { • rم }
$$

المسكن - محور السلامة من الحوادث المرتبطة بالأجهزة والأدوات والألعاب - محور السـلامة من الحوادث المرتبطة بالمواد الكيميائية والحشرات والحيوانات - محور السـلامة من الحوادث المرتبطـة بالعناية الثخصية للطفل) والسلامة المنزلية للأطفال عموماً، وهذا يعنى أنه توجد اختلافات ذات دلالة

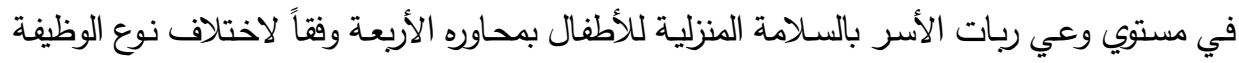
لهن عند مستوى دلالة (1 ..... لصالح نوع الوظيفة لهن (أعمال حرة).

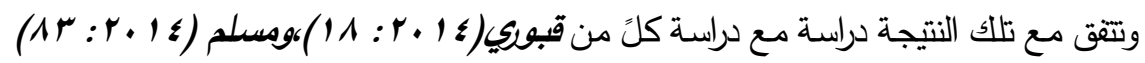
التي أوضحت وجود تباين بين ربات الأسر في كلً من مواصفات أثاث المسكن ومستوي الأمان لدي لداءي

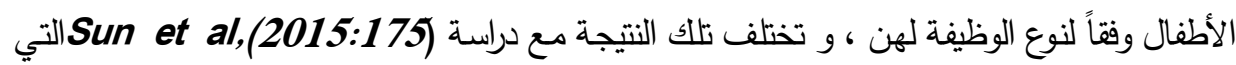

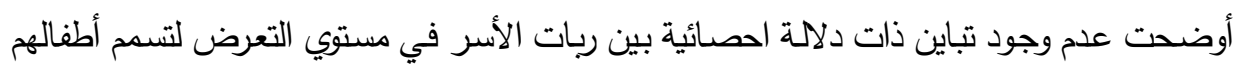
وفقاً لنوع الوظيفة لهن.

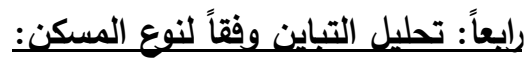

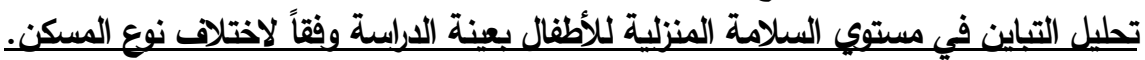

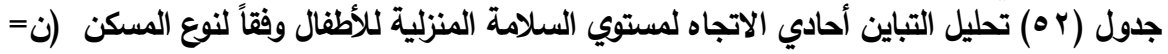

\begin{tabular}{|c|c|c|c|c|c|c|}
\hline مستوى الدلالة & قيمة ف & متوسط المربعات & الدرية & مجموع المربعات & مصادر التباين & المحاور \\
\hline$\because \cdots 1$ & $r \cdot .1 r$ & $\begin{array}{l}01.949 \\
r .011\end{array}$ & $\begin{array}{l}r \\
r q v \\
r 9 q\end{array}$ & 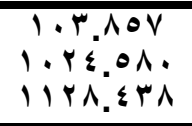 & داخل المجموعات & المرتبطة بتأثيثيث وترتيب الموادث \\
\hline$\because \cdots 1$ & $r .00$ & $\begin{array}{l}19.899 \\
0.49 .\end{array}$ & $\begin{array}{l}r \\
r q v \\
r q 9\end{array}$ & $\begin{array}{l}r \wedge .01 \\
\text { rirv.9rr } \\
r i r 0.99 .\end{array}$ & داخل المجموعات & 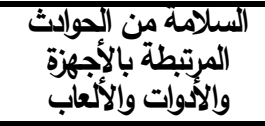 \\
\hline$\because \cdots 1$ & $\leqslant . \leqslant 9$ & $\begin{array}{l}\text { 19.YOR } \\
\text { S.YAN }\end{array}$ & $\begin{array}{l}r \\
r q v \\
r q q\end{array}$ & $\begin{array}{l}r \wedge .0 \ldots \\
i v \cdot \dot{r} \text { ivv } \\
i v \leq \cdot \text { TV }\end{array}$ & داخل المجموعات & 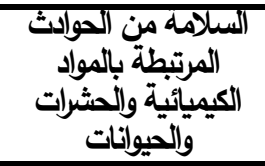 \\
\hline$\because \cdots 1$ & 7.71 & $\begin{array}{l}r Y . \wedge Y 0 \\
\varepsilon . Y Y\end{array}$ & $\begin{array}{l}r y \\
r q v \\
r q q\end{array}$ & $\begin{array}{l}0 Y . V T \cdot \\
109 V . V . \Lambda \\
1701 . \leqslant r \Lambda\end{array}$ & داخل المجموعات & 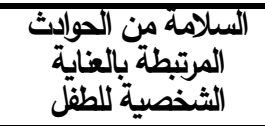 \\
\hline$\because \cdots 1$ & Y.OY & $\begin{array}{l}1 \cdot 1 . . r r \\
\varepsilon \cdot .1 \leqslant v\end{array}$ & $\begin{array}{l}r \\
r q v \\
r q q\end{array}$ & 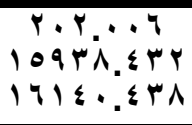 & داخل المجموعات & مستوي السلطلامة المنزلية \\
\hline
\end{tabular}

يتبين من جلول (rه): وجود تباين دال احصائياً في مستوي وعي ربات الأسر بالمحاور الأربعة(محور السلامة من الحوادث المرتبطة بتأثيث وترتيب المسكن - محور السلامة من الحوادث 


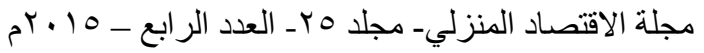

المرتبطة بالأجهزة والأدوات والألعاب - محور السلامة من الحوادث المرتبطة بالمواد الكيميائية والحشرات والحيوانات - محور السلامة من الحوادث المرتبطة بالعناية الشخصية للطفل) والسلامة

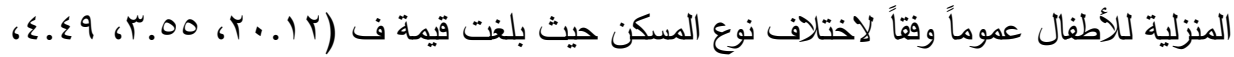

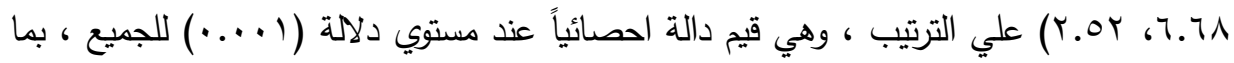
يعني تأثر مستوي السلامة المنزلية للأطفال بمحاوره الأربعة وفقاً لاختلاف نوع المئي المسكن.

جدول (ب ه) متوسط درجات الوعي لربات الأسر بالسلامة المنزلية للأطفال وفقاً لنوع المسكن(ن = . . ع ).

\begin{tabular}{|c|c|c|c|c|c|}
\hline اللمنلامةية & 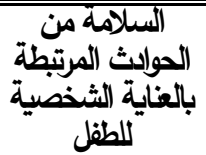 & 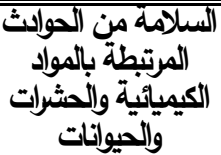 & 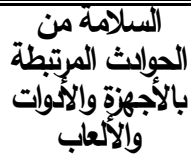 & 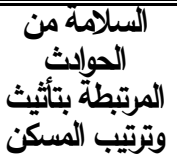 & نوع المسكن \\
\hline $114.0 \mathrm{~V}$ & rV. 97 & 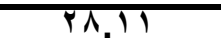 & r9.71 & r9.1T & ن \\
\hline $111.9 \mathrm{~V}$ & YV.IT & $T V . \varepsilon T$ & $Y \Lambda . \Lambda V$ & $Y \Lambda_{.} \cdot 1$ & ن \\
\hline $11 \% . \leqslant 0$ & YV.A\& & $Y V . \leqslant 9$ & $r 9 . r$. & $r \Lambda .1 T$ & 1 \\
\hline
\end{tabular}

وبتطبيق اختبارtukey يكثف جدول (rه): أن أعلي متوسط لدرجات ربات الأسر هي بنوع

المسكن (شقة) يليها (فيلا) ثم في النهاية (دور) ونلك بالمحاور الأربعة (محور السـلاهة من الحوادث المرتبطة بتأثثث وترتيب المسكن - محور السلامة من الحوادث المرتبطة بالأجهزة والأدوات والألعاب

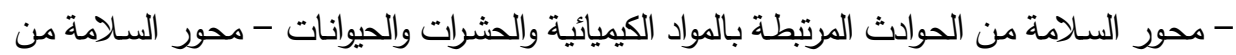
الحوادث المرتبطة بالعناية الثخصية للطفل) والسـلامة المنزلية للأطفال عموماً، وهذا يعنى أنـه توجد اختلافات ذات دلالمة في مستوي وعي ربات الأسر بالسـلامة المنزلية للأطفال بمحاوره الأربعة وفقاً لاختلاف نوع المسكن عند مستوى دلالة ( ( ....) لصالح نوع المسكن (شقة).

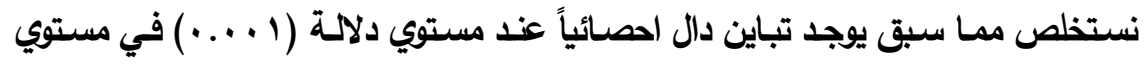
السلامة المنزلية للأطفال بعينة اللراسـة وفقاً لكلً من العمر والمستوي التعليمي ونوع الوظيفة لكل

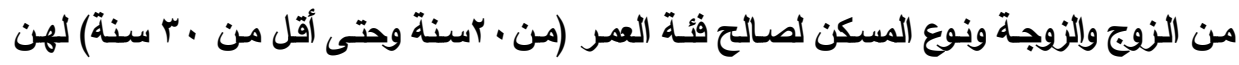

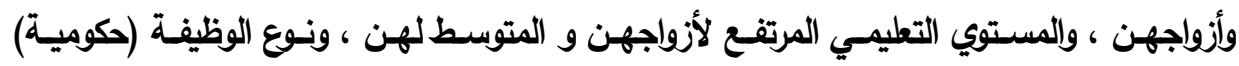
لأزواجهن و(أعمال حرة) لهن، ونوع المسكن (شقة).وبذلك يتحقق عدم صحة الفرض الثامن.

\section{ثالثا: ملفصر لأهم نتنائج الدراسة الميدانية}

1-توجد علاقة ارتباطيه موجبة عند مستوي دلالة (1 (...) بين مستوي وعي ربه الأسرة بإسلوب التعامل مع الحوادث المنزلية وبين مستوي السلامة المنزلية للأطفال. 


$$
\text { مجلة الاقتصاد المنزلي- مجلد هب- العدد الرابع - } 10 \text { • rم }
$$

ץ-توجد علاقة ارتباطيه سالبة عند مستوي دلالة ( ( . ..) بين مستوي وعي ربه الأسرة بإسلوب

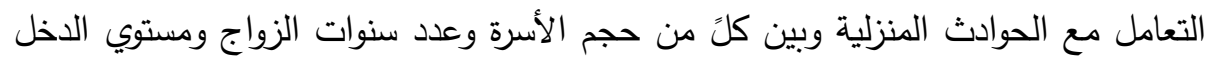

$$
\text { الشهري للأسرة. }
$$

r- توجد علاقة ارتباطيه سالبة بين حجم الأسرة ومستوي السلامة المنزلية للأطفال عند مستوى .

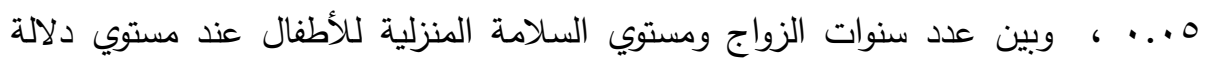
ا . .... بينما لا توجد علاقة بين الدخل الشهري وبين ومستوي السلامة المنزلية للأطفال. ع-توجد فروق ذات دلالة احصائية عند مستوي دلالة (1 ل.... بين بين ربات الأسر العاملات وغير العاملات

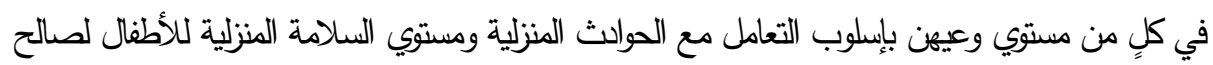

$$
\text { ربات الأسر العاملات. }
$$

ه- لا توجد فورق ذات دلالة إحصائية بين ربات الأسر الحضريات والريغيات في مستوي وعيهن بإسلوب التعامل مع الحوادث المتزلية ، بينما توجد فروق ذات دلالة احصائية عند مستوي دلالة (1 (....) في مستوي السلامة

$$
\text { الهنزلية للأطفال الصلح ربات الأسر الريفيات. }
$$

ج-توجد فروق ذات دلالة إحصائية عند مستوي دلالة (1 (...) بين ربات الأسر في كلٍ من مستوي وعيهن بإسلوب التعامل مع الحواثث المنزلية ومستوي السلادة المنزلية للأطفال وققاً لطبيعة المسكن لصالح ربات الأسنر

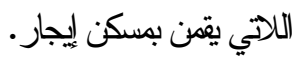

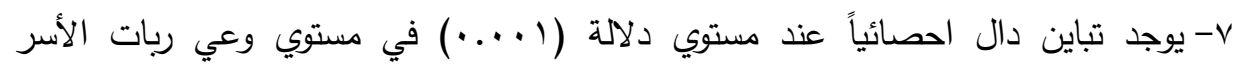

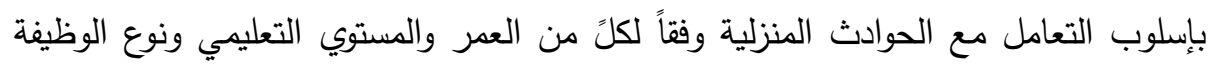

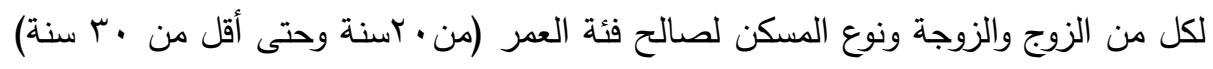

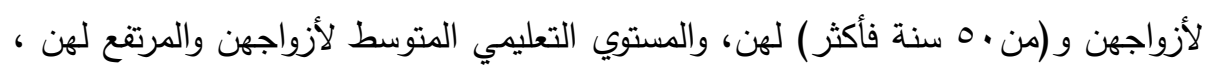
ونوع الوظيفة (أعمال حرة) لهن وأزواجهن، ونوع المسكن (فيلا).

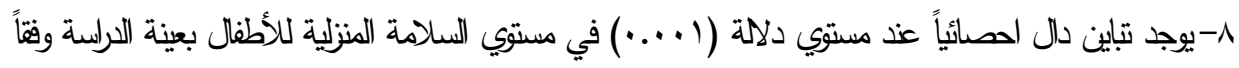

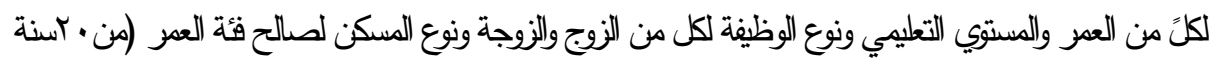

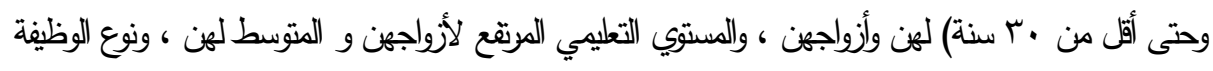
(حكومية) لأزواجهن و (أعمال حرة) لهن، ونوع المسكن (ثقة).

\section{رابـعاً: النتوصيات}




$$
\text { مجلة الاقتصاد المنزلي- مجلد هبـ العدد الرابع - } 10 \text { • rم }
$$

1- هنالك حاجة ماسـة إلي توجيه اهتمام الباحثين إلي إعداد البرامج الإششادية والندوات التوعوية الهادفة

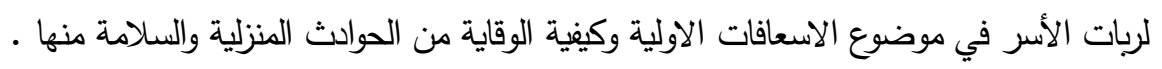

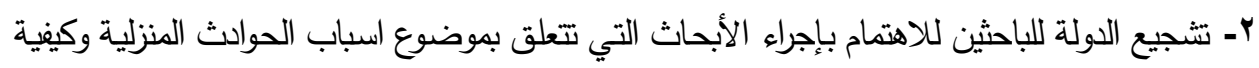

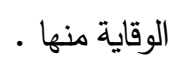

r- تتـاول البرامج الارشـادية القديمة بالتطوير والتحسيث لتلائم الاحتياجـات الفعلية والتطورات الحديثة

$$
\text { بالمجتمع. }
$$

عـ الاهتمام بتطوير مقررات التعليم بجميع المر احل التعليمية، بدمج بعد البيئة المنزلية والوقاية من الحوادث بها.

هـ علي الأسرة الاهتمام بالإجراءات الوقائية للسلامة من الحوادث المنزلية كاختيار الالعاب الملائمة لعمر

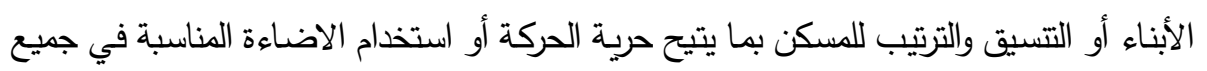

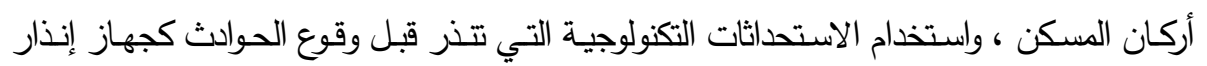

$$
\text { الحريق...الخ. }
$$

ז- تتشيط دور الإعلام بكافة أجزته لتوعية المجتمع وخاصة المرأة بأهمية الوقاية من الحواثث المنزلية ووسائلها

والتعامل معها.

\section{قائهة المراجمر}

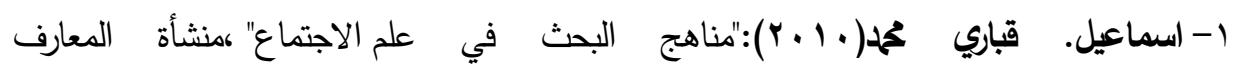

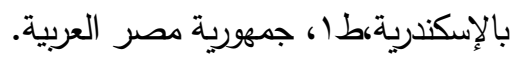

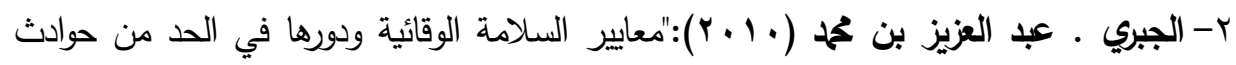

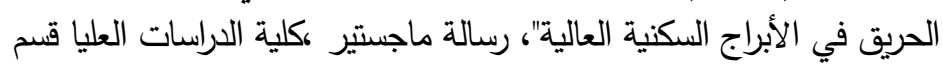

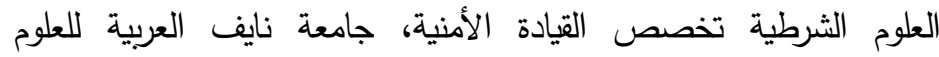

الأمنية،المملكة العربية السعودية.

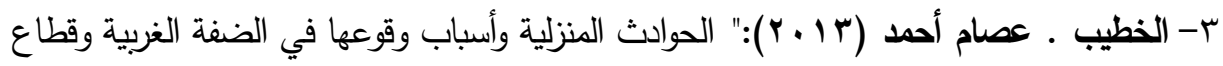

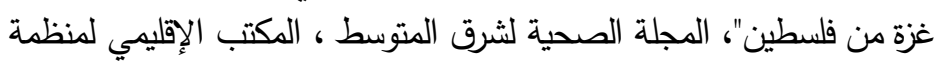

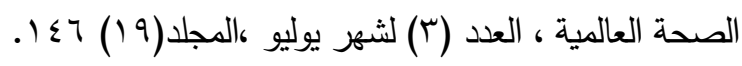

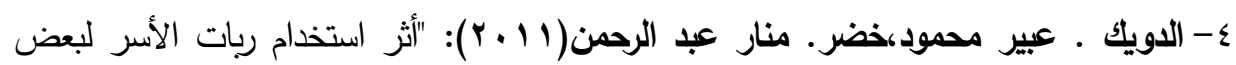

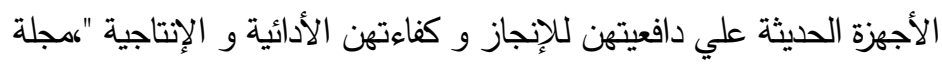

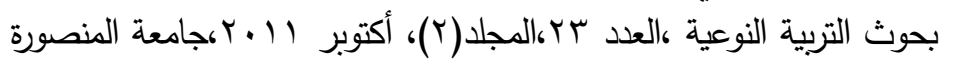

، جمهورية مصر العربية . 


$$
\text { مجلة الاقتصاد المنزليـ مجلد Or ـ العدد الرابع - } 10 \text { • ب م }
$$

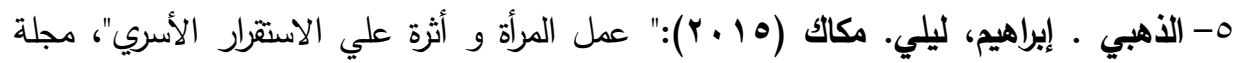

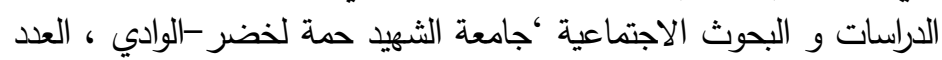

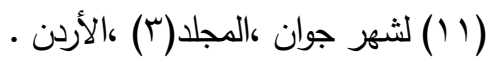

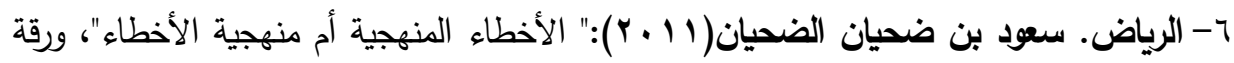

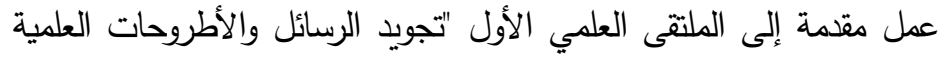

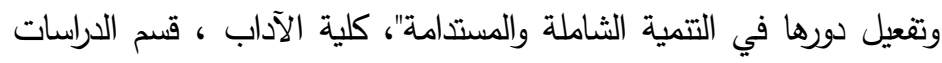

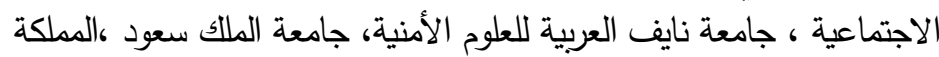

$$
\text { العربية السعودية. }
$$

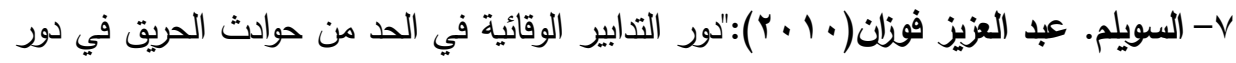

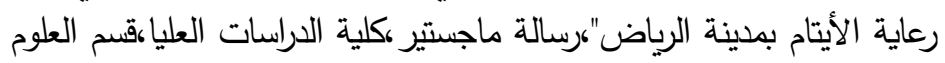
الثرطية،جامعة نايف العربية للعلوم الأمنية،المملكة العربية السعودية.

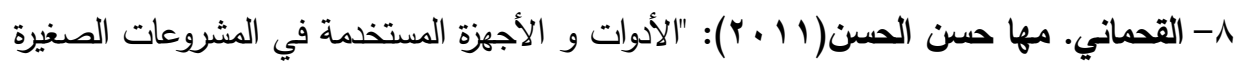

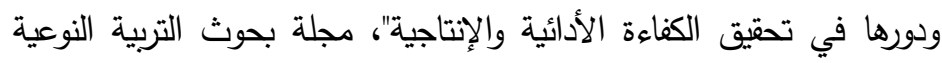

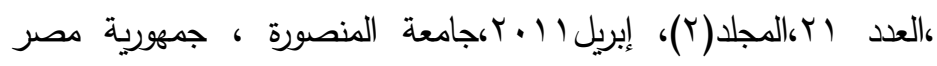

$$
\text { العربية. }
$$

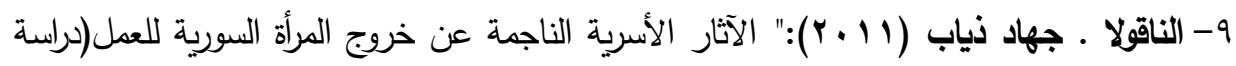

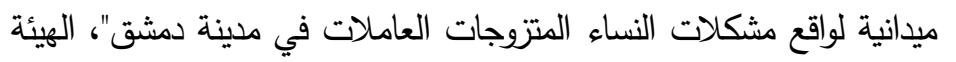

$$
\text { العامة السورية للكتاب كوزارة الثقافة ،سوريا. }
$$

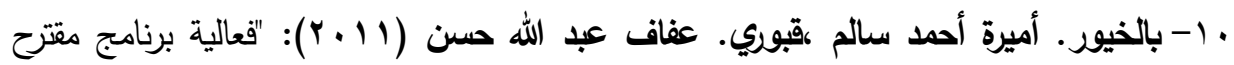

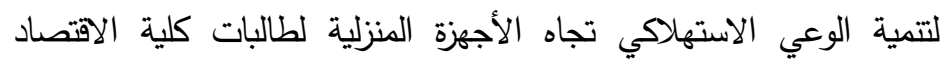

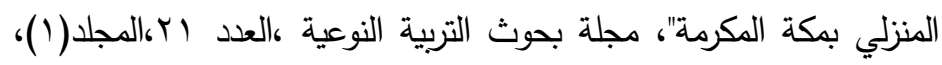

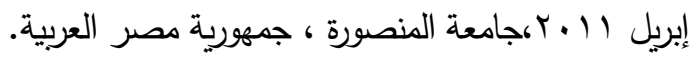

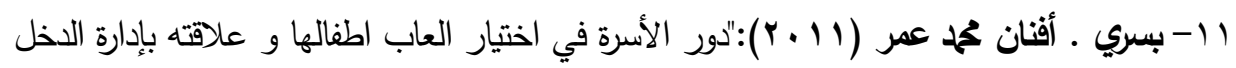

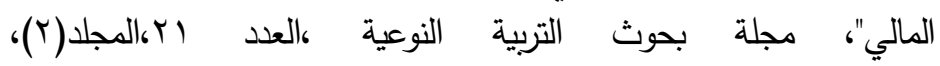
إبريل | | • ب، جامعة المنصورة ، جمهورية مصر العربية.

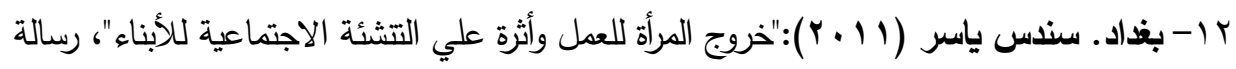
ماجستير، كلية التربية ،قسم أصول التربية، جامعة دمثق، لمسوريا. 


$$
\text { مجلة الاقتصاد المنزليـ مجلد مبـ العدد الرابع ـ } 10 \text { • بrم }
$$

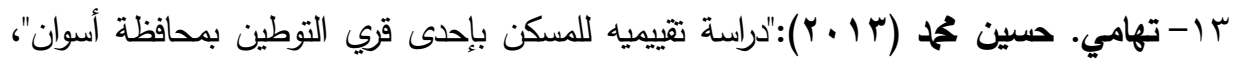

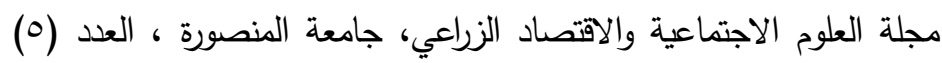

$$
\text { لشهر مايو ،المجلد(ع)، جمهورية مصر العربية. }
$$

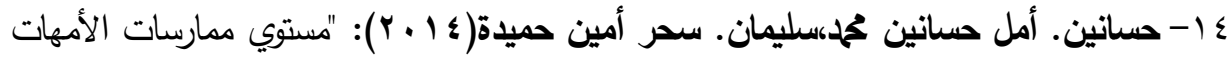

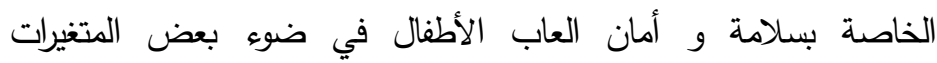

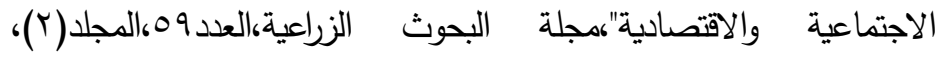

$$
\text { الاسكندرية، جمهورية مصر العربية. }
$$

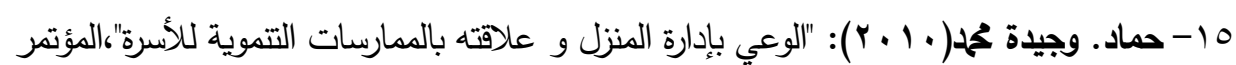

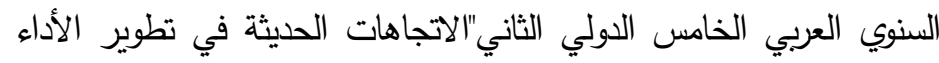

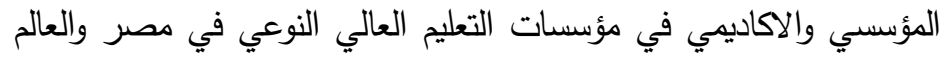

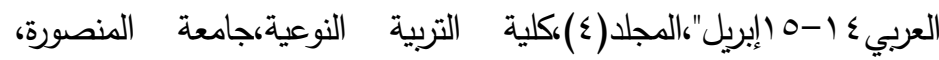

$$
\text { جمهورية مصر العربية. }
$$

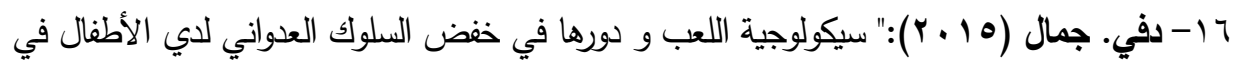

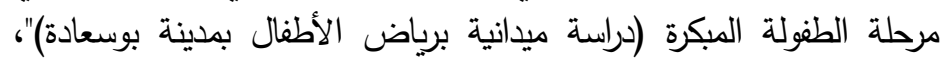

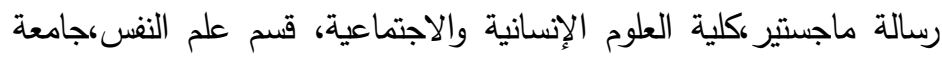

$$
\text { مولود معمري -تيزي وزو - ، الجزائر . }
$$

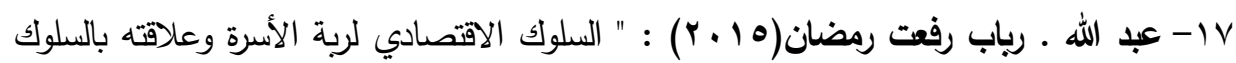

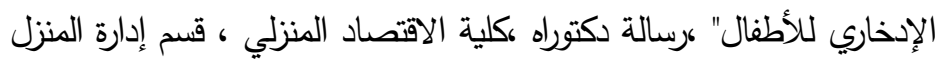

$$
\text { والمؤسسات، جامعة المنوفية، جمهورية مصر العربية. }
$$

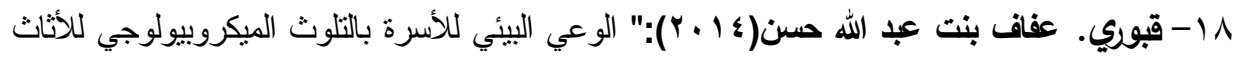

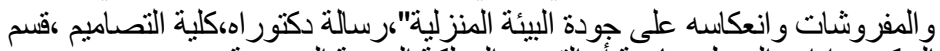
السكن و إدارة المنزل، جامعة أم القري، المملكة العربية السعودية.

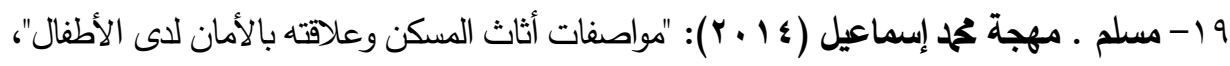

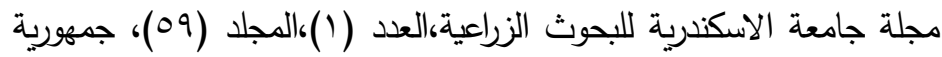

$$
\text { مصر العربية. }
$$

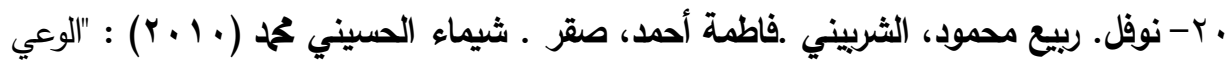

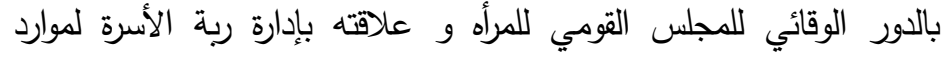

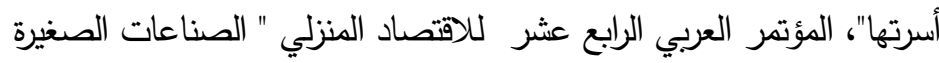

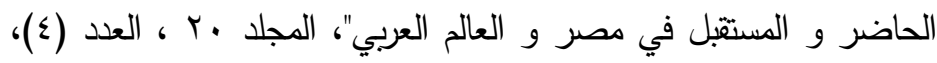

كلية الاقتصاد المنزلي،جامعة المنوفية، جمهورية مصر العربية. 


$$
\begin{aligned}
& \text { مجلة الاقتصاد المنزليـ مجلد مبـ العدد الر ابع ـ } 10 \text { • بم }
\end{aligned}
$$

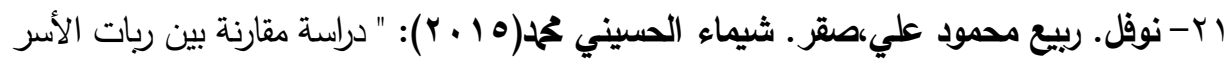

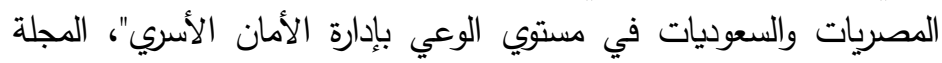

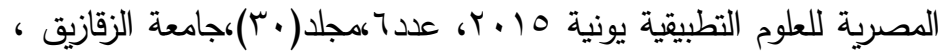

$$
\begin{aligned}
& \text { جمهورية مصر العربية. }
\end{aligned}
$$

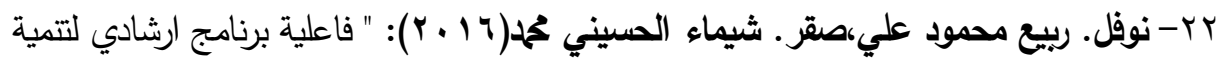

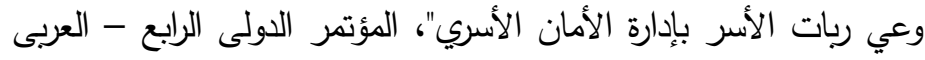

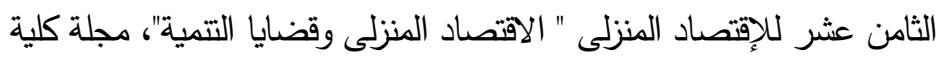

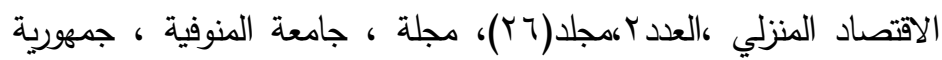

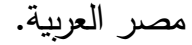

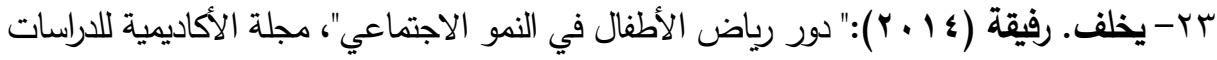

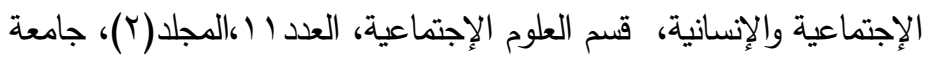

$$
\begin{aligned}
& \text { حسيبة بن بوعلي بالثلف،الجزائر . }
\end{aligned}
$$

24- Bai, Wan Dong ; Xu,Jia; and Zhang,Jun Zi (2014): "The Application of Paper Materials in Children Furniture", Advanced Materials Research, Vols. 945-949, www.scientific.net, Zurich, Switzerland.

25- Chen, Fei; Cheng,Hong Guang; and Cui, Xiang Fen (2015):"Predicting the Children's Blood Lead Level in a Lead and Zinc Smelting Area Based on IEUBK Model", Advanced Materials Research,Vols.1092-

1093,www.scientific.net,Zurich,Switzerland.

26- Cui, Na; Xie,Jing Chao; Bian,Wen Yue;Yanagi Hiroshi Yoshino; Zhang,Hui Bo;Li,Zhen Hai;Liu,Jing; and Lv, Yang (2013):"Study on the Relationship between Indoor Air Quality and Children's Health in Beijing", Applied Mechanics and Materials, Vols. 368370,www.scientific.net,Zurich, Switzerland.

27- Hao, Han Zhou; Shen,Yu Hui; Zhong,Ru Gang; Hu,Shui Bang; Liu,Cheng Wu ;and Zhong, Xue Bin (2012): "Lead Exposure Assessment for Chinese Children", Applied Mechanics and Materials, Vols. 209-211 www.scientific.net, Zurich, Switzerland.

28- Hao, Ping Ting ;and Yang, Zheng (2012):"Research into the Application of New Eco-Friendly Materials in Children Product Design", Advanced Materials Research, Vol. 599, www.scientific.net, Zurich, Switzerland. 


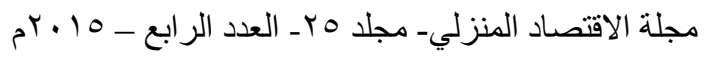

29- Kang,Shao Guo; and Zhu,Jian Xin (2014): "Matels Contamination and Leaching Potential in Plastic Toys Bought on the Beijing Market " Advanced Materials Research Vol. 878, www.scientific.net, Zurich, Switzerland.

30- Li, Xuan (2014):"A Brief Analysis of the Application of Green Textiles in Children's Space Environment Design", Advanced Materials Research, Vol. 1048, www.scientific.net, Zurich, Switzerland.

31-Liu,Li Bing (2014): "The Risk Factors for Pediatric Care and Preventive Measures", Advanced Materials Research, Vols. 989994,www.scientific.net, Zurich, Switzerland..

32- Liu,Xia ;and Luo,Hong Qi (2014): "Research on the Harm Mechanism and Related Standards of Children's Toys", Advanced Materials Research, Vol. 1037, www.scientific.net, Zurich, Switzerland.

33- Sun,Rui Rui; Chen, Hua Qing ; Li, Du Kang; and Yang,Dong Dong (2015):"Distribution Characteristics and Risk Assessment of Soil Lead at a Children's Blood Lead Exceeding Area in Fujian", Applied Mechanics and Materials , International Conference on Waste Management and Technology, By Trans Tech Publications Ltd, Vol. 768, www.scientific.net, Zurich, Switzerland.

34- Wang,Ji Hong; and Jiang,Hong Juan(2014): "Analysis and Study on Effects of Family Environment Improvement on Children with Asthma", Applied Mechanics and Materials, Vols. 675-677, www.scientific.net, Zurich, Switzerland.

35- Wu,Xiao Li ; Wang ,Yu Xing Yue;and Yao,Yang (2013): "Industrial Design and Engineering Analysis of Multi-Function Bicycle on Children Factors", Applied Mechanics and Materials, Vol. 364, www.scientific.net, Zurich, Switzerland.

36- Yahya,Mohd Shahir; Palaniandy,Thiyagu; Zainun, Noor Yasmin ;and Mohammad,Musli ( 2014): "Development of Malaysian Primary School Children Anthropometrics Data for Designing School Furniture Parameters", Applied Mechanics and Materials, Vols. 465-466, www.scientific.net.

37- Zou,Bin; Wang,Min;and Luo,Yan Qing (2013): "Children's Health Risk Assessment of Lead Exposure", Advanced 


$$
\text { مجلة الاقتصاد المنزلي- مجلد مr- العدد الرابع ـ } 10 \text { • بم }
$$

Materials Research, Vols. 610-613, www.scientific.net, Zurich, Switzerland.

38- https://ar.wikipedia.org/wiki.2016.

\section{Housewife's Awareness in a Manner of Dealing with Home Accidents and It's Relationship with Children's Home Safety}

Saker. Shaima Elhusini Mohammed

Assistant Professor of Home and Enterprise Management Faculty Of Designs\& Home Economics, Taif University The kingdom of Saudi Arabia

Abstract 


$$
\text { مجلة الاقتصاد المنزليـ مجلد 0rـ العدد الرابع - } 10 \text { • rم }
$$

The current study aims to discover the relationship between housewife awareness level in a manner of dealing with home accidents and between children's home safety level, Verify from the relationship between the housewife awareness level of in a manner of dealing with home accidents and between each of family size and the number of marriage years and the level of monthly income for the family, clarify the relationship between children's home safety level and between each of family size and the number of marriage years and the level of monthly income for the family, Verify from the differences between working housewives and non-working in each housewives awareness level in a manner of dealing with home accidents and children's home safety level, clarifying the nature of the variation at housewives awareness level in a manner of dealing with home accidents according to each of the age and educational level and the type of the job for them, and discover the nature of the variation in children's home safety level according to each of the age and educational level and the type of the job for them.

The study tools include public family data form, and a Housewife's Awareness in a manner of dealing with home accidents questionnaire, and children's home safety as mothers comprehends it questionnaire, And applied on a sample consist 400 Housewife have been selected by object-way who have sons in childhood period, they are from the Taif government and its villages, the Medina city and Makah, and from different educational, social and economic levels, and among of them 200 rural Housewife and 200 civil Housewife, 76 working housewife and 324 non- working, the study relied on the descriptive and analytical method.

The most important study results in existence a positive correlation relationship at the significance level (0.001) between housewife awareness level in a manner of dealing with home accidents and between children's home safety level, existence of a negative correlation at the significance level (0.001) between the housewife awareness level of in a manner of dealing with home accidents and between each of family size and the number of marriage years and the level of monthly income for the family, existence of a negative correlation at the significance level (0.001) between children's home safety level and between each of family size and the number of marriage years and the level of monthly income for the family, Thier are significant statistically differences in the level of significance $(0.001)$ between working housewives and non-working in each housewives awareness level in a manner of dealing with home accidents and children's home safety level in favor of working housewives, Thier are significant statistically variation in the significance level (0.001) at housewives awareness level in a manner of dealing with home accidents according to each of the age 


$$
\text { مجلة الاقتصاد المنزليـ مجلد هبـ العدد الرابع - } 10 \text { • ب م }
$$

and educational level and the type of the job for them in favor of the age group (50 years and over) for them, high educational level for them, and the type of job (free business) for them, also Thier are significant statistically variation in the significance level (0.001) at children's home safety level according to each of the age and educational level and the type of the job for them in favor of the age group (20 and even less than 30 years) for them, The average educational level for them, and the type of job (free business) for them,

On light of the results study provides an effective package of recommendations from them guiding the attention of researchers to preparation of guidance programs aimed to housewives in the first aid topic and how to prevent accidents in the home and the safety from it, and activate the role of the media and all it's apparatuses to awareness the community especially women about the prevention of accidents home and it's means and deal with them. 